AUTARQUIA ASSOCIADA À UNIVERSIDADE DE SÃO PAULO

\title{
ANÁLISE EXPERIMENTAL DE VELOCIDADE CRÍTICA EM ELEMENTO COMBUSTÍVEL TIPO PLACA PLANA PARA REATORES NUCLEARES DE PESQUISA
}

\author{
ALFREDO JOSÉ ALVIM DE CASTRO
}

Tese apresentada como parte dos requisitos para obtenção do Grau de Doutor em Ciências na Área de Tecnologia Nuclear - Reatores

Orientador:

Prof. Dr. Delvonei Alves de Andrade 
INSTITUTO DE PESQUISAS ENERGÉTICAS E NUCLEARES

Autarquia associada à Universidade de São Paulo

\section{ANÁLISE EXPERIMENTAL DE VELOCIDADE CRÍTICA EM ELEMENTO COMBUSTÍVEL TIPO PLACA PLANA PARA REATORES NUCLEARES DE PESQUISA}

\section{ALFREDO JOSÉ ALVIM DE CASTRO}

Tese apresentada como parte dos requisitos para obtenção do Grau de Doutor em Ciências na Área de Tecnologia Nuclear - Reatores

Orientador:

Prof. Dr. Delvonei Alves de Andrade

Versão Corrigida

Versão Original disponível no IPEN

São Paulo 
Dedicado à minha família. Por seu amor, dedicação e doação, a minha amada esposa Sonia Maria. Por sua compreensão e carinho, aos meus filhos Raphael e Danielle. Por seu respeito e admiração, Sheila e Stefan. 


\section{Agradecimentos}

Gostaria de agradecer àquele cuja Majestade, Glória, Soberania, Fidelidade, Benevolência, Graça e Misericórdias são infinitas, Àquele sem o qual nada seria possível, Deus.

Ao Prof. Delvonei Alves de Andrade, orientador desta tese, exemplo de pesquisador, professor e amigo, com o qual passei muitos momentos aprendendo, discutindo e crescendo profissionalmente.

À minha querida esposa Sonia Maria, companheira ao longo de 35 anos de casamento, sempre paciente e compreensiva.

Aos meus filhos Raphael e Danielle pelo amor e respeito dedicados à minha pessoa e aos meus ideais de vida.

À minha nora Sheila pelo amor e respeito dedicado ao meu filho e respeito à minha pessoa.

Ao meu futuro genro Stefan pelo seu exemplo de determinação e superação dos obstáculos da vida, pelo seu amor e respeito à minha filha, e pelo respeito à minha pessoa.

Aos pesquisadores, amigos e companheiros de toda uma vida profissional, Dr. Walmir Máximo Torres, Dr. Pedro Umbehaum, Dr. José Eduardo Rosa e Dr. Miguel Mattar Neto pelas sugestões e boas ideias fornecidas para superação dos desafios tecnológicos surgidos durante a pesquisa.

Aos meus ex-alunos de coorientação científica, Marcus Vinicius Hamann Silveira, Thomas Pedrinelli e Henrique Daer Ortolan pelo apoio técnico e sugestões para o desenvolvimento da bancada experimental e seção de testes.

Ao técnico Murilo Santos pela montagem da bancada experimental, seção de testes e suporte mecânico durante o comissionamento.

Ao CNPq pelo apoio financeiro para montagem da bancada experimental e seção de testes através do projeto de pesquisa $\mathrm{n}^{\circ}$ 481193/2012-0.

Aos meus alunos e ex-alunos por verem em mim um exemplo profissional em suas vidas. 
“Mas a sabedoria que do alto vem é, primeiramente pura, depois pacifica, moderada, tratável, cheia de misericórdia e de bons frutos, sem parcialidade, e sem hipocrisia, Ora, o fruto da justiça semeia-se na paz, para os que exercitam a paz. ",

Tiago 3:17-18

"Todo aquele que se dedica ao estudo da ciência chega a convencer-se de que nas leis do Universo se manifesta um Espírito sumamente superior ao do homem, e perante o qual nós, com os nossos poderes limitados, devemos humilhar-nos."

Albert Einstein 


\title{
ANÁLISE EXPERIMENTAL DE VELOCIDADE CRÍTICA EM ELEMENTO COMBUSTÍVEL TIPO PLACA PLANA PARA REATORES NUCLEARES DE PESQUISA
}

\author{
Alfredo José Alvim de Castro
}

\begin{abstract}
RESUMO
Os elementos de combustível de um reator nuclear de pesquisa tipo MTR ("Material Testing Reactor") são, em sua grande maioria, formados por placas de combustível revestidas com alumínio contendo no cerne silicileto de urânio $\left(\mathrm{U}_{3} \mathrm{Si}_{2}\right)$ disperso em matriz de alumínio. Essas placas possuem espessura da ordem de milímetros e comprimentos muito maiores em relação à sua espessura. Elas são dispostas paralelamente no conjunto que forma o elemento combustível, de maneira a formar canais entre elas com poucos milímetros de espessura, por onde escoa o fluido de refrigeração (água leve ou água pesada). Essa configuração, associada à necessidade de um escoamento com altas vazões para garantir o resfriamento das placas em operação, pode gerar problemas de falhas mecânicas das placas de combustível devido às vibrações induzidas pelo escoamento nos canais e, consequentemente, acidentes de proporções graves no caso de velocidade crítica que possa gerar o colapso das placas. Embora não haja ruptura das placas de combustível durante o colapso, as deflexões permanentes excessivas das placas podem causar bloqueio do canal de escoamento no núcleo do reator e levar ao superaquecimento nas placas. Para este trabalho, foram desenvolvidas uma bancada experimental com capacidade para altas vazões volumétricas $\left(\mathrm{Q}=100 \mathrm{~m}^{3} / \mathrm{h}\right)$ e uma seção de testes que simula um elemento combustível do tipo placa com três canais de resfriamento. A seção de testes foi construída com placas de alumínio e acrílico e foi instrumentada com sensores de deformação, sensores de pressão, um acelerômetro e um tubo de pitot. As dimensões da seção de testes foram baseadas nas dimensões do Elemento Combustível do Reator Multipropósito Brasileiro (RMB), cujo projeto está sendo coordenado pela Comissão Nacional de Energia Nuclear - CNEN. Os experimentos realizados alcançaram o objetivo de chegar à condição de velocidade crítica de Miller com o colapso das placas. A velocidade crítica foi atingida com 14,5 m/s levando a consequente deformação plástica das placas que formam o canal do escoamento. O canal central na entrada da seção de testes apresentou uma abertura de $3 \mathrm{~mm}$ em seu centro, causando um grande bloqueio do escoamento nos canais laterais. Este comportamento foi
\end{abstract}


constatado visualmente durante a desmontagem da seção de testes, ilustrado e discutido na análise de resultados apresentado neste trabalho. O bloqueio dos canais também foi observado por meio de gráficos de queda de pressão e por gráficos das deformações da entrada, centro e saída das placas contra a velocidade média da seção de testes. Observou-se uma queda da resistência hidráulica da seção de testes devido ao aumento da seção transversal de escoamento no canal central e um aumento exponencial das deformações quando da ocorrência da velocidade crítica. Comparativamente, o valor experimental obtido para velocidade crítica na seção de testes foi da ordem de $85 \%$ do valor obtido por cálculo com a expressão teórica de Miller. Os experimentos realizados permitiram um melhor entendimento da interação fluido estrutura em elementos de combustível tipo placa como: valores de frequências de vibrações naturais, instabilidade fluido elástica e desenvolvimento de técnicas para a detecção de valores de velocidade crítica. 


\title{
EXPERIMENTAL ANALYSIS OF CRITICAL VELOCITY IN FLAT PLATE FUEL ELEMENT FOR NUCLEAR RESEARCH REACTORS
}

\author{
Alfredo José Alvim de Castro
}

\begin{abstract}
The fuel elements of a MTR (Material Testing Reactor) type nuclear reactor are mostly composed of aluminum-coated fuel plates containing the core of uranium silica (U3Si2) dispersed in an aluminum matrix. These plates have a thickness of the order of millimeters and are much longer in relation to their thickness. They are arranged in parallel in the assembly forming the fuel element to form channels between them a few millimeters in thickness, through which there is a flow of the coolant (light water or heavy water). This configuration, combined with the need for a flow at high flow rates to ensure the cooling of the fuel element in operation, may create problems of mechanical failure of fuel plate due to the vibration induced by the flow in the channels. In the case of critical velocity may cause collapse of the plates. Although there is no rupture of the fuel plates during collapse, excessive permanent deflections of the plates can cause blockage of the flow channel in the reactor core and lead to overheating in the plates. For this study were developed an experimental bench capable of high volume flows $\left(\mathrm{Q}=100 \mathrm{~m}^{3} / \mathrm{h}\right)$ and a test section that simulates a plate-like fuel element with three cooling channels. The test section was constructed with aluminum and acrylic plates and was instrumented with straingauge sensors, pressure sensors, accelerometer and a tube of pitot. The dimensions of the test section were based on the dimensions of the Fuel Element of the Brazilian Multipurpose Reactor (RMB), whose project is being coordinated by the National Commission of Nuclear Energy (CNEN). The experiments performed attained the objective of reaching Miller's critical velocity condition with the collapse of the plates. The critical velocity was reached with $14.5 \mathrm{~m} / \mathrm{s}$ leading to the consequent plastic deformation of the plates forming the flow channel. The central channel had a $3 \mathrm{~mm}$ aperture in its center, causing a large blockage of the flow in the lateral channels. This behavior was observed visually during the disassembly of the test section, illustrated and discussed in the results analysis presented in this work. Blocking of the channels was also observed by means of graphs of pressure drop and graphs of the deformations of the entrance, center and exit of the plates against the average speed
\end{abstract}


of the section of tests. It was observed a decrease of the hydraulic resistance of the section of tests due to the increase of the transversal section of flow in the central channel and an exponential increase of the deformations when the critical speed occurrence. Comparatively, the value obtained for critical velocity in the test section through the experiments was of the order of $85 \%$ of the value obtained by calculation with Miller's theoretical expression. The experiments allowed a better understanding of the structure fluid interaction in plate type fuel elements such as: natural vibration frequency values, elastic fluid instability and development of techniques for the detection of critical velocity values. 


\section{SUMÁRIO}

1. INTRODUÇÃO

2. OBJETIVOS

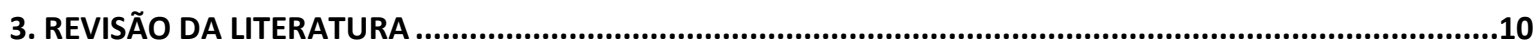

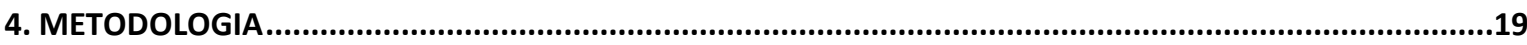

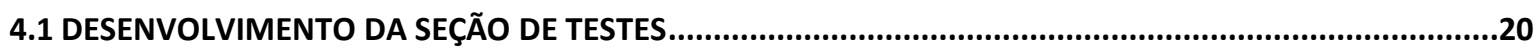

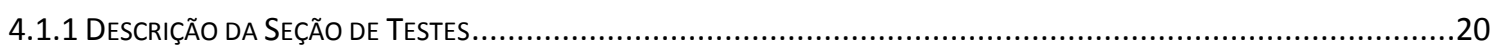

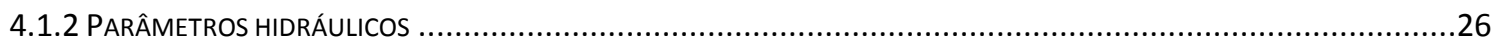

4.2 DESENVOLVIMENTO DA BANCADA EXPERIMENTAL................................................................................29

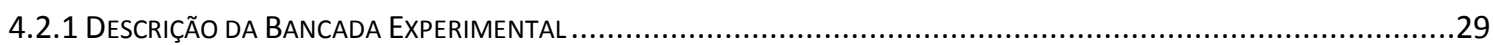

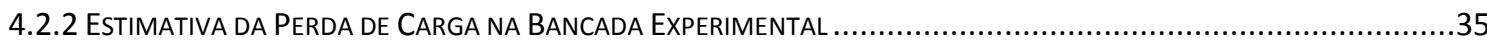

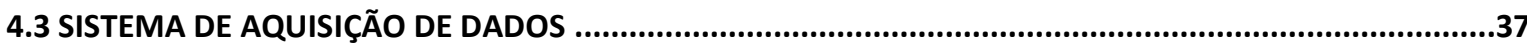

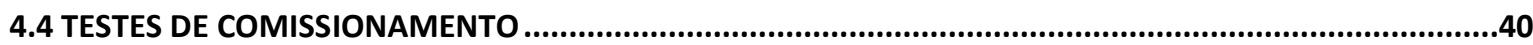

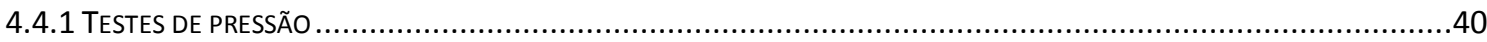

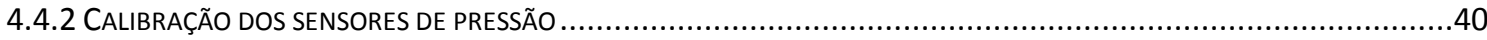

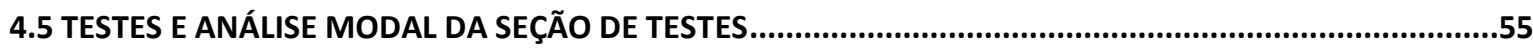

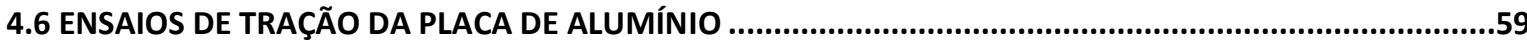

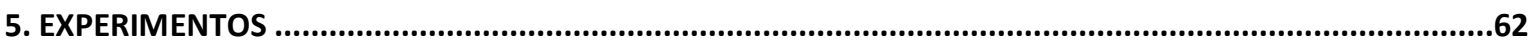

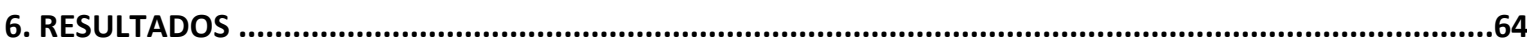

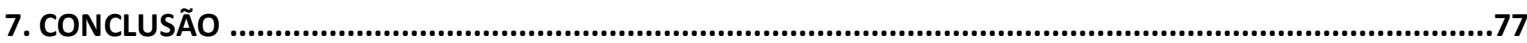

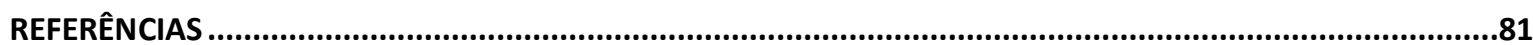




\section{LISTA DE TABELAS}

Tabela 1. 1 - Lista de componentes do EC do RMB

Tabela 1. 2 - Principais características do elemento combustível padrão do RMB. .8

Tabela 4. 1 - Cálculos estimativos da perda de carga para velocidade crítica de Miller. 28

Tabela 4. 2 - Velocidade média nos canais, vazão volumétrica, tubo de pitot e placa de orifício. 33

Tabela 4. 3 - Perdas de carga para a condição de velocidade crítica ........................................................36

Tabela 4. 4 - Calibração do transdutor de pressão piezoresistivo, PST1 .............................................42

Tabela 4. 5 - Calibração do transdutor de pressão piezoresistivo PST2 .................................................44

Tabela 4. 6 - Calibração do transdutor de pressão piezoresistivo PST3...............................................45

Tabela 4.7 - Calibração do transdutor de pressão piezoresistivo PST4................................................46

Tabela 4. 8 - Calibração do transdutor de pressão HYDAC ..............................................................47

Tabela 4. 9 - Calibração do transdutor de pressão tubo pitot ................................................................48

Tabela 4. 10 - Calibração do transdutor de pressão saída seção testes...................................................49

Tabela 4. 11 - Calibração do transdutor de pressão da placa de orifício ....................................................50

Tabela 6. 1 - Dados do experimento de velocidade crítica ..................................................................64

Tabela 6. 2 - Desvio padrão médio dos dados de processo ............................................................65

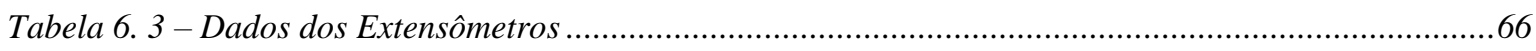




\section{LISTA DE FIGURAS}

Figura 1. 1 - Esquema de montagem de um elemento combustível de placas .............................................1

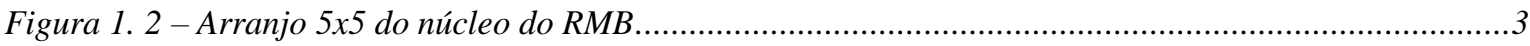

Figura 1. 3 - Elemento combustivel do RMB. Montagem dos componentes................................................5

Figura 1. 4 - Representação esquemática do combustível a dispersão .................................................6

Figura 1. 5-Dimensões do elemento combustível do RMB......................................................................7

Figura 1. 6 - Seção transversal e detalhes do elemento combustível do RMB.........................................7

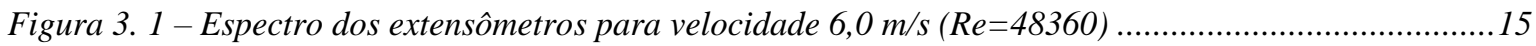

Figura 3. 2 - Vista da seção de testes placas planas após falha por velocidade crítica .............................16

Figura 3. 3 -Velocidade $x$ sinais de extensômetros para experimento de colapso de placas ......................16

Figura 3. 4 - Comportamento da velocidade média com a falha de colapso de placas ...............................17

Figura 4. 1 -Desenho das placas para montagem da seção de testes ................................................22

Figura 4. 2 - Modelo do elemento combustível tipo placas planas .........................................................22

Figura 4. 3 - Extensômetros instalados na seção de testes .............................................................22

Figura 4. 4 - Seção de testes para os experimentos com o modelo de elemento Combustível.......................24

Figura 4. 5 - Fotografia da Seção de Testes com o simulador instrumentado do elemento combustível .......24

Figura 4. 6- Placa de fixação do modelo simulador do elemento combustível tipo placas planas................25

Figura 4. 7 - Desenho esquemático da bancada experimental ...........................................................22

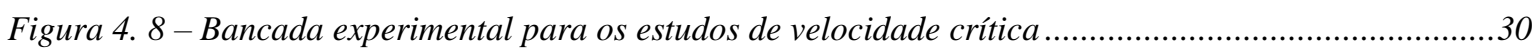

Figura 4. 9 - Quadro de comando elétrico da bomba......................................................................30

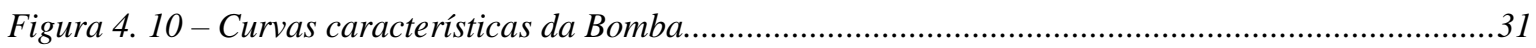

Figura 4. 11 - Placa de orifício com o sensor tipo diafragma e a eletrônica associada.............................32

Figura 4. 12 - Isométrico da Bancada de Estudos de Velocidade Crítica montada ......................................34

Figura 4. 13 - Aquisição de dados : Hardware NI-DAQ e o Software LabVIEW10...................................37

Figura 4. 14 - Painel frontal do programa de monitoração e aquisição de sinais .......................................39

Figura 4. 15 - Diagrama de blocos do programa de monitoração e aquisição de sinais ..............................39 
Figura 4. 16-Trocador de Calor

Figura 4. 17 - Falha na Janela de acrílico .....................................................................................42

Figura 4. 18 - Calibrador Cappo P e a bomba pneumática. ..............................................................42

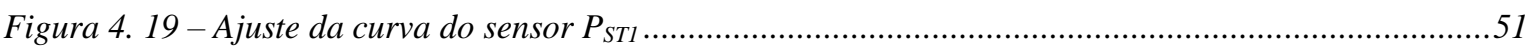

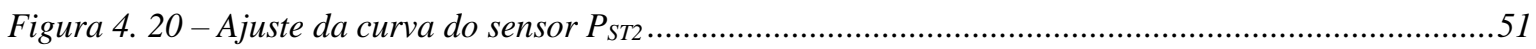

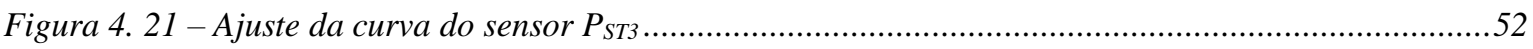

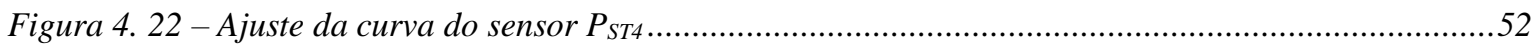

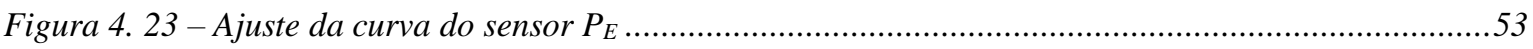

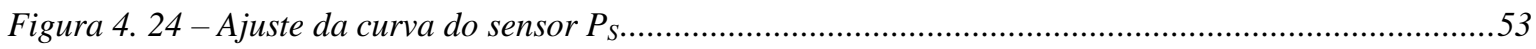

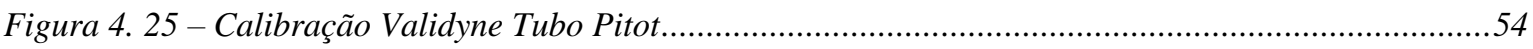

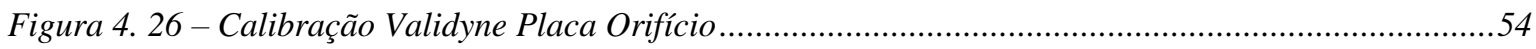

Figura 4. 27 - Ajuste da Velocidade Pitot x sinal saída Validyne ..........................................................55

Figura 4. 28 - Ajuste vazão volumétrica seção testes $x$ sinal saída Validyne ..............................................55

Figura 4. 29 - Sistema de aquisição de sinais dos extensômetros ........................................................56

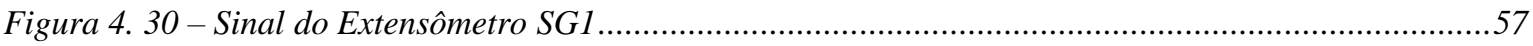

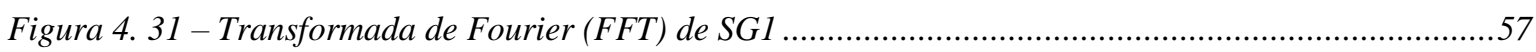

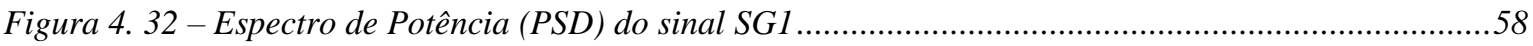

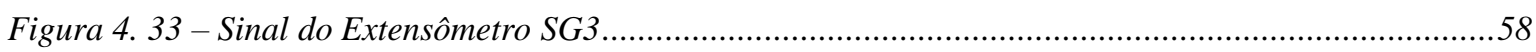

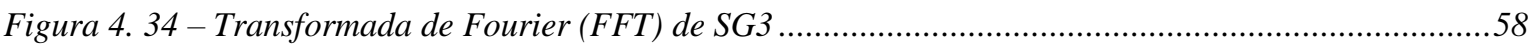

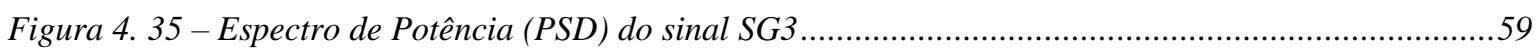

Figura 4. 36 - Corpos de Prova para os ensaios de Tração .................................................................60

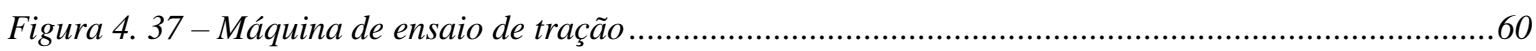

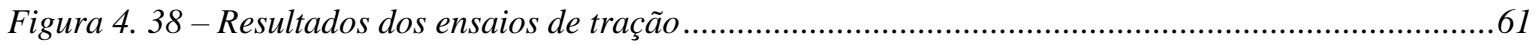

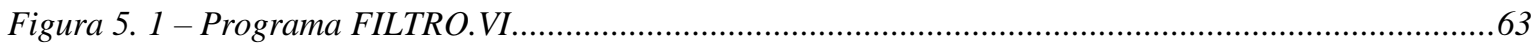

Figura 6. 1 - Queda de pressão na seção de testes.................................................................................65

Figura 6. 2 - Deformações do straingauge de saída.............................................................................67

Figura 6. 3 - Deformações do straingauge no centro da seção de testes ..................................................67

Figura 6. 4 - Deformações do straingauge na entrada da seção de testes ..............................................68 
Figura 6. 5 - Sinal do extensômetro SG1 no transiente de 13,5 para $14,0 \mathrm{~m} / \mathrm{s}$ .68

Figura 6. 6 - Sinal do extensômetro SG3 no transiente de 13,5 para $14,0 \mathrm{~m} / \mathrm{s}$ 69

Figura 6. 7 - Sinal do extensômetro SG6 no transiente de 13,5 para $14,0 \mathrm{~m} / \mathrm{s}$ 69

Figura 6. 8 - Sinal do extensômetro SG1 no transiente de 14,0 para $14,5 \mathrm{~m} / \mathrm{s}$ . .70

Figura 6. 9 - Sinal do extensômetro SG3 no transiente de 14,0 para $14,5 \mathrm{~m} / \mathrm{s}$ . .70

Figura 6. 10 - Sinal do extensômetro SG6 no transiente de 14,0 para $14,5 \mathrm{~m} / \mathrm{s}$. 70

Figura 6. 11 - Sinal do extensômetro SG1 no transiente de 14,5 para $15,0 \mathrm{~m} / \mathrm{s}$. .71

Figura 6. 12 - Sinal do extensômetro SG3 no transiente de 14,5 para $15,0 \mathrm{~m} / \mathrm{s}$. .71

Figura 6. 13 - Sinal do extensômetro SG6 no transiente de 14,5 para $15,0 \mathrm{~m} / \mathrm{s}$. .72

Figura 6. 14 - Vista da entrada da seção de testes após a realização dos ensaios de velocidade crítica.......72

Figura 6. 15 - Vista da entrada da seção de testes após limpeza foco na deformação ................................73

Figura 6. 16 - Vista da entrada da seção de testes após limpeza foco nas dimensões canal .........................73

Figura 6. 17 - Espectro de potência dos straingauge na entrada da seção de testes...................................74

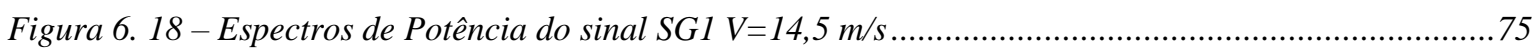

Figura 6. 19 - Espectros de Potência do sinal SG3 V=14,5 m/s ...................................................75

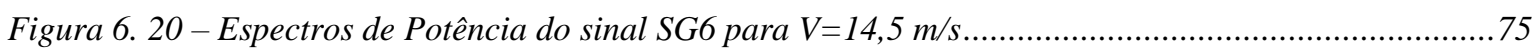

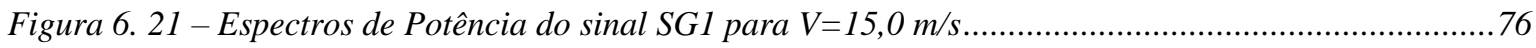

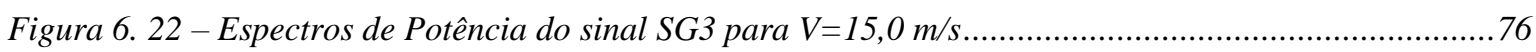

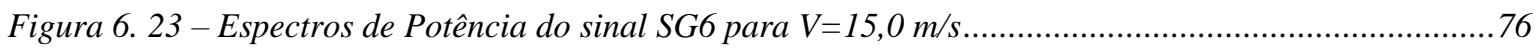




\section{LISTA DE ABREVIATURAS E/OU SIGLAS}

ABNT Associação Brasileira de Normas Técnicas

ANSTO Autralian Science and Technology Organization

ASME The American Society of Mechanical Engineers

ASTM American Society for Testing and Materials

CEN Centro de Engenharia Nuclear

CFD Computational Fluid Dynamics

CNEN Comissão Nacional de Energia Nuclear

DOE/USA Department of Energy-United States of America

EC Elemento Combustível

ETR Engineering Test Reactor

FEA Finite Element Analysis

HEU High Enriched Uranium

IAEA International Atomic Energy Agency

IPEN Instituto de Pesquisas Energéticas e Nucleares

LEU Low Enriched Uranium

MTR Material Testing Reactor

OPAL Open Pool Australian Lightwater Reactor

RERTR Reduced Enrichment for Research and Test Reactors

RMB Reator Multipropósito Brasileiro

RRR Replacement Research Reactor

SG Extensômetro - Straingauge

TP Tomada de Pressão Estática

USNRC United States Nuclear Regulatory Commission 


\section{INTRODUÇÃO}

Os elementos de combustível de um reator nuclear de pesquisa tipo MTR ("Material Testing Reactor") são, em sua grande maioria, formados por placas de combustível revestidas com alumínio contendo no cerne silicileto de urânio $\left(\mathrm{U}_{3} \mathrm{Si}_{2}\right)$ disperso em matriz de alumínio. Essas placas possuem espessura da ordem de milímetros e comprimentos muito maiores em relação à sua espessura. Elas estão dispostas paralelamente no conjunto que forma o elemento combustível, de maneira a formar canais entre elas com poucos milímetros de espessura, por onde escoa o fluido de refrigeração (água leve ou água pesada), conforme pode ser observado no esquema de montagem da Figura 1. 1, Torres, et al., [1].

Essa configuração, associada à necessidade de um escoamento com altas vazões para garantir o resfriamento das placas em operação, pode gerar problemas de falhas mecânicas das placas de combustível devido às vibrações induzidas pelo escoamento nos canais e, consequentemente, acidentes de proporções graves.

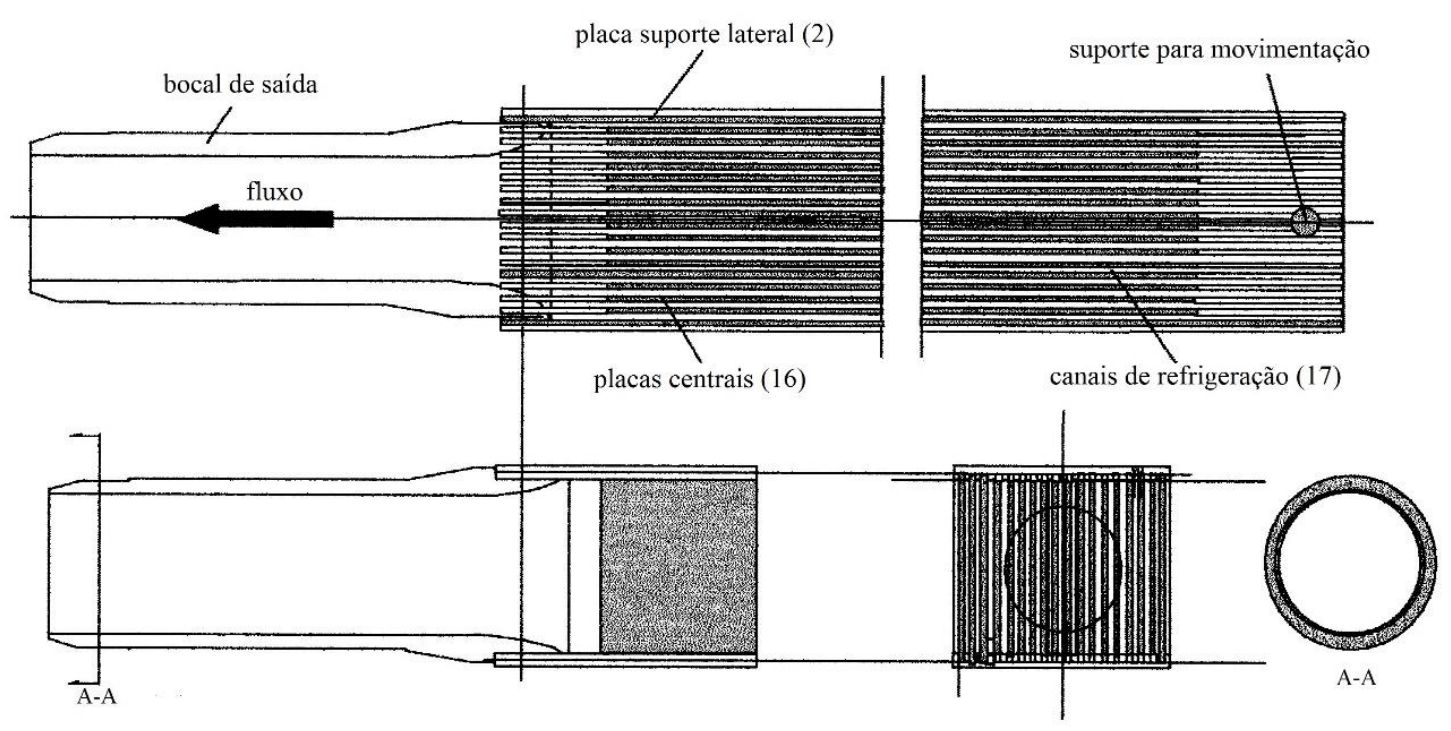

Figura 1. 1 - Esquema de montagem de um elemento combustível de placas planas

A maioria dos núcleos de reatores nucleares não possuem as condições ideais de escoamento. Fatores como rugosidade das placas, tolerâncias de fabricação, turbulências, escoamento axial não uniforme e flutuações de pressão produzidas pela bomba principal e outros equipamentos de processo causam estas distorções. Por esta razão, não se pode assumir uma distribuição uniforme de vazão do fluido refrigerante através de cada canal do elemento combustível tipo placas. Miller, [2], um dos pioneiros das pesquisas sobre estabilidade das placas de combustível, descreve o colapso das placas como devido a 
diferença das velocidades entre canais adjacentes. Esta diferença de velocidades produz uma diferença de pressões entre ambos os lados de uma placa. Quando a pressão resultante é suficientemente grande para a placa resistir, ocorre a deflexão máxima e deformação plástica.

O colapso das placas combustíveis se origina das vibrações induzidas pelo escoamento. Quando o fluido escoa por canais muito estreitos, a energia de pressão é convertida em energia de velocidade (cinética) e cria uma força de sucção na parede. Quando a parede pode se movimentar como no caso de placas planas paralelas de combustível, a seção transversal do canal diminui obstruindo o escoamento. A obstrução ao escoamento aumenta a pressão local com o escoamento tentando vencer a constrição. Desta forma, a placa combustível é empurrada abrindo a seção transversal do escoamento. Esta ação de puxar e empurrar a placa atua periodicamente, provocando vibrações na estrutura que pode levar a grandes deflexões na placa e superaquecimento localizado.

A velocidade crítica é a velocidade na qual as placas retangulares irão flexionar e colapsar como resultado de vibrações induzidas por escoamento e da distribuição assimétrica de pressões no interior do elemento combustível. Embora não haja ruptura das placas combustíveis durante o colapso, as deflexões permanentes excessivas nas laterais das placas podem causar bloqueio ao escoamento no núcleo do reator e levar a superaquecimento nas placas.

O fenômeno de colapso de placas tem sido bastante estudado e abordado por pesquisadores no intuito de se encontrar condições de operação (velocidade do fluido, capacidade de resfriamento das placas, integridade das placas etc.) que garantam a operação segura do núcleo do reator e uma grande disponibilidade de seus componentes.

Isto se torna um problema importante em usinas nucleares e reatores de pesquisa, nas quais as condições de trabalho podem variar muito e o sistema pode ficar exposto a um número maior de condições instáveis de equilíbrio com o aumento de esforços mecânicos gerados pelas vibrações.

O Reator Multipropósito Brasileiro (RMB), que está sendo concebido e projetado sob coordenação da Comissão Nacional de Energia Nuclear (CNEN), deverá utilizar um núcleo composto por elementos de combustível formados por placas planas paralelas. De acordo com Silva, [3], o núcleo do RMB será constituído por elementos de combustível do tipo placa, contendo siliceto de urânio $\left(\mathrm{U}_{3} \mathrm{Si}_{2}\right)$ disperso em alumínio, com uma densidade de urânio de até $4,8 \mathrm{gU} / \mathrm{cm}^{3}$. A placa matriz do núcleo possui 25 posições, num arranjo $5 \times 5$, 
localizada no interior da chaminé, sendo que desse total, 23 posições deverão ser ocupadas por elementos de combustível e duas posições internas do núcleo para irradiação de materiais ou de combustíveis, conforme mostra a Figura 1.2.

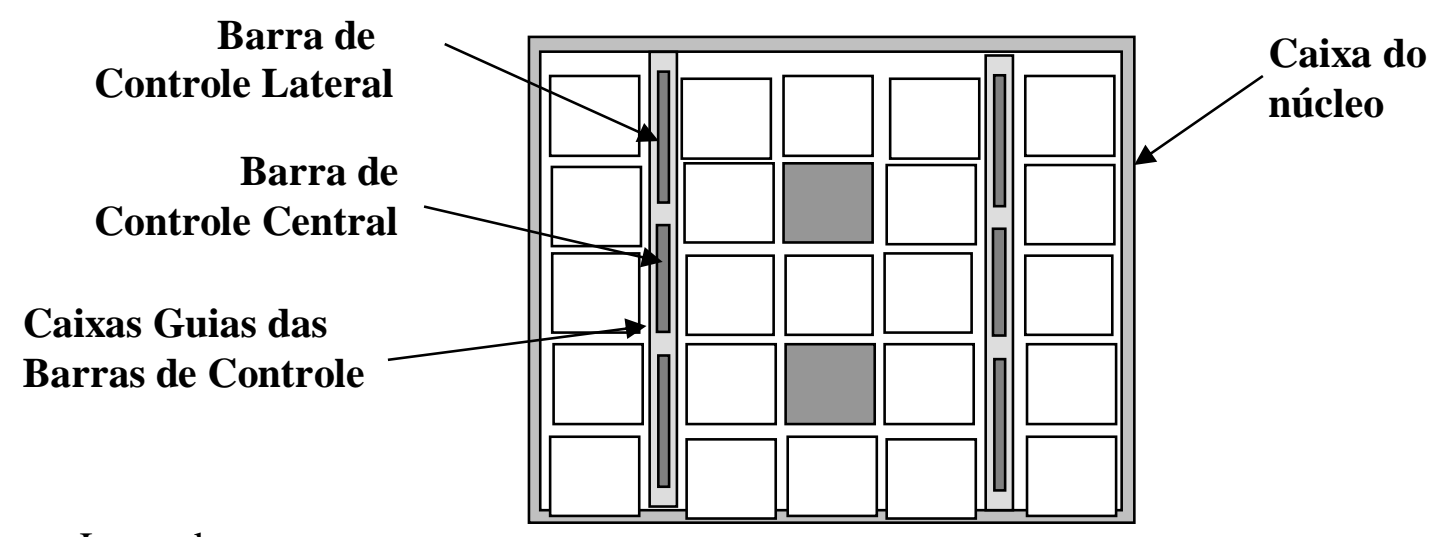

Legenda:

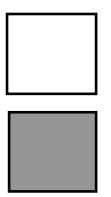

Elemento Combustível

Posição para irradiação de materiais estruturais/combustíveis

Figura 1. 2 - Arranjo 5x5 do núcleo do RMB

O elemento combustível do RMB possui seção transversal quadrada e é formado pela montagem de 21 placas de combustível planas com dois suportes laterais, os quais mantêm sustentação e paralelismo das placas de combustível. Cada placa combustível contém uma região central, de fina espessura, denominada "cerne", constituída de partículas de $\mathrm{U}_{3} \mathrm{Si}_{2}$ $\left(19,75 \%\right.$ de enriquecimento em peso de $\left.\mathrm{U}^{235}\right)$ dispersas numa matriz de alumínio (Al). O cerne combustível é hermeticamente selado entre duas placas de alumínio que constituem o revestimento da placa combustível. Para o elemento combustível do RMB são previstos dois tipos de placas de combustível, as internas e as externas. As duas placas de combustível externas $\left(1^{\mathrm{a}}\right.$ e a $\left.21^{\mathrm{a}}\right)$ possuem revestimento com maior espessura $(0,445 \mathrm{~mm})$, enquanto que as placas de combustível internas possuem revestimento menos espesso $(0,37 \mathrm{~mm})$. A utilização de uma maior espessura do revestimento das placas de combustível externas visa conferir maior rigidez estrutural ao conjunto e proporcionar maior proteção do cerne quanto a eventuais danos (deformações) durante manuseio na piscina. A espessura do cerne é igual para todas a placas de combustível $(0,61 \mathrm{~mm})$.

O elemento combustível (EC) do RMB deverá ser constituído pelos seguintes componentes, relacionados na Tabela 1.1 . 


\begin{tabular}{lcl}
\hline Componente & Quantidade & \multicolumn{1}{c}{ Material } \\
\hline Placa combustível interna & 19 & Cerne de $\mathrm{U}_{3} \mathrm{Si}_{2}$-Al, revestido com Al \\
Placa combustível externa & 2 & Cerne de $\mathrm{U}_{3} \mathrm{Si}_{2}$-Al, revestido com Al \\
Suporte lateral & 2 & Al ASTM 6061-T6 \\
Bocal de extremidade & 1 & Al ASTM 6061-T6 \\
Pino de manuseio & 1 & Al ASTM 6061-T6 \\
Pente & 1 & Al ASTM 6061-T6 \\
Pino de fixação do pente & 1 & Al ASTM 6061-T6 \\
Parafusos & 8 & Al ASTM 6262-T6 \\
\hline
\end{tabular}

A Figura 1. 3 mostra a concepção geométrica do EC do RMB, indicando a respectiva montagem dos seus componentes.

A utilização do combustível a dispersão de siliceto de urânio está baseada na larga experiência internacional acumulada de irradiação, que têm demonstrado excelente comportamento e êxito na operação de muitos reatores de pesquisas e de testes de materiais no mundo, indicando que os combustíveis a dispersão alcançaram maturidade tecnológica.

O programa internacional Reduced Enrichment for Research and Test Reactors (RERTR) contribuiu para o desenvolvimento de combustíveis do tipo dispersão, com baixo enriquecimento (Low enriched Uranium - LEU), que permitiram a conversão de um grande número de reatores de pesquisas que usavam combustíveis com urânio altamente enriquecido (High enriched Uranium - HEU). Para obter comportamento comparável ao previamente utilizado com combustível HEU, o novo combustível LEU deve possuir maior densidade de urânio no cerne. Desta maneira o RERTR promoveu o desenvolvimento internacional de combustíveis LEU com alta densidade de urânio, particularmente do combustível constituído de siliceto de urânio disperso em alumínio e, mais recentemente, ainda em licenciamento, dos combustíveis baseados em ligas de urânio-molibdênio (Snelgrove, J.L. et al., [4] e [5]). 


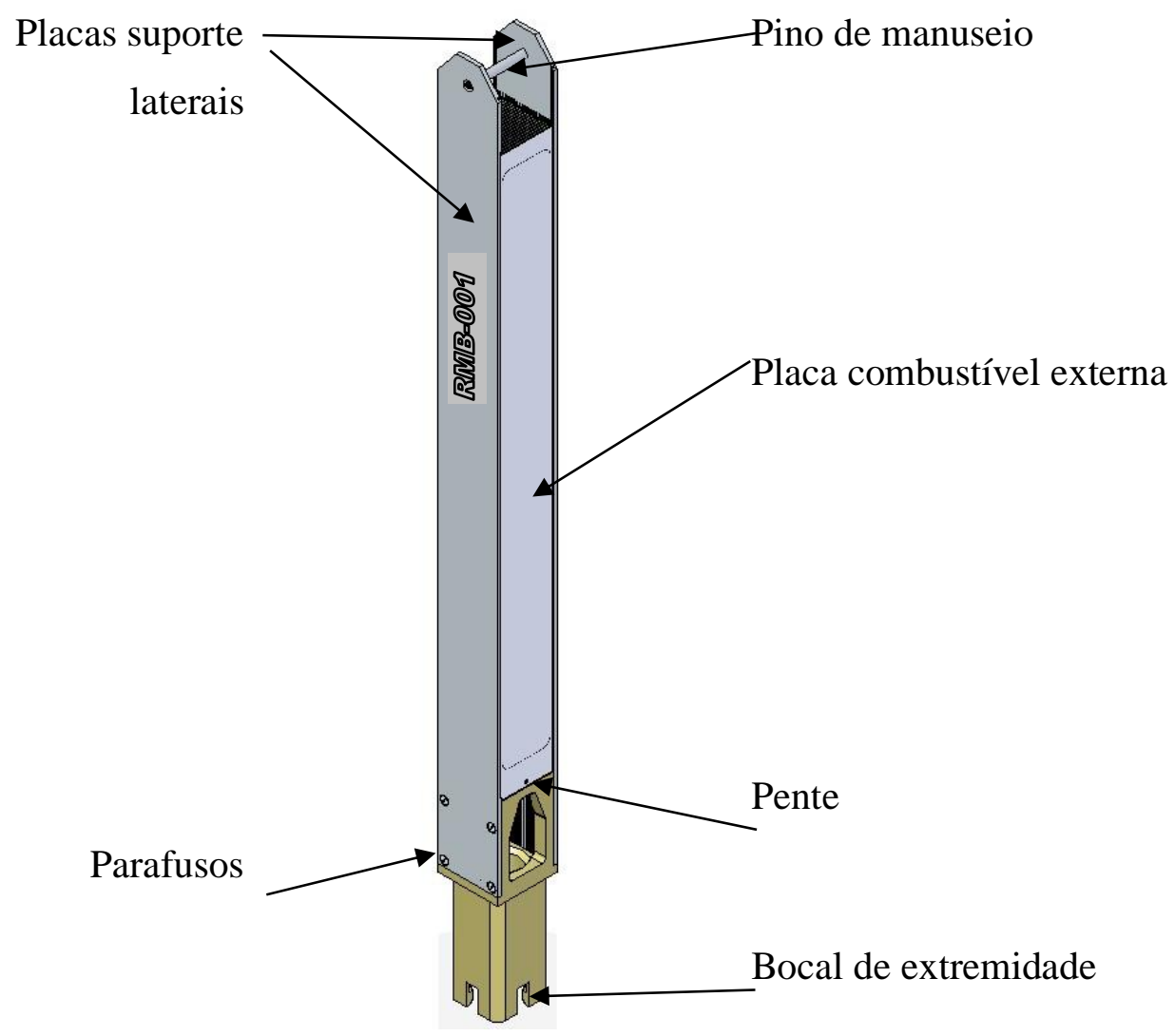

Figura 1. 3 - Elemento combustível do RMB. Montagem dos componentes

A Figura 1.4 ilustra, de maneira esquemática, um combustível a dispersão, onde as partículas combustíveis (fase físsil) estão dispersas numa matriz metálica (fase contínua de material estrutural). São ilustradas dispersões com maior (A) e menor (B) carregamentos em volume da fase físsil. A fim de minimizar os efeitos da radiação e prover resistência mecânica e ductilidade, a matriz metálica deve preferencialmente predominar no volume, formando uma matriz contínua envolvendo a fase físsil, como ilustrado na Figura 1. 4(B), Perrota, [6]. 


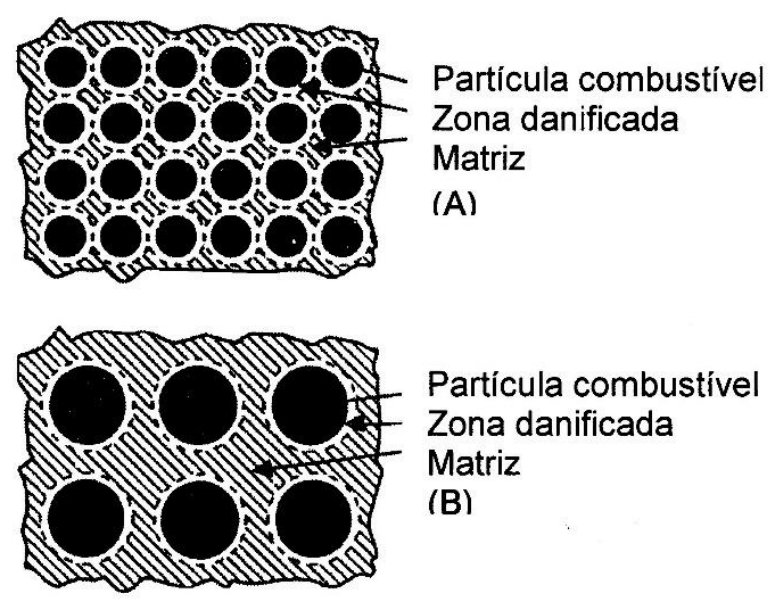

Figura 1. 4 - Representação esquemática do combustível a dispersão

Para se alcançar os objetivos desejados de bom desempenho num combustível tipo dispersão, os seguintes itens devem ser observados:

- o tamanho da partícula dispersa (físsil) deve ser grande comparado ao percurso médio de um fragmento de fissão;

- a distribuição das partículas dispersas na matriz deve ser a mais uniforme possível;

- a densidade do material da fase dispersa (físsil) deve ser alta;

- a fase contínua da matriz de metal deve ter o máximo de volume possível na dispersão.

Muitos experimentos com miniplacas, placas e elementos de combustível foram realizados (Hofman, G., 1988, [7]; Snelgrove, J.L. et al., 1996, [4]; Chaussi, J.M., et al., 1999, [8]), os quais permitiram confirmar o bom comportamento sob irradiação do siliceto de urânio para densidades de até $4,8 \mathrm{gU} / \mathrm{cm}^{3}$. Já em 1988, este combustível foi totalmente qualificado para uso em reatores de pesquisas pela U.S. Nuclear Regulatory Commission (USNRC). O Relatório de Avaliação de Segurança deste combustível é apresentado no documento NUREG-1313 (U.S. Nuclear Regulatory Commission, 1988, [9]).

O combustível de siliceto de urânio tem sido largamente utilizado no mundo, devido permitir alta densidade de urânio, o que o torna adequado para a maioria dos reatores de pesquisas ou de testes. Além disso, o $\mathrm{U}_{3} \mathrm{Si}_{2}$ possui tecnologia de fabricação bem estabelecida, permitindo a fabricação confiável de placas e elementos de combustível. Este combustível possui propriedades satisfatórias e apresenta excelente comportamento sob irradiação. Para este tipo de combustível, o processo/tecnologia de fabricação é de domínio nacional.

As Figura 1. 5 e Figura 1. 6 exibem as dimensões principais em milímetros, a seção 
transversal e detalhes do elemento combustível tipo placa que está sendo projetado para o RMB, [10].

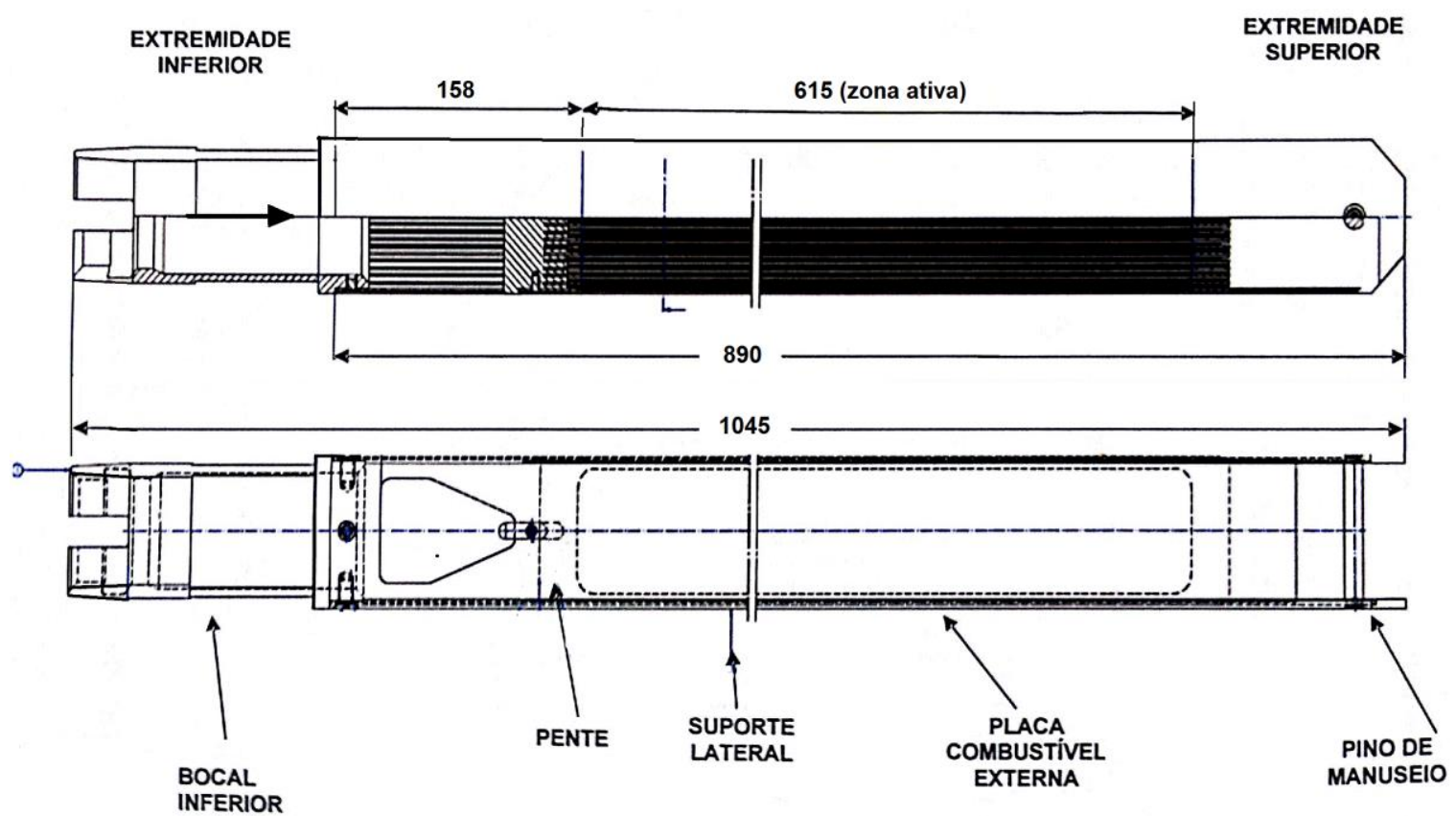

Figura 1. 5 - Dimensões do elemento combustível do RMB

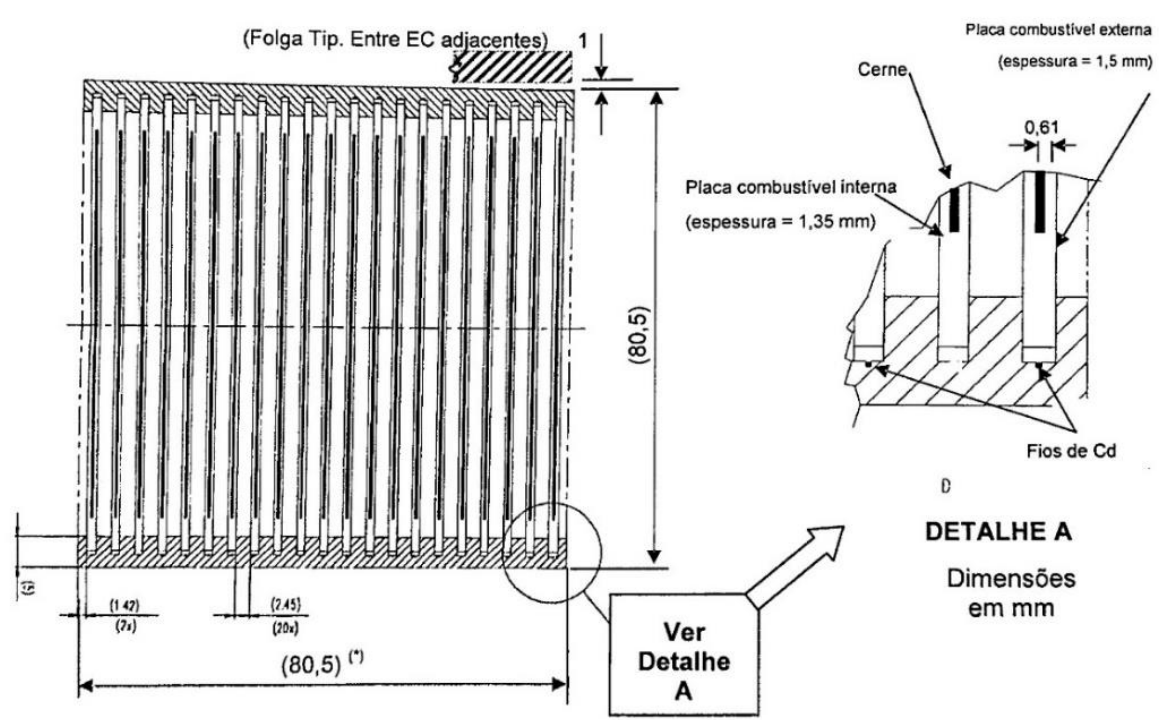

Figura 1. 6 - Seção transversal e detalhes do elemento combustível proposto para o RMB

A Tabela 1. 2 apresenta as principais características e parâmetros termo-hidráulicos do elemento de combustível padrão e do núcleo proposto para o RMB, [3]. 
Tabela 1. 2 - Principais características do elemento combustível padrão e do núcleo proposto para o

\begin{tabular}{|c|c|}
\hline \multicolumn{2}{|c|}{ RMB } \\
\hline ITEM & ESPECIFICAÇÃO \\
\hline \multicolumn{2}{|l|}{ ELEMENTO COMBUSTÍVEL } \\
\hline -Dimensões da seção transversal & $80,50 \mathrm{~mm} \times 80,50 \mathrm{~mm}$ \\
\hline -Número de placas de combustível & 21 \\
\hline -Comprimento ativo & $615 \mathrm{~mm}$ \\
\hline -Largura ativa & $65 \mathrm{~mm}$ \\
\hline -Espessura da placa combustível & $1,35 \mathrm{~mm}$ (placas internas) \\
\hline & $1,50 \mathrm{~mm}$ (placas externas) \\
\hline -Dimensões do canal de refrigeração & $2,45 \mathrm{~mm} \times 70,5 \mathrm{~mm}$ \\
\hline -Espessura do cerne combustível & $0,61 \mathrm{~mm}$ \\
\hline \multicolumn{2}{|l|}{ NÚCLEO ATIVO (cerne) } \\
\hline -Material combustível & Dispersão de $\mathrm{U}_{3} \mathrm{Si}_{2}$ \\
\hline -Densidade do $\mathrm{U}_{3} \mathrm{Si}_{2}$ & $12,2 \mathrm{~g} \cdot \mathrm{cm}^{-3}$ \\
\hline -Densidade de Urânio no cerne & 4,8 gU.cm ${ }^{-3}$ \\
\hline -Densidade do cerne & $6,5 \mathrm{~g} \cdot \mathrm{cm}^{-3}$ \\
\hline -Fração em volume do $\mathrm{U}_{3} \mathrm{Si}_{2}$ na mistura & $42,5 \%$ \\
\hline \multicolumn{2}{|l|}{ REVESTIMENTO (“cladding”) } \\
\hline -Material do revestimento & Liga de $\mathrm{Al}(6061)$ \\
\hline -Densidade do Alumínio & $2,7 \mathrm{~g} \cdot \mathrm{cm}^{-3}$ \\
\hline PARÂMETROS TERMO-HIDRÁULICOS & ESPECIFICAÇÔES / ESTIMATIVAS \\
\hline -Tipo de Reator/ Potência Térmica Nominal & Piscina aberta / $30 \mathrm{MW}$ \\
\hline -Vazão no núcleo ativo (combustíveis) & $3.000 \mathrm{~m}^{3} / \mathrm{h}(827 \mathrm{~kg} / \mathrm{s})$ \\
\hline -Vazão pelas barras de controle & $300 \mathrm{~m}^{3} / \mathrm{h}(83 \mathrm{~kg} / \mathrm{s})$ \\
\hline -Vazão de sucção chaminé & $300 \mathrm{~m}^{3} / \mathrm{h}(83 \mathrm{~kg} / \mathrm{s})$ \\
\hline -Vazão de saída da piscina & $3.600 \mathrm{~m}^{3} / \mathrm{h}=1 \mathrm{~m}^{3} / \mathrm{s} \quad(993 \mathrm{~kg} / \mathrm{s})$ \\
\hline -Temperatura de entrada no núcleo & $38^{\circ} \mathrm{C}$ - valor nominal \\
\hline -Temperatura de saída do núcleo & $46^{\circ} \mathrm{C}-$ valor nominal \\
\hline - Densidade de potência núcleo ativo & $290 \mathrm{~kW} /$ litro $\left(290 \mathrm{~W} / \mathrm{cm}^{3}\right)$ para $30 \mathrm{MW}$ \\
\hline -Margem para ONB (“Onset of Nucleate Boiling”) & MONB $>2,0$ \\
\hline $\begin{array}{l}\text {-Velocidade média de escoamento do refrigerante } \\
\text { nos elementos de combustível }\end{array}$ & $9,0 \mathrm{~m} / \mathrm{s}$ \\
\hline -Vazão por elemento combustível & $120 \mathrm{~m}^{3} / \mathrm{h}(33,1 \mathrm{~kg} / \mathrm{s})$ \\
\hline -Queda de pressão no núcleo & $\begin{array}{l}300 \mathrm{kPa}(3,0 \text { bar }) \text { para } 9,0 \mathrm{~m} / \mathrm{s} \text { e } 335 \mathrm{kPa}(3,35 \text { bar }) \\
\text { para } 9,5 \mathrm{~m} / \mathrm{s}\end{array}$ \\
\hline $\begin{array}{l}\text {-Coeficiente de perda de pressão no núcleo, } \\
\mathrm{K}=2 .\left(\Delta \mathrm{P} / \rho \cdot \mathrm{V}^{2}\right)\end{array}$ & 7,4 \\
\hline - Queda de pressão Sistema Resfriamento Primário & $600 \mathrm{kPa}(6,0$ bar $)$ \\
\hline
\end{tabular}




\section{OBJETIVOS}

O presente projeto de pesquisa tem como principal objetivo a investigação experimental de vibrações induzidas pelo escoamento do fluido refrigerante, o fenômeno de colapso de placas e a ocorrência da velocidade crítica em placas paralelas de elementos de combustível de reatores de pesquisa do tipo MTR.

Como objetivo secundário, a investigação produzirá dados experimentais para estudos da interação das placas de combustível com o fluido refrigerante em uma faixa variada de vazões em condições estáveis de distribuição de pressão e temperatura para dar subsídios a projetos de elementos de combustível do tipo placas paralelas.

Os dados experimentais poderão ser utilizados para a simulação com o programa computacional, ANSYS-CFX, [11], permitindo estudos de:

- distribuição de velocidade e pressão em elemento combustível tipo placa;

- levantamento de propriedades termo-hidráulicas;

- influência do campo de pressão na placa combustível (domínio sólido); e

- deformações plásticas e vibrações nas placas combustíveis.

O ineditismo do trabalho se dá na detecção da velocidade crítica por meio da análise do comportamento dos sinais dos sensores de deformação da placa de combustível e de queda de pressão no canal de resfriamento da seção de testes, tanto no campo temporal como no campo de frequência.

Além disso, as dificuldades vivenciadas durante a fase experimental permitem o desenvolvimento dos conhecimentos tecnológicos necessários para o projeto e montagem de uma nova bancada experimental visando os estudos e testes de avaliação da estabilidade hidráulica para um elemento combustível dummy (21 placas combustíveis) que está em concepção para o projeto do RMB, com combustível de siliceto de urânio disperso em matriz de alumínio laminado com placas de alumínio. 


\section{REVISÃO DA LITERATURA}

Deflexões induzidas por escoamento e vibrações de placas planas tem sido estudadas por numerosos pesquisadores. Isto acontece porque a geometria de placas planas possui menor resistência mecânica que outras geometrias de placas de combustível, por exemplo placas curvas, [12].

Um dos primeiros estudos com placas de combustível e fenômenos induzidos por escoamento foi realizado por Stromquist and Sisman, [13]. Eles criaram uma das primeiras bancadas experimentais dedicadas aos estudos de instabilidades induzidas por escoamento para placas de combustível de reatores nucleares e testaram placas planas e curvas. Eles conseguiram medir a queda de pressão no elemento de teste, as frequências e amplitudes das vibrações observadas. Tambem foi observado deformações plásticas em algumas placas de combustível devido a diferença de pressões entre canais de escoamento. Nesta referência, a deformação plástica foi uma das primeiras observações do que hoje é chamado de colapso de placas. Stromquist and Sissman concluiram que as placas testadas tinham resistência adequada para os fenômenos de vibrações medidos. Também fizeram importantes observações notando que as dimensões dos canais, as condições de fixação das placas na borda e tolerâncias de fabricação contribuiram para a ocorrência do fenômeno de deformação das placas.

Em 1958, o fenômeno de colapso em placas de combustível de reatores nucleares de pesquisa foi observado pela primeira vez em um reator de pesquisa (Engineering Test Reactor-ETR-DOE/USA-Idaho-USA). Algumas placas apresentaram sinais de falha através da constatação por visualização de pequenas deformações de torção. Doan, [14], publicou um relatório sobre questões técnicas que surgiram durante o início da operação. Ele relatou a ocorrência de um diferencial de pressão formado entre dois canais de escoamento adjacentes, o que levou a instabilidades mecânicas da placa. Ele propôs um conjunto de modificações no elemento combustível para mitigar os efeitos observados.

Também em 1958, Miller, [2], publicou seu trabalho apresentando uma expressão para cálculo de velocidades críticas que causam colapso em placas. O seu trabalho é importante porque representou na primeira tentativa e na mais utilizada expressão para cálculo de velocidade crítica em escoamento. Miller estudou placas planas e placas curvas e idealisou um modelo para predição da velocidade crítica do escoamento através do 
acoplamento de mecânica de fluidos com mecânica de sólidos. Miller considerou o domínio sólido admitindo que a deflexão da placa é causada por uma força distribuida em sua superfície. Esta força distribuida é análoga a diferença de pressões que surge entre 2 canais de escoamento adjacentes desenvolvida no domínio do fluido. Miller usou a teoria de placas para equacionar a diferença de pressões entre os canais de resfriamento com a força de recuperação elástica da placa para estimar a velocidade crítica $\left(U_{d}\right)$ na qual as placas colapsam. Com esta hipótese, a deflexão da placa pode ser quantificada usando a equação de Euler-Bernoulli aplicada a vigas em conjunto com aproximações lineares para vigas largas. Esta deflexão é usada para achar a distorção relativa do escoamento no canal. Com a equação de Bernoulli linearizada, calcula-se a variação de velocidade nos canais adjacentes devido a deflexão da placa e então se obtem a velocidade crítica do escoamento. Este acoplamento do domínio fluido com o domínio sólido é importante, pois demonstra que a estabilidade hidromecânica das placas não é somente dependente das condições hidráulicas mas também depende das condições mecânicas do sólido. Alguns autores denotam esta velocidade crítica do escoamento como "Velocidade de Miller". Embora Miller tenha desenvolvido um modelo novo e bastante útil para predizer a deflexão das placas quando submetidas a carregamentos hidráulicos, foi necessário um número significante de hipóteses simplificadoras.

Para placas planas, Miller assumiu as seguintes hipóteses, [2] e [15]:

- A placa é isotrópica, homogênea, linearmente elástica, inicialmente não deformada e perfeitamente plana, deformação simétrica sobre o eixo neutro, tem constantes mecânicas perfeitas ( Módulo de Young (E), razão de Poison (v) ) e as suas deformações são suficientemente pequenas para permitir o uso do teorema de EulerBernoulli para vigas,

- O fluido é incompressível e isotérmico e o escoamento está em regime permanente e é uniforme para todos os canais em qualquer ponto ao longo do comprimento dos canais,

- A tensão de cisalhamento nas placas é considerada desprezível e é aplicada a hipótese de estado plano de tensões,

- Os suportes na borda das placas são perfeitamente rígidos. 
É importante observar que Miller usou a equação de deformações para vigas engastadas e as aproximações de vigas largas, o que é apenas uma aproximação dos efeitos observados. As placas em questão são placas com combustível em seu interior e não vigas.

A equação (3.1) apresenta a expressão teórica de Miller para predizer a velocidade crítica do escoamento $\left(\mathbf{U}_{\mathbf{d}}\right)$ na qual um feixe longo de placas paralelas pode colapsar. Esta expressão é uma função das propriedades e da geometria da placa, do canal e das características do fluido:

$$
U_{d}=\left[\frac{15 \cdot E \cdot t_{p} \cdot t_{w}}{\rho \cdot W^{4}\left(1-v^{2}\right)}\right]^{0.5}
$$

Onde:

$\mathrm{U}_{\mathrm{d}}=$ Velocidade crítica de Miller $(\mathrm{m} / \mathrm{s})$,

$\mathrm{E}=$ Módulo de elasticidade da placa $(\mathrm{kPa})$,

$\mathrm{t}_{\mathrm{p}}=$ Espessura da placa $(\mathrm{mm})$,

$\mathrm{t}_{\mathrm{w}}=$ Espessura do canal de refrigerante $(\mathrm{mm})$,

$\rho=$ Massa específica do refrigerante $\left(\mathrm{kg} / \mathrm{m}^{3}\right)$,

$\mathrm{W}=$ Largura do canal de refrigerante $(\mathrm{mm})$,

$V$ = Coeficiente de Poisson da placa.

Em sequência aos estudos de Miller, Zabriskie, [16] e [17] conduziu trabalhos experimentais para validar a equação da velocidade crítica de Miller. Ele testou diferentes montagens de seção de testes com placas simples, placas múltiplas, diferentes dimensões de canais, diferentes comprimentos e larguras de placas. O resultado mais notável de Zabriskie foi que a velocidade crítica de escoamento predita pelo modelo de Miller não gerava o colapso do canal de escoamento, mas sim a condição de deflexão máxima das placas era alcançada. Ele também observou que os efeitos sobre o bordo de entrada das placas na entrada do escoamento foram bastante pronunciados, e que poderiam ser facilmente corrigidos por meio de um pente de suporte na entrada para melhorar a estabilidade dos canais de escoamento. Uma das principais tendências iniciadas por Zabriskie foi a de comparar a velocidade crítica medida como uma razão com a velocidade crítica predita pelo método de Miller. Subsequentes autores continuaram com esta tendência, não só comparando os seus valores medidos de velocidade crítica com o método de Miller mas também comparando seus proprios modelos de velocidade critica com o método de Miller. 
Em sequência a Zabriskie, Kane, [18], obteve progressos na área de hidromecânica conduzindo análises teóricas em que variava as condições de espaçamento na entrada do canal de resfriamento. Seus resultados mostraram que pequenas diferenças nas condições de espaçamento na entrada geraram grandes efeitos nas deflexões observadas.

Em 1963, Groninger and Kane, [19], realizaram investigações experimentais com seções de teste com 3 placas paralelas. Seu trabalho teve uma significativa relevância porque algumas das placas testadas tiveram construção heterogênea. Eles trabalharam empiricamente testando estas placas de uma maneira a criar uma placa hipotéticamente equivalente homogenea de zircônio com uma espessura equivalente. Esta placa hipotética foi aplicada ao método de Miller para predizer a velocidade crítica do escoamento. A validade desta metodologia é difícil de avaliar porque Groninger and Kane não detalharam os resultados destes testes empíricos realizados. O estudo apresentado tem muitos resultados interessantes, os quais mostraram que as placas testadas não tiveram um colapso violento mas apresentaram grandes deformações, também confirmado por Zabriskie, [16]. Eles também observaram que o início das vibrações das placas ocorreu em aproximadamente 1,9 vezes a velocidade crítica des escoamento prevista por Miller. Eles tambem observaram que as placas adjacentes deformaram consistentemente em direções opostas com magnitudes similares.

Muitos autores propuseram modificações no trabalho de Miller. Isto ocorreu de uma forma padronizada através de uma variedade de coeficientes multiplicativos de correção. Johansen, [20], foi o primeiro a fazer isto, e incluiu termos para quantificar a redistribuição de fluidos e efeitos de atrito no canal adjacente da placa de interesse. Wambsganss, [21], também fez isto; ele procurou capturar parte da informação perdida no processo de linearização aproximando o contorno de deformação na direção da largura do canal. Desta modificações, o trabalho de Smith, [22], é o mais utilizado na área de segurança nuclear. Smith escolheu redefinir a velocidade crítica de escoamento como pressão dinâmica crítica. O modelo de Smith também é um modelo semi-empírico, baseado em uma série de experimentos realizados com escoamento na fase gasosa e diferentes placas de material homogêneo. Ele modificou o tipo de análise incluindo fatores que quantificassem o aumento de deflexão nas borda e no ângulo de ataque produzido na borda. Estes termos foram classificados como modificação de área e modificação de sustentação. 
Em 1968, Smissaert, [23], desenvolveu trabalhos que envolveram pesquisa experimentais e analíticas sobre deflexões induzidas por escoamento e vibrações de placas planas. Smissaert testou vários conjuntos de placas planas. O mais notável foi que ele realizou experimentos com vazões muito altas equivalentes a 3,5 vezes a velocidade crítica de Miller. Ele observou experimentalmente duas velocidades críticas de escoamento, a primeira a velocidade critica predita por Miller que significa o início das grandes deformações estáticas. A segunda foi denominada de velocidade de vibração (flutter velocity) e significou o início das vibrações das placas. A velocidade de vibração foi observada no valor de aproximadamente 2 vezes a velocidade crítica de Miller. Em suas conclusões, Smisseart considerou o colapso das placas como uma instabilidade fluido elástica produzindo alternativamente abertura e fechamento dos canais de refrigeração com as placas colapsando em direções opostas.

Nos experimentos apresentados surgiram alguns resultados não coerentes como: (a) deflexão das placas em velocidades levemente inferiores a velocidade crítica de Miller e, (b) ausência do repentino colapso da placa previsto por Miller na velocidade crítica ou em sua proximidade. Nestes experimentos foi observado movimento gradual das placas em relação a sua posição central a cada incremento positivo da velocidade. Desta forma, o fenômeno de colapso das placas é considerado como sendo o momento no qual as placas se tocam após o movimento gradual.

Em 1977, Kim and Scarton, [24], usaram várias ferramentas computacionais para melhor analisar as deflexões induzidas pelo escoamento próximo a entrada em elementos combustíveis do tipo placa. Eles concluiram que o cisalhamento viscoso tem uma importância muito grande nas deflexões causadas na borda de entrada das placas. Eles tambem confirmaram resultados anteriores que recomendavam o uso de placas com pequenas razões de aspecto, razão entre o comprimento e a largura da placa.

Kim e Davis, [25], concluíram em investigação analítica que o colapso de placas é um tipo de falha de instabilidade estática que ocorre em velocidades moderadas, identificada como velocidade crítica estática divergente, $\mathrm{U}_{\mathrm{d}}$. Falhas do tipo instabilidade estática não devem ser confundidas com a instabilidade dinâmica de alta velocidade que ocorre com a velocidade crítica de ressonância $U_{R}$, quando a frequência de excitação do escoamento coincide com a frequência natural das placas de combustível.

Mais recentemente, em 2007, um conjunto de experimentos foram realizados por Ho, Hong e Mack, [26], para dar suporte ao projeto de concepção do Replacement Research 
Reactor - RRR da Australian Science and Technology Organisation - ANSTO, [27]. A seção de testes utilizada foi montada a partir de duas placas idênticas de alumínio que dividiam um conduto retangular em três canais de escoamento idênticos. As placas de alumínio tinham as dimensões de $780 \mathrm{~mm}$ x $78 \mathrm{~mm}$ e $1,2 \mathrm{~mm}$ e foram fixadas mecanicamente por meio de parafusos nas laterais. A seção transversal dos canais de escoamento possui as dimensões de $78 \mathrm{~mm}$ x 4,3 mm. A velocidade para o colapso das placas calculada com a equação de Miller foi de $15,4 \mathrm{~m} / \mathrm{s}$. O reator de pesquisa RRR é o projeto precursor ao Reator OPAL, que tem sido a base para o projeto do RMB.

Ho et al., [26], observaram deformações elásticas da abertura e fechamento do canal entre as placas por meio de sinais de extensômetros (straingauges) mesmo com baixas velocidades $(6,0 \mathrm{~m} / \mathrm{s})$. A Figura 3. 1 abaixo apresenta os resultados obtidos por Ho et al. para a monitoração da instabilidade fluido elástica.

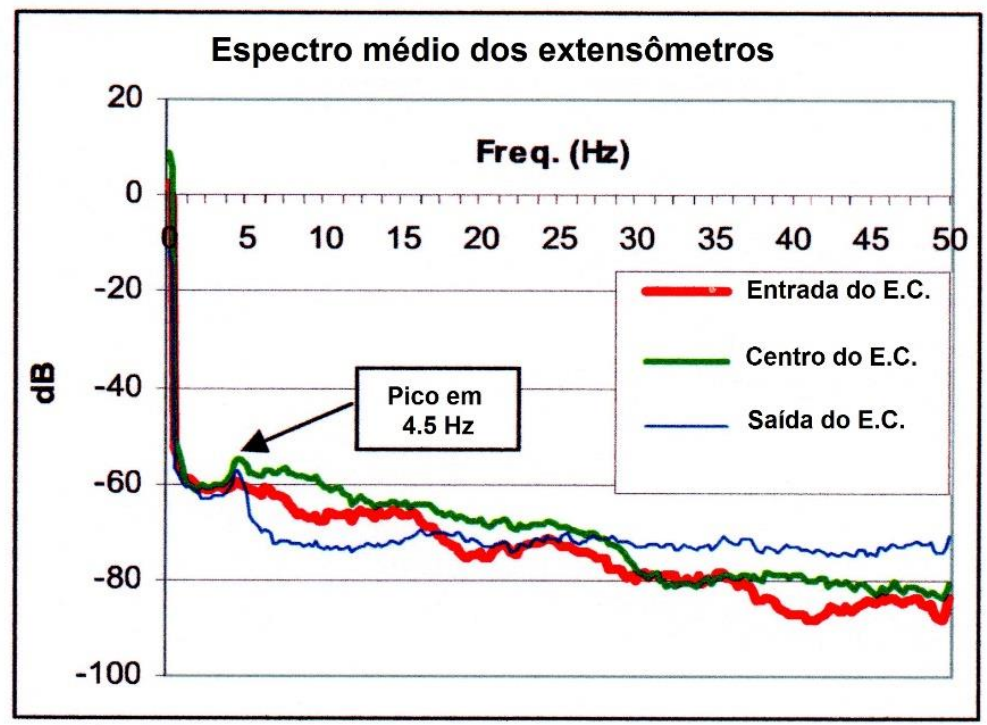

Figura 3. 1 - Espectro dos extensômetros para velocidade $6,0 \mathrm{~m} / \mathrm{s}(\operatorname{Re}=48360)$

Os resultados apresentaram uma vibração de baixa frequência que aparentemente permanece constante em $4,5 \mathrm{~Hz}$ para escoamentos turbulentos. Os resultados também mostraram que o aumento da velocidade do escoamento gerou maiores amplitudes de vibrações nesta frequência. Isto denota que o aumento da velocidade é acompanhado por uma excitação das placas devido à instabilidade fluido dinâmica até a ocorrência do colapso das placas com deformação plástica.

A Figura 3. 2 apresenta a seção de teste utilizada por Ho et al., [26], no pós-falha dos ensaios de velocidade crítica. Esta seção era composta por duas placas de alumínio formando três canais de escoamento. Ho et al., observaram que a máxima deflexão das placas ocorreu 
a $75 \%$ da velocidade crítica de escoamento de Miller, $12 \mathrm{~m} / \mathrm{s}$. Importante observar que nos experimentos realizados por Ho et al. não foram utilizados pentes de estabilização na entrada da seção de testes. Isto é significativo porque boa parte dos autores conseguiram obter melhores concordância dos seus resultados com a velocidade crítica de Miller quando usaram o pente de estabilidade.

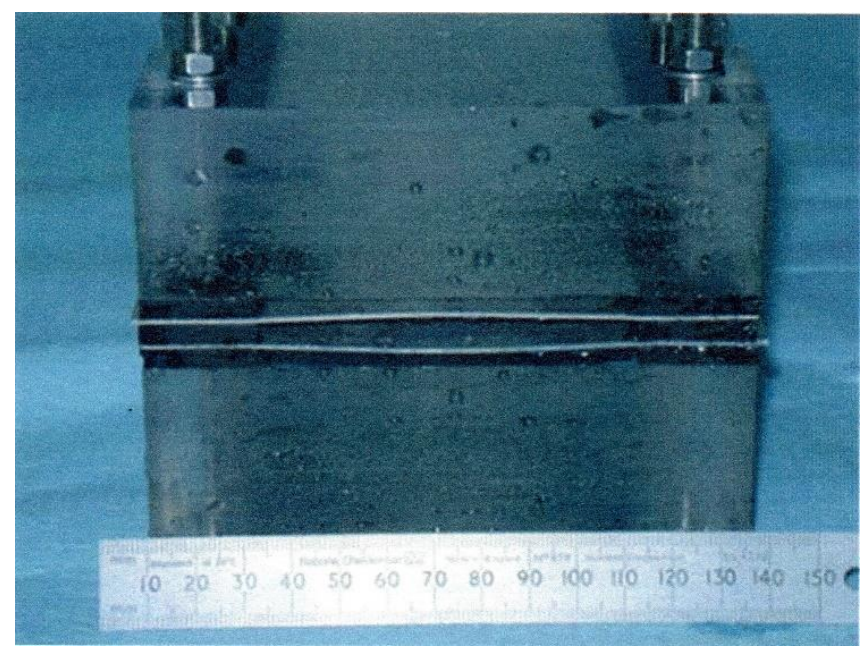

Figura 3. 2 - Vista da seção de testes placas planas após falha por velocidade crítica

A Figura 3. 3 apresenta os resultados de detecção do colapso das placas por Ho et al. utilizando extensometria.

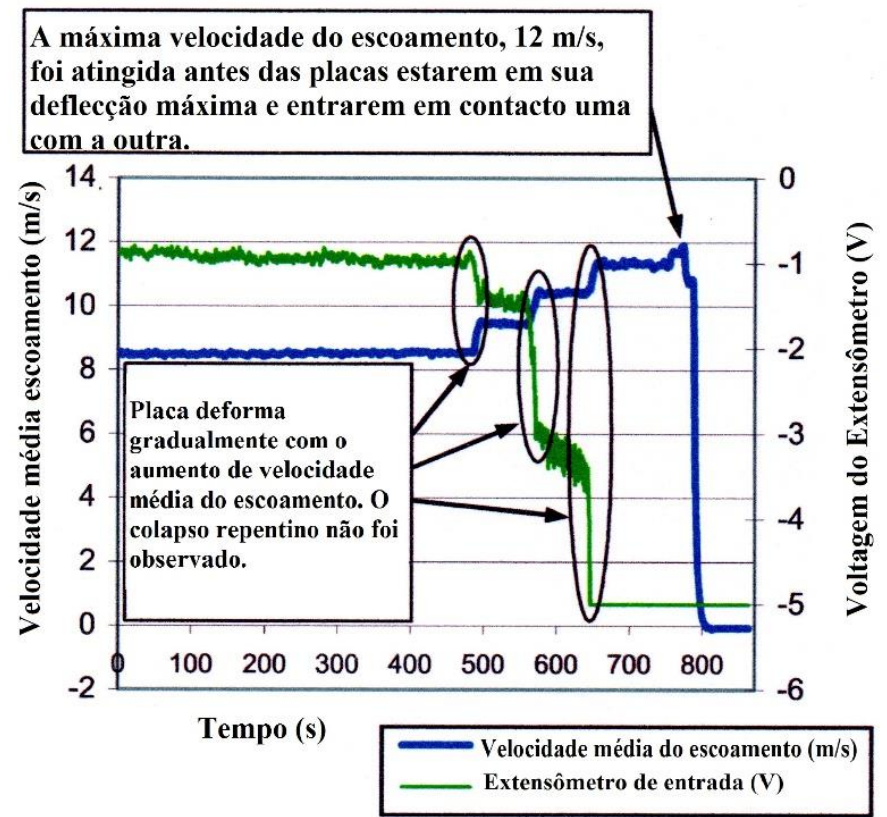

Figura 3. 3 - Velocidade $\mathrm{x}$ sinais de extensômetros para experimento de colapso de placas 
A medida da pressão estática serve como um método secundário para a detecção do colapso das placas. Isto se deve as mudanças nas características de perda de carga nos canais devido à deformação das placas. Na Figura 3. 4 abaixo pode ser observado o comportamento da velocidade do escoamento após a ocorrência da falha por colapso de placas no experimento de Ho et al..

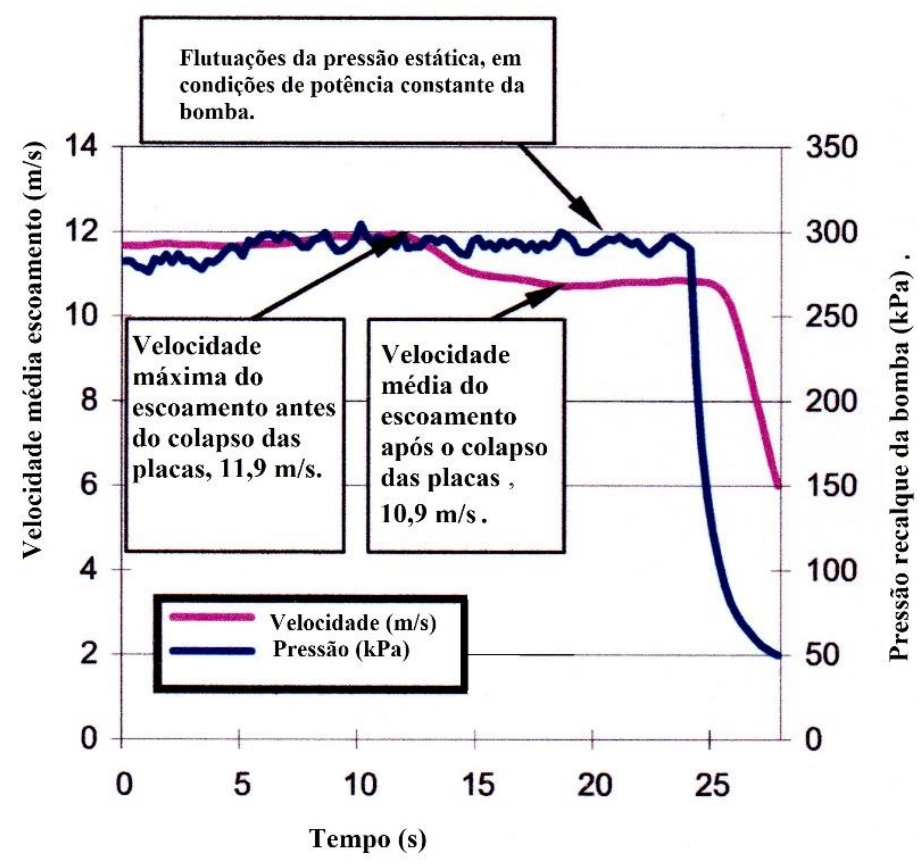

Figura 3. 4 - Comportamento da velocidade média com a falha de colapso de placas

Apesar da velocidade crítica de Miller ser uma representação teórica básica de uma fenomenologia bastante complicada e em parte ultrapassada quando comparada com as técnicas de Computational Fluid Dynamics (CFD) e Finite Element Analysis (FEA), [31], [32], [33], [34], [35], [36] e [37], é bastante utilizada devido a sua simplicidade para fornecer uma velocidade aproximada na qual o colapso das placas ocorrerá. Devido às incertezas, os projetistas usam uma boa margem de segurança entre os valores da velocidade crítica de Miller e a velocidade média do refrigerante nos canais. De acordo com IAEA-TECDOC233, [28], a velocidade média máxima do refrigerante nos canais deve ser $2 / 3 \mathrm{U}_{\mathrm{d}}$.

A necessidade de se impor uma margem de segurança foi mostrada nas investigações analíticas conduzidas por Kim and Davis, [25], as quais mostraram a ocorrência do colapso de placas abaixo da velocidade crítica de Miller, $0.9 \mathrm{U}_{\mathrm{d}}$.

O conhecimento da velocidade crítica de fluido refrigerante nas placas de combustível a serem utilizadas no RMB é de grande importância na fase de concepção dos 
elementos combustíveis, o que justifica a importância dos estudos propostos neste projeto de pesquisa. Um primeiro cálculo da velocidade crítica nos elementos combustíveis do RMB foi apresentado por Oliveira e Mattar, [29]. Utilizando a expressão de Miller com os dados do projeto de concepção do núcleo do $\mathrm{RMB}$, chegou-se ao valor de $\mathrm{U}_{\mathrm{d}}=16,8 \mathrm{~m} / \mathrm{s}$. Neste mesmo trabalho, Oliveira e Mattar também utilizaram uma expressão modificada para a velocidade de Miller, ver equação (3.2) abaixo, que leva em consideração o material das placas combustíveis e a espessura do revestimento $\left(t_{c}\right)$, o que está de acordo com IAEATECDOC-233, [28]. Com a expressão modificada a velocidade crítica de Miller foi $\mathrm{U}_{\mathrm{d}^{*}}=$ $16,0 \mathrm{~m} / \mathrm{s}$.

$$
\mathrm{U}_{\mathrm{d}^{*}}=\left[\frac{15 \cdot \mathrm{E} \cdot\left(\mathrm{t}_{\mathrm{p}}-\mathrm{t}_{\mathrm{c}}\right) \cdot \mathrm{t}_{\mathrm{w}}}{\rho \cdot \mathrm{W}^{4}\left(1-v^{2}\right)}\right]^{0.5}
$$

Usando o conceito da velocidade crítica de Miller, a velocidade média máxima nos canais de refrigerante para o RMB deve ser de 10,6 m/s, o que é consistente com a experiência internacional em projetos similares.

Em 2013, Jensen, [30], realizou pesquisas onde foi desenvolvido um modelo para cálculos de velocidade crítica em placas combustíveis de ligas de Urânio (U-Mo) dispersas em uma matriz de alumínio revestidas com alumínio laminado, estrutura tipo sanduiche. O estudo investigou dois métodos para determinação da velocidade crítica de placas laminadas. O objetivo foi realizado pela incorporação de um termo de rigidez à flexão na formulação da velocidade crítica de Miller, e empregando a teoria de estrutura sanduiche para determinar o termo de rigidez. O termo de rigidez a flexão foi derivado de duas maneiras. A primeira maneira foi chamada de analogia monocoque, e somente considera a contribuição mecânica do material das regiões externas para o cálculo da rigidez à flexão da placa. A segunda maneira considera a contribuição de cada camada para a rigidez à flexão. Os métodos apresentados por Jensen permitem cálculos simples para predizer a velocidade do escoamento ou pressão dinâmica que pode causar o colapso das placas. A simplicidade destes métodos permite que projetistas tenham uma ferramenta bastante útil para complementar outras formas de análises. $\mathrm{O}$ trabalho resultou em uma simples equação para cada tipo das 3 condições de fixação das bordas das placas, as quais predizem de uma forma confiável o início do colapso das placas. 


\section{METODOLOGIA}

Para alcançar os objetivos da pesquisa, o trabalho foi desenvolvido em sete etapas que são apresentadas ao longo deste texto:

1) Identificação dos métodos existentes para medir, estimar e predizer o começo da deformação plástica (colapso) em placas planas típicas de elementos de combustível através de carregamentos hidráulicos e isotérmicos.

2) Desenvolvimento, montagem e instrumentação de uma seção de testes com duas placas de alumínio e duas placas de acrílico, simulando três canais de refrigeração de elemento combustível. Esta seção foi instrumentada com sensores de deformação, sensores de pressão do tipo piezoelétrico, tubo de pitot e acelerômetro.

3) Desenvolvimento e montagem de uma bancada experimental com capacidade de fornecer escoamento com altas vazões e pressões para promover escoamentos que permitam carregamentos hidráulicos suficientes para a ocorrência de colapso das placas.

4) Desenvolvimento do Sistema de Aquisição de Dados.

5) Testes de comissionamento da Seção de Testes acoplada com a Bancada Experimental e o Sistema de Aquisição de Dados.

6) Realização de experimentos com a seção de teste em duas etapas:

- Experimentos variando a velocidade média da seção de testes até $12 \mathrm{~m} / \mathrm{s}$ para observar o comportamento da bancada experimental e as vibrações induzidas pelo escoamento e efeitos da instabilidade fluido elástica através das flutuações dos sinais de deformações e de pressões na seção de testes, - Experimentos com a velocidade média nos canais variando até atingir a velocidade crítica para observar o colapso das placas através dos sinais de deformação e de pressão na seção de testes.

7) Validação da técnica de detecção do colapso de placas, tipo de colapso e determinação dos valores de velocidade crítica através da análise dos resultados.

A primeira etapa é apresentada no capítulo 3 anterior de Revisão da Literatura. As etapas 2, 3, 4 e 5 são apresentadas neste capítulo, enquanto as etapas 6 e 7 são apresentadas respectivamente nos capítulos 5 e 6 referentes aos Experimentos e Análise de Resultados. 


\subsection{DESENVOLVIMENTO DA SEÇÃO DE TESTES}

Para o estudo do fenômeno de colapso de placas, detecção da velocidade crítica e análise do acoplamento fluido estrutura em placas planas, decidiu-se por um modelo de seção de testes que simulasse o elemento combustível com as características dimensionais básicas do projeto de um reator de pesquisa, como por exemplo o Reator Multipropósito Brasileiro, RMB.

\subsubsection{Descrição da Seção de Testes}

O modelo da seção de testes é composto por duas placas de alumínio, seis espaçadores de alumínio e duas placas de acrílico montadas em uma estrutura sanduiche que divide a seção de escoamento retangular em três canais de resfriamento idênticos. A Figura 4. 1 mostra um desenho esquemático dos componentes da estrutura. As placas são fixadas rigidamente por meio de trinta e seis parafusos allen de aço inox, M $6 \mathrm{~mm}$ x $50 \mathrm{~mm}$, ao longo do seu comprimento para formar a seção de testes. Existe uma diferença de comprimento entre as placas de acrílico e as placas de alumínio e os espaçadores das placas. Colocou-se um comprimento de entrada de $100 \mathrm{~mm}$ e um comprimento de saída de $50 \mathrm{~mm}$ dos canais para simular os bocais de entrada e saída na seção de testes. O bocal de entrada tem a sua importância na uniformização do escoamento para os canais. A seção de testes possui a parte superior e inferior livres com dimensões de $850 \mathrm{~mm}$ x 100,5 mm x 30,5 mm. Os bocais de entrada e saída são fechados através de quatro espaçadores complementares em acrílico, dois de $100 \mathrm{~mm}$ x $15 \mathrm{~mm}$ x 10,05 mm na entrada e dois de $50 \mathrm{~mm}$ x $15 \mathrm{~mm}$ x 10,05 mm. Na Figura 4. 1, também podem ser observados os sensores de deformação que estão posicionados na entrada, meio e saída da placa de alumínio. O modelo do elemento combustível tem uma das placas de alumínio instrumentada com extensômetros de 350 Ohm em três posições: na entrada (SG1 e SG2), centro (SG3 e SG4) e saída (SG5 e SG6) dos canais de refrigeração. Em cada uma das posições estão colocados dois extensômetros, um de cada lado da placa, para detectar as vibrações e deflexões para diferentes velocidades nos canais. Os extensômetros servem como método primário para detecção da deflexão na placa devido ao seu contato direto. Estes extensômetros são colados com epóxi na superfície da placa e selados com cola epóxi, Araldite. 
$\mathrm{Na}$ Figura 4. 2 são apresentados a estrutura sanduiche e um corte transversal do modelo do elemento combustível placas planas mostrando a seção de escoamento com três canais de refrigerante, $70,5 \mathrm{~mm} \times 2,45 \mathrm{~mm}$.

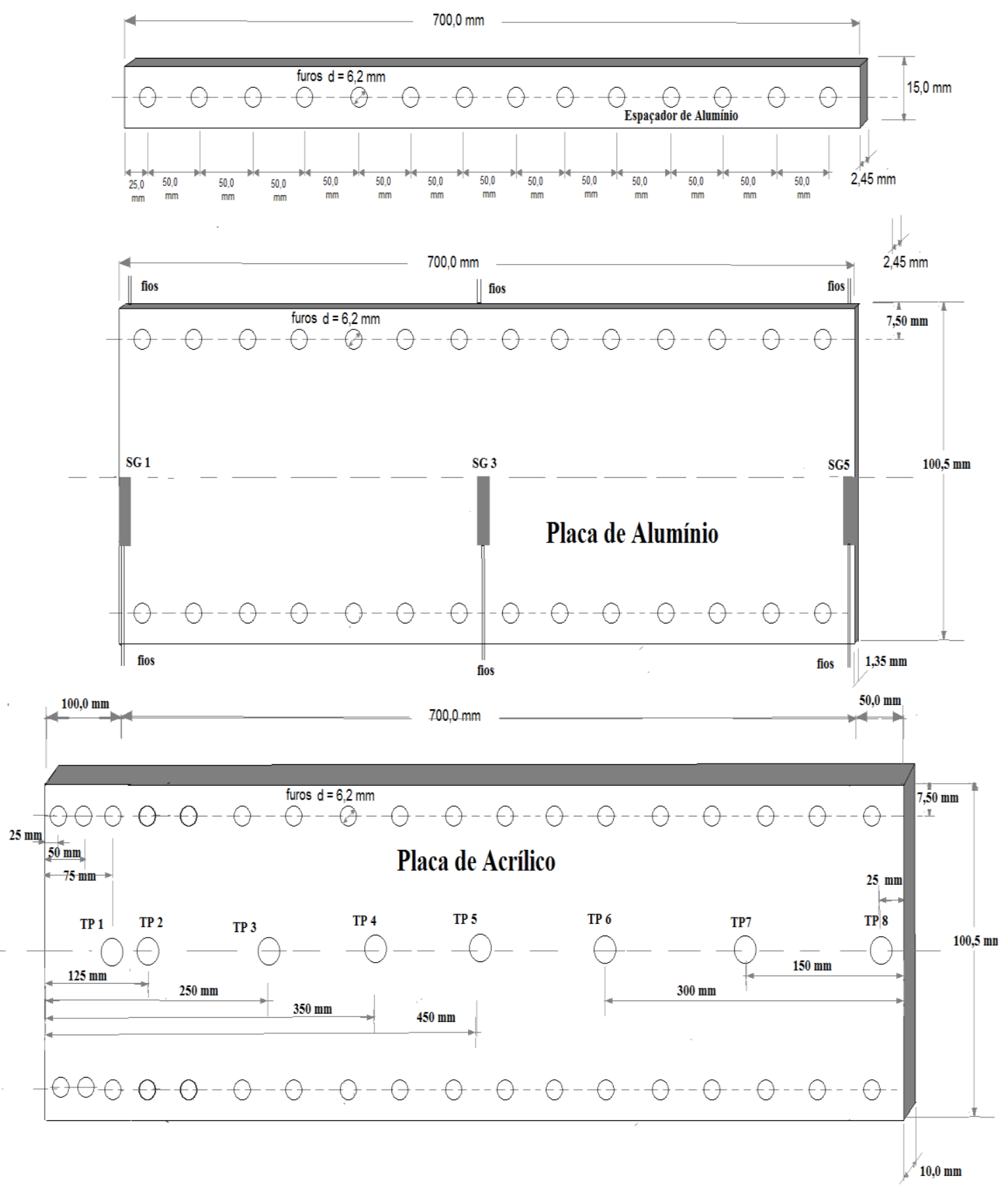

Figura 4. 1 - Desenho das placas para montagem da seção de testes 

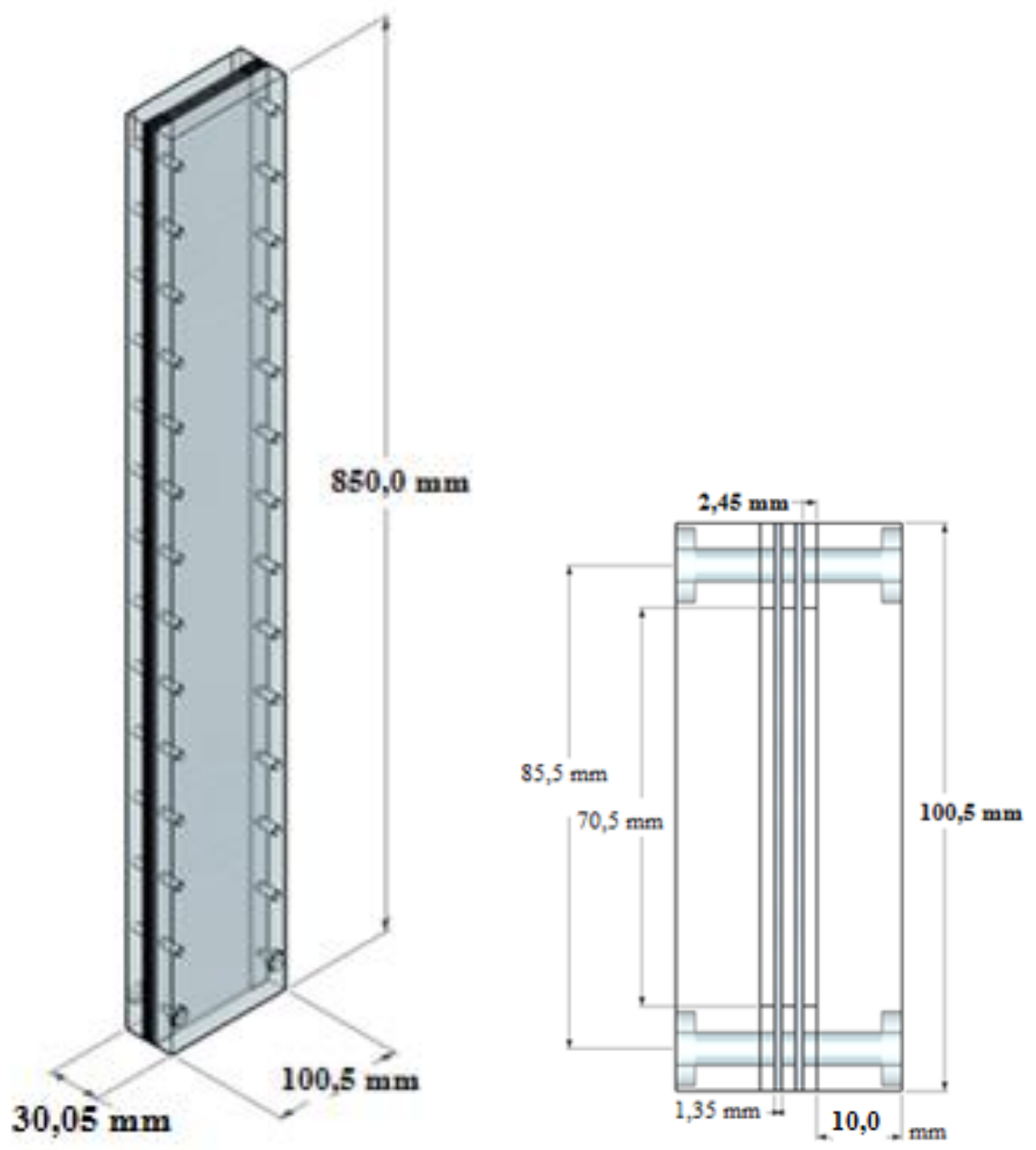

Figura 4. 2 - Modelo do elemento combustível tipo placas planas

A medida da pressão estática serve como um método secundário para a detecção do colapso das placas. Isto se deve as mudanças nas características de perda de carga nos canais devido à deformação das placas.

O modelo também está equipado com oito tomadas de pressão estática em intervalos axiais ao longo das placas de acrílico. Para a medida da pressão estática no canal de resfriamento estão instalados quatro microsensores piezoresistivos da fabricante "Kulite" na placa de acrílico externa ao canal de escoamento próximo aos sensores de deformação, extensômetros fornecidos pela Excel. Com relação à Figura 4. 1, os microtransdutores de pressão estão instalados nas posições TP1, TP2, TP5 e TP8.

A Figura 4. 3 mostra fotos dos extensômetros instalados na seção de testes. 


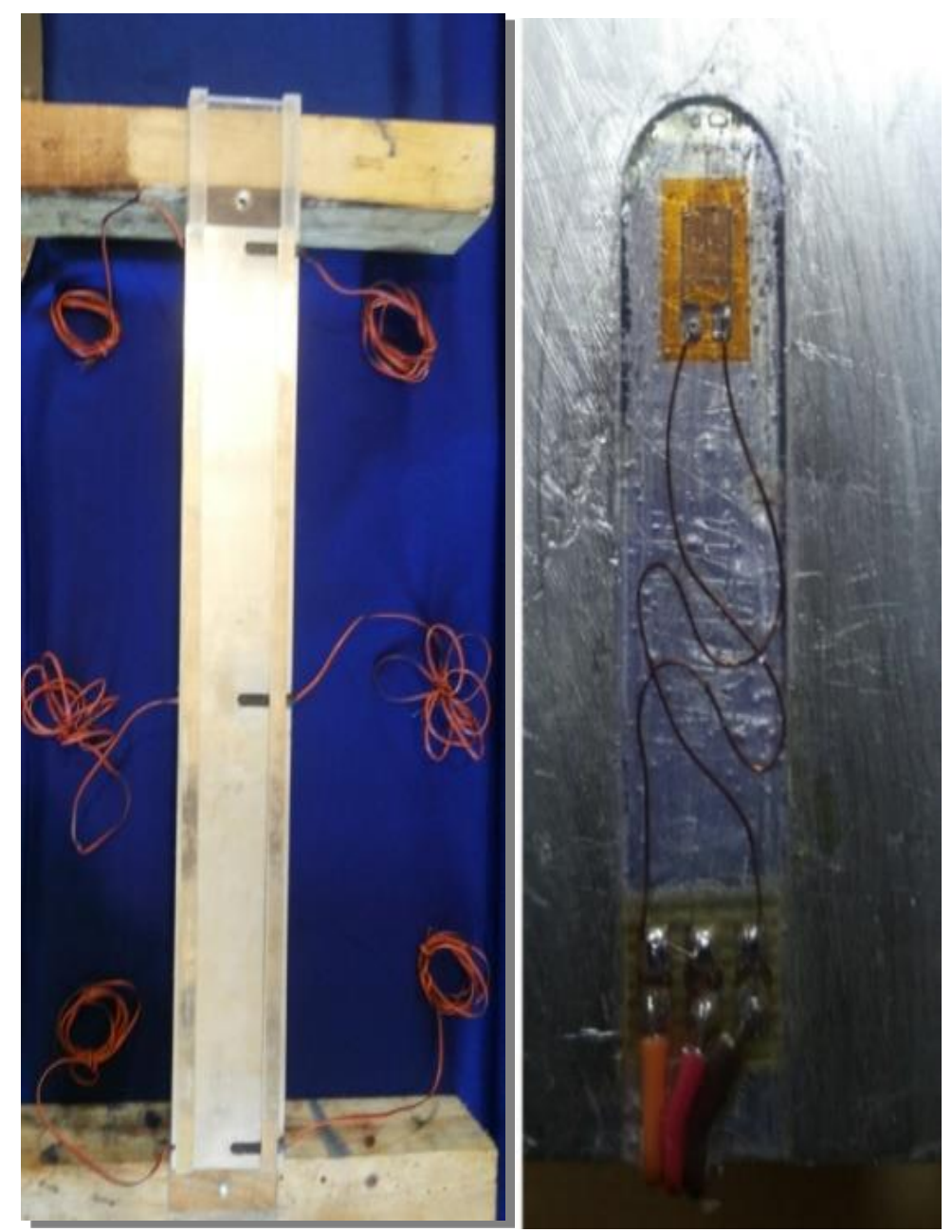

Figura 4. 3 - Extensômetros instalados na seção de testes

Para a realização dos experimentos, o modelo está montado verticalmente na seção de testes sendo fixado na tampa superior da câmara de entrada ( $D=500 \mathrm{~mm}, \mathrm{~h}=635 \mathrm{~mm})$. Esta câmara de entrada é construída em alumínio e forma um Plenum que produz a entrada do escoamento com velocidade uniforme para os três canais de resfriamento. Na parte externa ao modelo do elemento está fixado um canal quadrado de alumínio (250 mm x 250 $\mathrm{mm} \times \mathrm{h}=940 \mathrm{~mm}$ ) com janelas em policarbonato (inicialmente acrílico), que tem a função principal de permitir o retorno do escoamento ao circuito da bancada experimental, saída e vedação da instrumentação do modelo, visualização e acesso de um anemômetro a laser aos canais de refrigerante no futuro. A seção de testes para os experimentos pode ser visualizada na Figura 4. 4 e na fotografia apresentada na Figura 4. 5, onde pode-se observar os sensores de deformação e de pressão estática. 

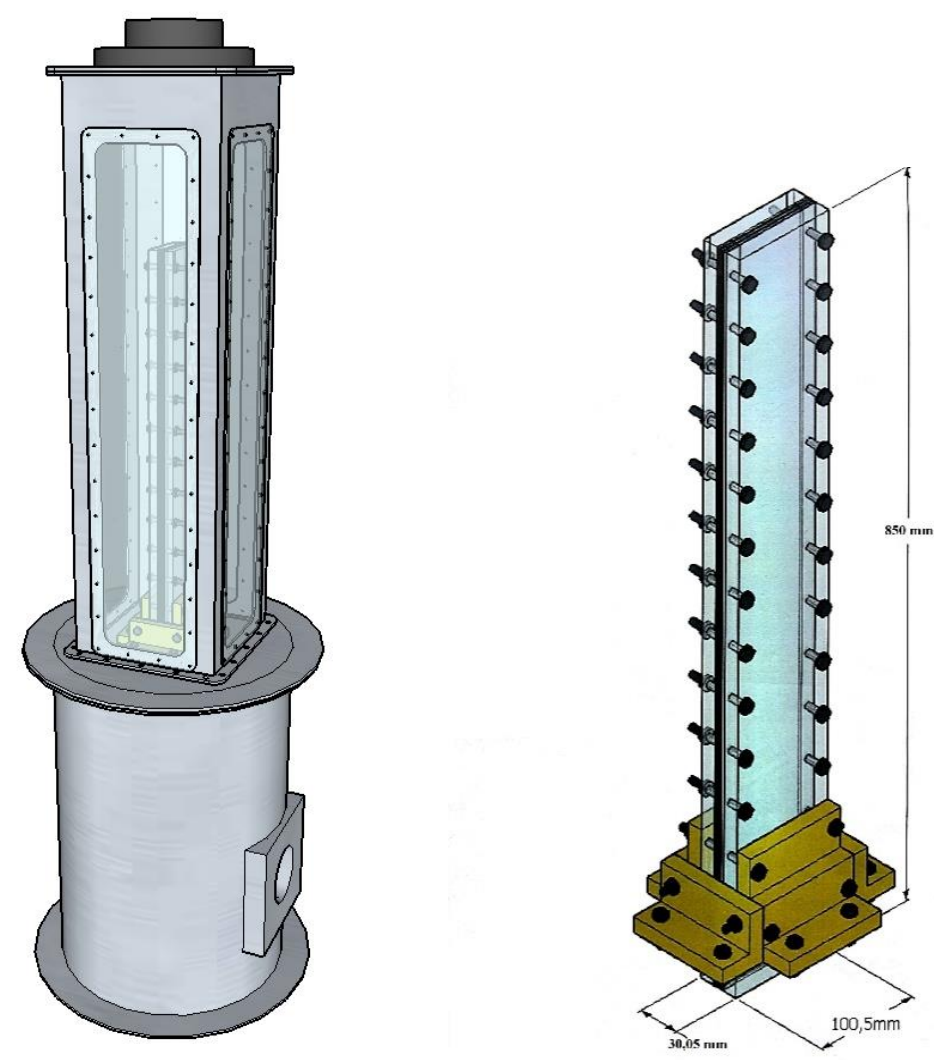

Figura 4. 4 - Seção de testes para os experimentos com o modelo de elemento Combustível

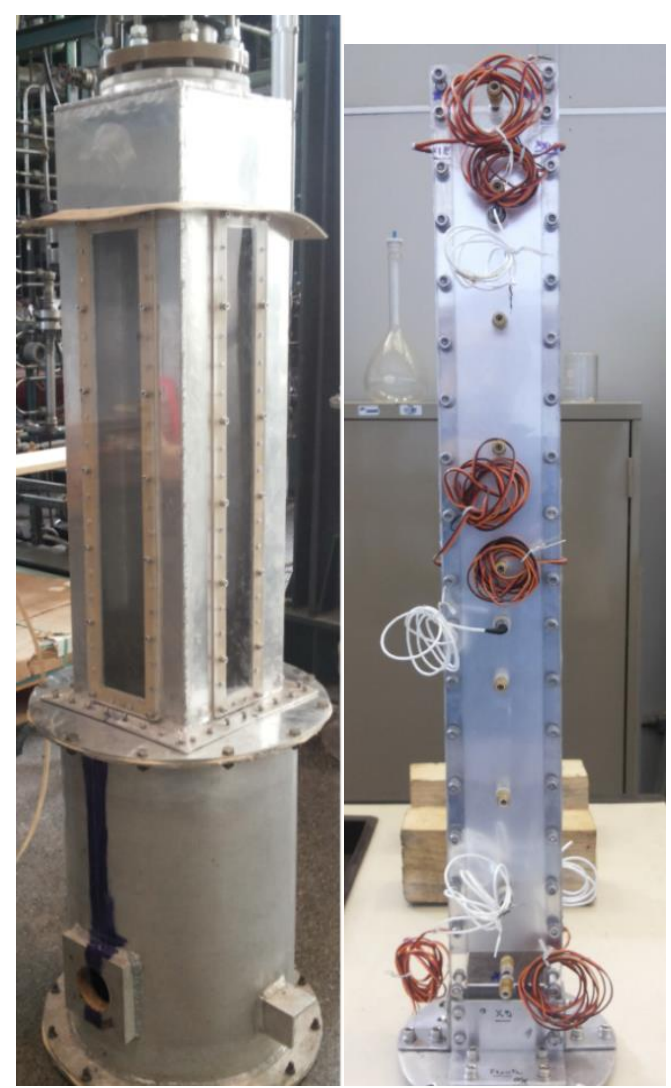

Figura 4. 5 - Fotografia da Seção de Testes com o simulador instrumentado do elemento combustível 
O posicionamento do modelo simulador do elemento combustível na câmara de entrada do escoamento é obtido através da placa de fixação de alumínio de $5 \mathrm{~mm}$ de espessura que é mostrada na Figura 4. 6. O conjunto que forma o modelo do elemento combustível se encaixa na placa e é fixado através de cantoneiras de alumínio aparafusadas na placa de fixação de alumínio e nas placas externas de acrílico do simulador do elemento por meios de parafusos allen M6 de aço inox. A placa de fixação é posicionada na tampa superior da câmara de entrada por meio de parafusos M10 com cabeça sextavada de aço carbono. As cantoneiras e a placa de fixação podem também ser observados na Figura 4. 4 e Figura 4. 5.

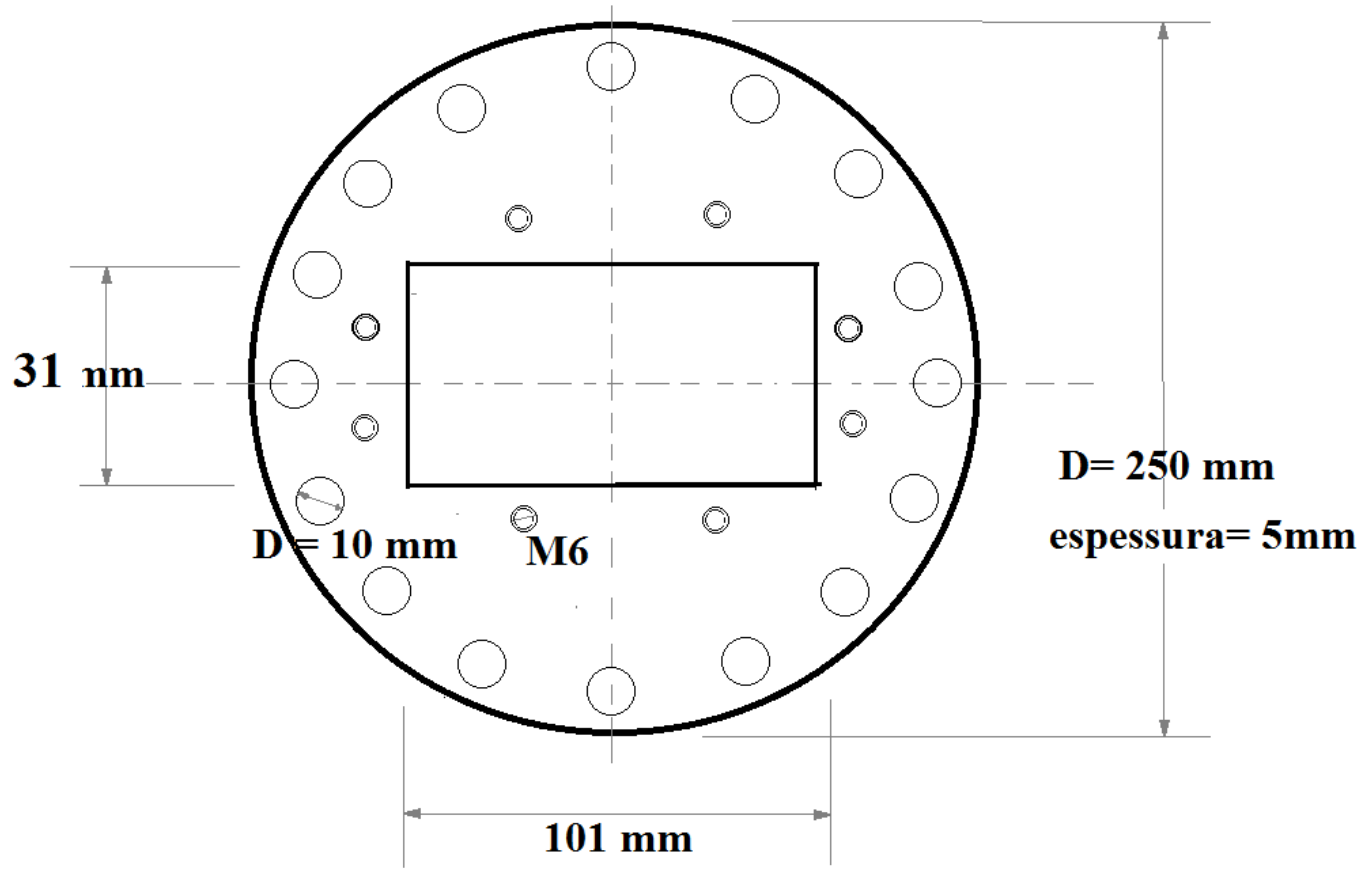

Figura 4. 6 - Placa de fixação do modelo simulador do elemento combustível tipo placas planas

Para o conhecimento da velocidade nos canais do modelo do elemento combustível foi instalado um tubo de pitot no centro do bocal de saída. O sinal do tubo de pitot é direcionado para um medidor de pressão do tipo diafragma, marca "Validyne". Para o cálculo da velocidade máxima (m/s) na saída do canal, é utilizada a Equação 4.1 derivada da Equação de Bernoulli, [38] a [41] e [61] a [62], onde o $\Delta \mathbf{P}$ (Pascal) é obtido através de sensor tipo diafragma. 


$$
V=\sqrt{\frac{\Delta P_{p t} \cdot 2 g}{\gamma_{H 2 O}}}, \quad[\mathrm{~m} / \mathrm{s}]
$$

Onde:

- $\mathrm{g}=9,8 \mathrm{~m} / \mathrm{s}$, constante gravitacional;

- $\Delta \mathrm{P}=$ diferença entre pressão total e pressão estática, pressão dinâmica;

$-\gamma_{\mathrm{H} 2 \mathrm{O}}=10.000 \mathrm{~N} / \mathrm{m}^{3}$, peso específico da água.

O plenum da seção de testes também foi instrumentado com um termopar do tipo K da Ômega e um manômetro de bourdon (escala 0 a $6 \mathrm{kgf} / \mathrm{cm}^{2}$ ). O canal quadrado de fechamento da seção de testes está instrumentado com um acelerômetro fornecido pela "Bruel\&Kjaer", um termopar tipo K fornecido pela Ômega e um manômetro de bourdon (escala $0-4 \mathrm{kgf} / \mathrm{cm}^{2}$ ).

A pressão de entrada na seção de testes é obtida através de um transdutor de pressão piezoelétrico da empresa "Hydac"(escala 0-10 bar).

O propósito dos manômetros na seção de testes é a medida rápida e visual da queda de pressão ao longo da seção de testes e a verificação da estanqueidade entre o plenum de entrada e a caixa de saída da seção de testes.

\subsubsection{Parâmetros hidráulicos}

Para definição dos parâmetros hidráulicos dos experimentos de colapso de placas e consequente medição de valores de velocidade crítica, adotou-se a Equação de Miller, Eq.3.1, e os parâmetros dimensionais e propriedades dos materiais das placas combustíveis do projeto de concepção do RMB.

Considerando:

$$
\begin{aligned}
& \mathrm{E}=70,0 \text { × } 10{ }^{9} \mathrm{~Pa} \text {, módulo de elasticidade do alumínio; } \\
& v=0,33 \text {, razão de poisson alumínio; }
\end{aligned}
$$


$\mathrm{t}_{\mathrm{p}}=1,35 \mathrm{~mm}$, espessura da placa de alumínio;

$\mathrm{w}=70,5 \mathrm{~mm}$, largura do canal de escoamento;

$\mathrm{t}_{\mathrm{w}}=24,5 \mathrm{~mm}$,espessura do canal de escoamento;

$\rho_{\text {água }}=998,2 \mathrm{~kg} / \mathrm{m}^{3}$, densidade do refrigerante à $25^{\circ} \mathrm{C}$.

Utilizando-se a Eq. 3.1, chegou-se a um valor da velocidade crítica de Miller de $\mathrm{U}_{\mathrm{d}}=16,97 \mathrm{~m} / \mathrm{s}$. Utiliza-se o valor de $\mathbf{U}_{\mathbf{d}}=\mathbf{1 7 , 0} \mathbf{~ m} / \mathbf{s}$.

Para área de escoamento de cada canal de resfriamento tem-se:

$$
A_{\text {esc }}=t_{w} \times w=2,45 \mathrm{~mm} \times 70,5 \mathrm{~mm}=172,73 \mathrm{~mm}^{2}=172,73 \times 10^{-6} \mathrm{~m}^{2} .
$$

A vazão volumétrica para um canal de resfriamento é dada por:

$$
Q_{\text {canal }}=U_{d} \times A_{\text {esc }}=2,93610^{-3} \mathrm{~m}^{3} / \mathrm{s}=2,936 \mathrm{l} / \mathrm{s}=10,571 \mathrm{~m}^{3} / \mathrm{h} \text {. }
$$

A vazão volumétrica para a seção de testes é dada pela vazão de três canais de resfriamento,

$$
Q_{\text {seção }}=3 . Q_{\text {canal }}=8,80810^{-3} \mathrm{~m}^{3} / \mathrm{s}=8,808 \mathrm{l} / \mathrm{s}=31,712 \mathrm{~m}^{3} / \mathrm{h}
$$

Para análise das perdas de carga na seção de testes, a mesma foi dividida em um bocal de entrada, três canais de escoamento das placas planas e um bocal de saída. A perda de carga é dividida em perdas distribuídas e perdas singulares. As perdas singulares ocorrem na contração do bocal de entrada para os canais de escoamento e na expansão dos canais para o bocal de saída. Para os cálculos do fator de atrito é utilizado o gráfico de "Moody" obtidos de Brunetti, [38] e Fox [40]. Os fatores de perda singular para expansões e contrações foram obtidos de Çengel\&Cimbala, [39] e Munsen, [41]. Os resultados são apresentados na Tabela 4. 1 de cálculos das perdas de carga na seção de testes. Somadas todas as perdas estimadas chega-se a um valor de $\Delta \mathbf{P}_{\text {total }}=\mathbf{4 5 , 7 7} \mathbf{m}$. 
Tabela 4. 1 - Cálculos estimativos da perda de carga para velocidade crítica de Miller

\begin{tabular}{|c|c|c|c|}
\hline 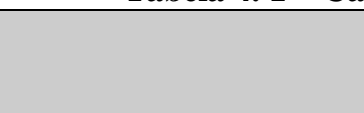 & Bocal de Entrada & $\begin{array}{c}\text { Canal de } \\
\text { Escoamento }\end{array}$ & Bocal de Saída \\
\hline $\begin{array}{c}\text { Área escoamento } \\
\mathbf{A}_{\text {esc }}\end{array}$ & $708,525 \times 10^{-6} \mathrm{~m}^{2}$ & $518,175 \times 10^{-6} \mathrm{~m}^{2}$ & $708,525 \times 10^{-6} \mathrm{~m}^{2}$ \\
\hline $\begin{array}{c}\text { Velocidade Média } \\
\text { V }\end{array}$ & $12,43 \mathrm{~m} / \mathrm{s}$ & $17,0 \mathrm{~m} / \mathrm{s}$ & $12,43 \mathrm{~m} / \mathrm{s}$ \\
\hline $\begin{array}{c}\text { Diâmetro } \\
\text { Hidráulico } \\
\mathbf{D}_{\mathbf{H}}\end{array}$ & $17,592 \times 10^{-3} \mathrm{~m}$ & $4,735 \times 10^{-3} \mathrm{~m}$ & $17,592 \times 10^{-3} \mathrm{~m}$ \\
\hline $\begin{array}{c}\text { Reynolds } \\
\mathbf{R e}=\mathbf{V} . \mathbf{D}_{\mathbf{H}} / \mathbf{v}\end{array}$ & 218.669 & 80.500 & 218.669 \\
\hline $\begin{array}{c}\text { Coeficiente Atrito } \\
\mathbf{f} \\
\text { (Gráfico Moody) }\end{array}$ & $\mathbf{0 , 0 1 6}$ & $\mathbf{0 , 0 1 9}$ & 0,016 \\
\hline $\begin{array}{l}\text { Perda distribuída } \\
\boldsymbol{h}_{\boldsymbol{f}}=\boldsymbol{f} \cdot \frac{\boldsymbol{L}}{\boldsymbol{D}_{\boldsymbol{h}}} \cdot \frac{\boldsymbol{V}^{2}}{2 \cdot \boldsymbol{g}}\end{array}$ & $0,53 \mathrm{~m}$ & $40,29 \mathrm{~m}$ & $0,53 \mathrm{~m}$ \\
\hline $\begin{array}{l}\text { Perda singular } \\
\boldsymbol{h}_{\boldsymbol{s}}=\boldsymbol{K}_{\boldsymbol{s}} \cdot \frac{\boldsymbol{V}^{2}}{\mathbf{2} \cdot \boldsymbol{g}}\end{array}$ & $2,21 \mathrm{~m}$ & L & $2,21 \mathrm{~m}$ \\
\hline $\begin{array}{l}\text { Perda Total } \\
\mathbf{H}_{\mathbf{P}}=\boldsymbol{h}_{\mathbf{f}}+\mathbf{h}_{\mathbf{s}}\end{array}$ & $2,74 \mathrm{~m}$ & 40,29 & $2,74 \mathrm{~m}$ \\
\hline $\begin{array}{c}\text { Perda Total na } \\
\text { Seção de Teste, } \text { HPT }_{\mathbf{P}}\end{array}$ & & & $\begin{array}{c}H_{P T}=\Sigma H_{P i} \\
45,77 \mathrm{~m}\end{array}$ \\
\hline
\end{tabular}




\subsection{DESENVOLVIMENTO DA BANCADA EXPERIMENTAL}

Para o desenvolvimento da pesquisa de velocidade crítica em elementos de combustível tipo placas planas paralelas foi desenvolvida e montada uma nova bancada de testes experimentais no Centro de Engenharia Nuclear (CEN), Figura 4. 7, com o apoio parcial do CNPq através projeto CNPq n. 481193/2012-0 do Edital Universal 14/2012, [42] e [43].

\subsubsection{Descrição da Bancada Experimental}

A bancada possui um tanque de $2,5 \mathrm{~m}^{3}$, uma bomba principal (B1) com capacidade de $100 \mathrm{~m}^{3} / \mathrm{h}$ de vazão volumétrica e 60 metros de altura manométrica, seção de testes, medidor de vazão tipo placa de orifício (PO), filtros, radiador para resfriamento da potência dissipada da bomba, deaerador, válvula globo para regulagem de vazão, válvulas borboleta para desvios de vazão, manômetros e tubulações de PVC industrial $(\mathrm{D}=110 \mathrm{~mm}, \mathrm{D}=85 \mathrm{~mm}$ e $\mathrm{D}=60 \mathrm{~mm})$.

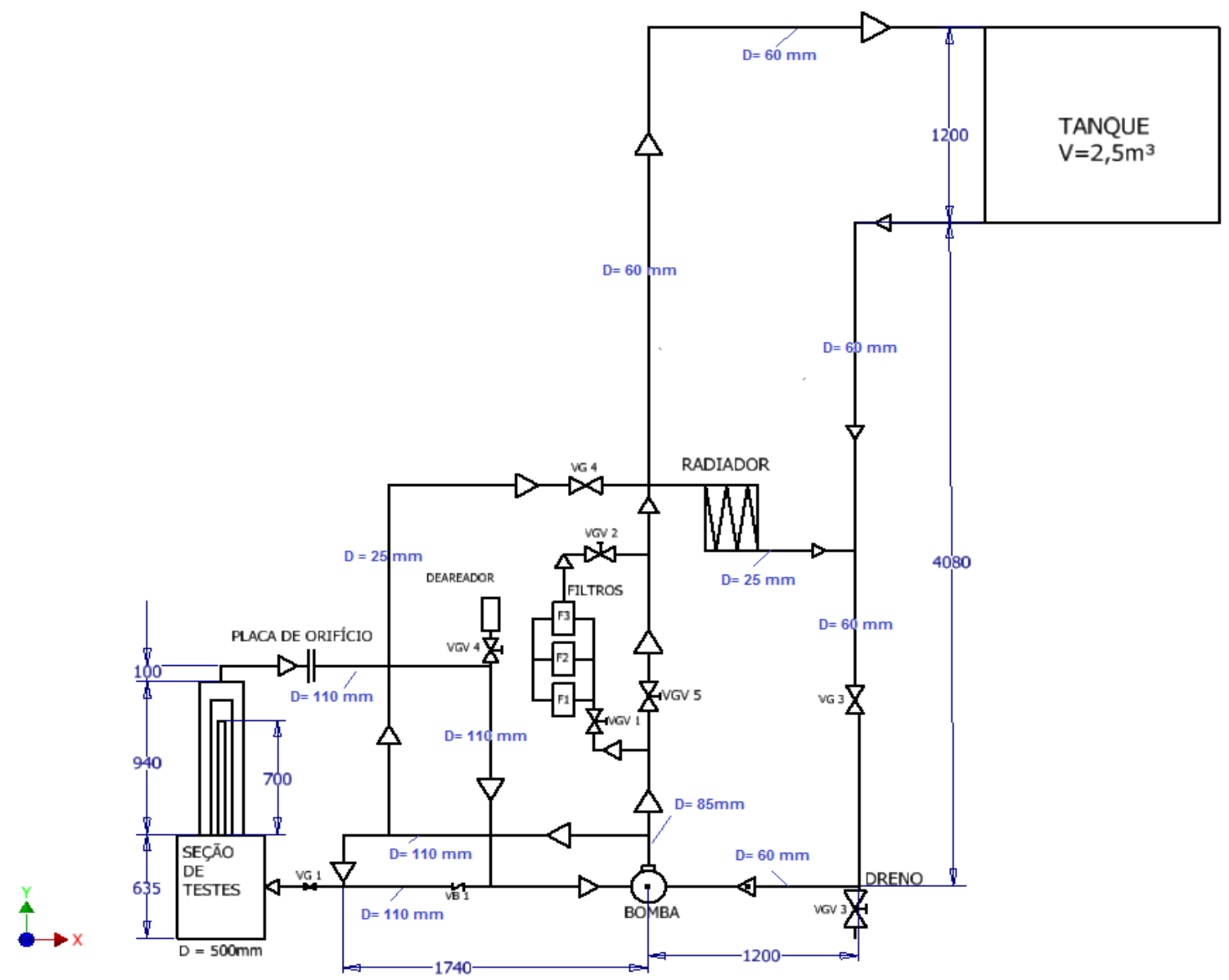

Figura 4. 7 - Desenho esquemático da bancada experimental 
A Figura 4. 8 mostra a bancada experimental com a seção de testes montada e a Figura 4. 9 mostra o novo quadro de comando elétrico da bomba.

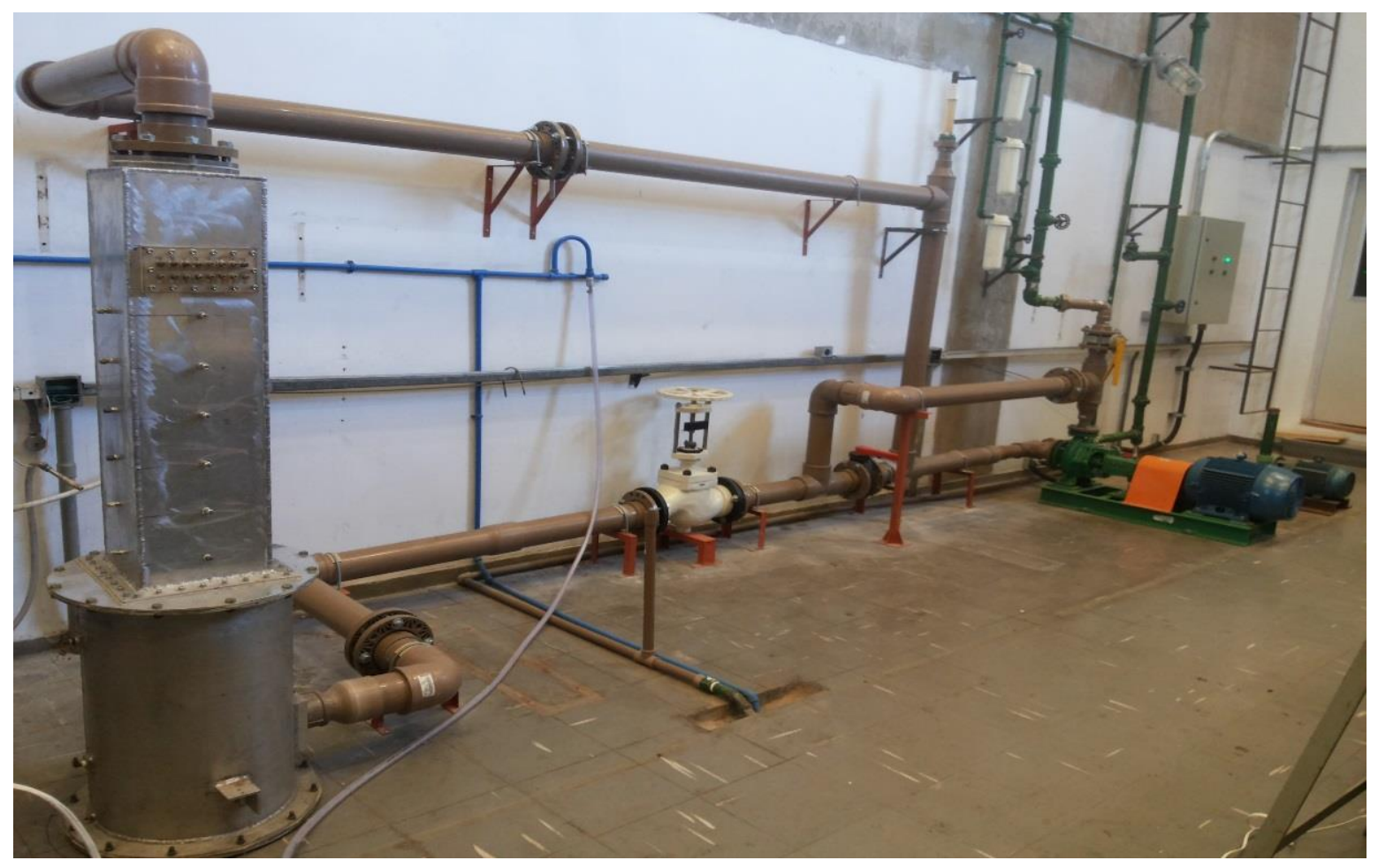

Figura 4. 8 - Bancada experimental para os estudos de velocidade crítica
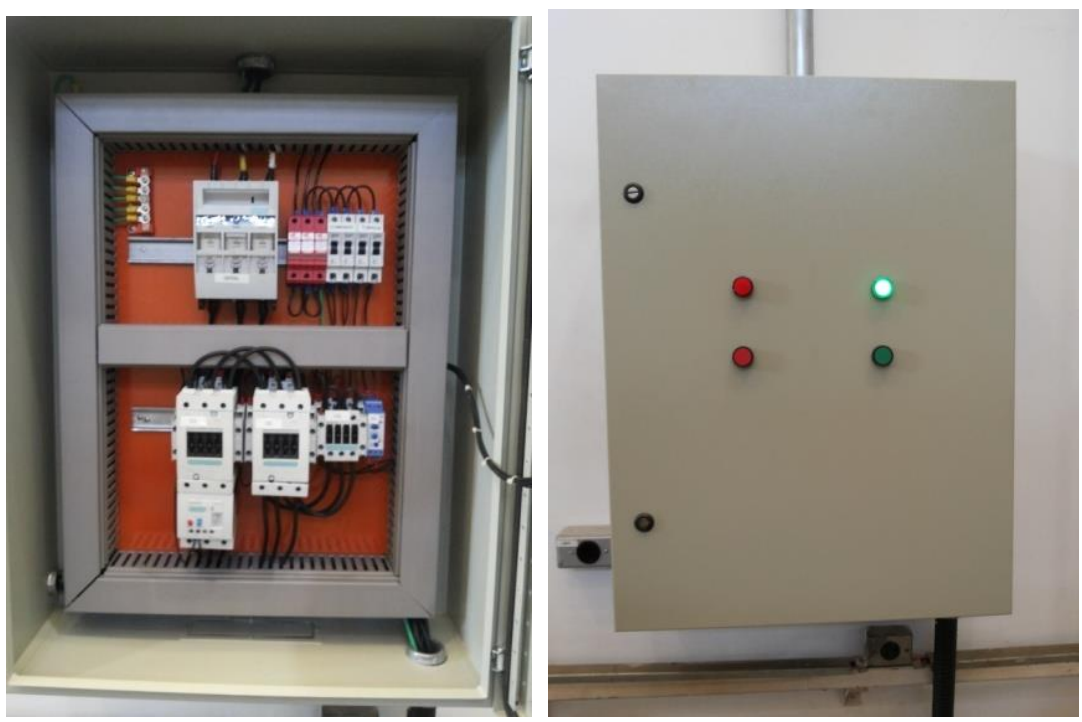

Figura 4. 9 - Quadro de comando elétrico da bomba 
A bancada experimental foi desenvolvida e dimensionada para fornecer as condições operacionais necessárias para os ensaios da seção de testes para experimentos de instabilidade fluido elástica e testes de colapso de placas por velocidade crítica com a seção de teste do modelo simulador com três canais de escoamento e duas placas planas de alumínio baseadas no projeto do elemento combustível do RMB.

Para a montagem da bancada foi montada uma bomba centrífuga com capacidade de vazão volumétrica de $100 \mathrm{~m}^{3} / \mathrm{h}$ e altura manométrica de 50 metros de coluna de água. Esta bomba foi fornecida pela empresa IMBIL, bomba modelo INI 50-160 com rotação de 3500 rpm. A Figura 4. 10 apresenta as curvas características da bomba.

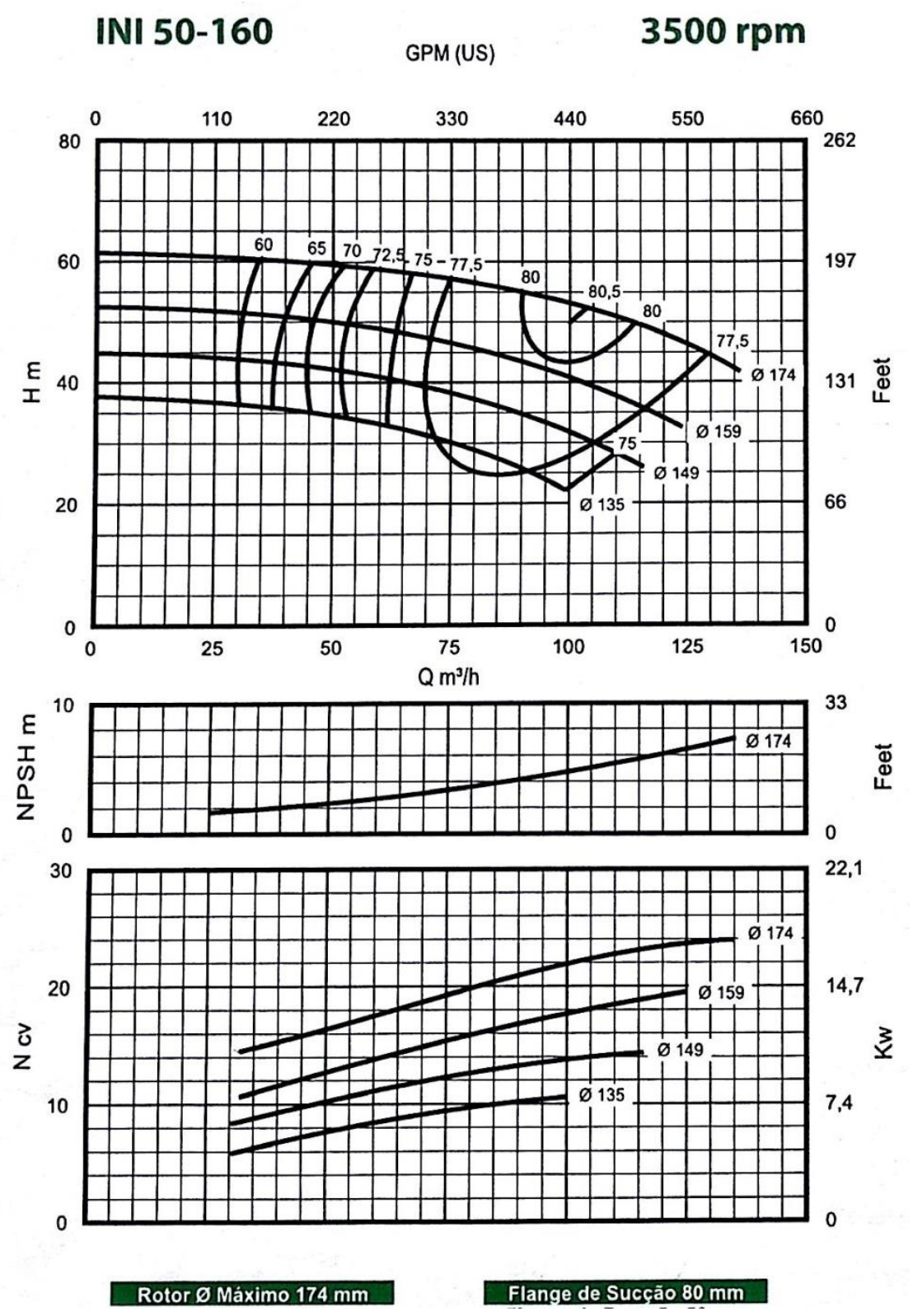

Figura 4. 10 - Curvas características da bomba 
Uma placa de orifício é responsável pela medida de vazão volumétrica que escoa pelos três canais de resfriamento. Para medida da vazão foi utilizado uma placa com orifício de $D_{0}=37 \mathrm{~mm}$ e espessura e=3,2 $\mathrm{mm}$, fixada e centralizada entre flanges, na tubulação de saída da seção de testes de diâmetro externo $D_{\mathrm{e}}=110 \mathrm{~mm}$ e diâmetro interno $\mathrm{D}_{\mathrm{i}}=96 \mathrm{~mm}$. São utilizadas tomadas de pressão à distâncias $\mathrm{D}$ e $\mathrm{D} / 2$, respectivamente à montante e à jusante do escoamento. Para uniformização do escoamento, a placa está localizada à 1520 milímetros da última singularidade, um joelho de $90^{\circ}$ de $\mathrm{D}=110 \mathrm{~mm}$. Para cálculos da vazão utiliza-se a Equação 4.2, derivada da equação de bernoulli e da equação de conservação de massa para fluidos incompressíveis, [38] e [41], considerando $\beta=\left(\mathrm{D}_{\mathrm{o}} / \mathrm{D}_{\mathrm{i}}\right)=0,3875$, e um coeficiente de descarga $C_{D}=0,6037$. O coeficiente de descarga foi calculado utilizando a norma NBRISO5167-1 da ABNT, [44].

$$
\begin{array}{lll}
Q_{\text {seção }}=2,94 \cdot 10^{-3} \cdot \sqrt{\Delta P_{p o} / \gamma} \quad, & {\left[\mathrm{m}^{3} / \mathrm{s}\right]} \\
Q_{\text {seção }}=10,5828 \cdot \sqrt{\Delta P_{p o} / \gamma} \quad, & {\left[\mathrm{m}^{3} / \mathbf{h}\right]}
\end{array}
$$

Onde:

- $\Delta \mathrm{P}_{\mathrm{po}}=$ diferença entre pressão antes e após a placa de orifício em Pascal, medida por um sensor de pressão do tipo diafragma, marca Validyne.

$-\gamma=10.000 \mathrm{~N} / \mathrm{m}^{3}$, peso específico da água.

A Figura 4. 11 mostra detalhes da Placa de orifício, do sensor tipo diafragma e da eletrônica associada aos sensores da placa de orifício, tubo de pitot e perda de carga total na seção.

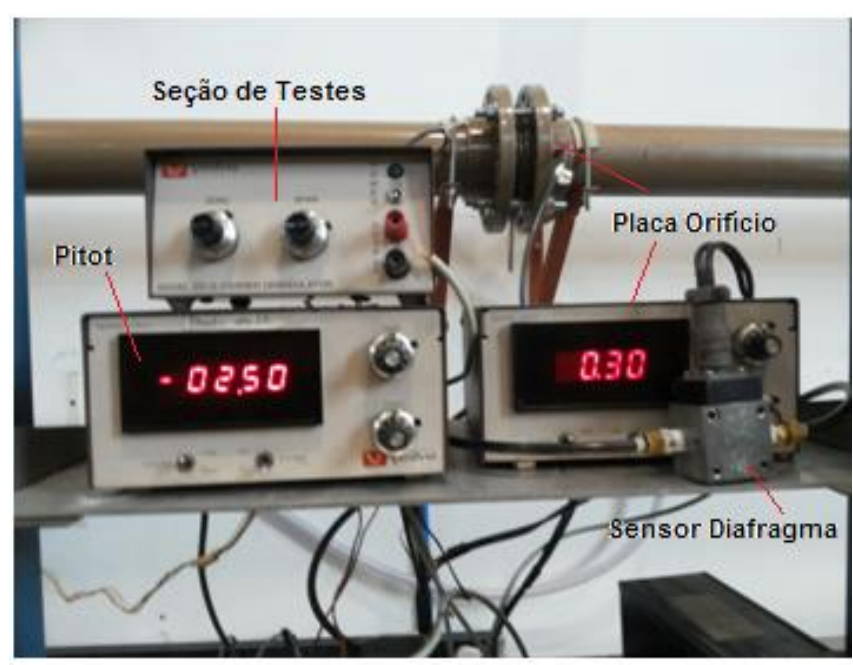

Figura 4. 11 - Placa de orifício com o sensor tipo diafragma e a eletrônica associada. 
A velocidade média nos canais de escoamento da seção de testes é calculada pela divisão da vazão volumétrica medida pela placa de orifício dividida pela área de escoamento dos três canais. Assume-se a hipótese de que a vazão é distribuída uniformemente nos canais. De acordo com a norma NBRISO5167-1, [44], e o manual Fluid Meters da ASME, [45], a incerteza da placa de orifício é da ordem de $5 \%$ no máximo.

A Tabela 4. 2 apresenta comparações entre os valores de velocidade média nos canais de escoamento e o $\Delta \mathrm{P}$ a ser medido nos tubos de pitot e na placa de orifício. Para a estimativa da queda de pressão no tubo de pitot é assumida a hipótese que a vazão da seção de testes é distribuída uniformemente no bocal de saída.

Tabela 4. 2 - Velocidade média nos canais, vazão volumétrica, tubo de pitot e placa de orifício

\begin{tabular}{|c|c|c|c|c|c|c|}
\hline \multirow{2}{*}{$\begin{array}{c}\text { Velocidade média } \\
\text { no canal, V } \\
{[\mathrm{m} / \mathrm{s}]}\end{array}$} & \multicolumn{2}{|c|}{$\begin{array}{l}\text { Vazão volumétrica } \\
\text { na seção de testes }\end{array}$} & \multicolumn{2}{|c|}{$\begin{array}{l}\text { Pitot } \\
\Delta \mathrm{P}_{\mathrm{pt}}\end{array}$} & \multicolumn{2}{|c|}{$\begin{array}{c}\text { Placa de Orifício } \\
\qquad \Delta \mathrm{P}_{\mathrm{pó}}\end{array}$} \\
\hline & $1 / \mathrm{s}$ & $\mathrm{m}^{3} / \mathrm{h}$ & $\mathrm{Pa}$ & bar & $\mathrm{Pa}$ & bar \\
\hline 7,0 & 3,627 & 13,058 & $24.974,5$ & 0,250 & $15.224,8$ & 0,152 \\
\hline 8,0 & 4,145 & 14,923 & $32.619,8$ & 0,326 & $19.884,3$ & 0,199 \\
\hline 9,0 & 4,664 & 16,789 & $41.284,4$ & 0,413 & $25.168,0$ & 0,252 \\
\hline 10,0 & 5,182 & 18,654 & $50.968,4$ & 0,510 & $31.070,1$ & 0,311 \\
\hline 11,0 & 5,700 & 20,520 & $61.671,8$ & 0,617 & $37.597,0$ & 0,376 \\
\hline 12,0 & 6,218 & 22,385 & $73.394,5$ & 0,734 & $44.741,8$ & 0,447 \\
\hline 13,0 & 6,736 & 24,251 & $86.136,6$ & 0,861 & $52.511,9$ & 0,525 \\
\hline 14,0 & 7,254 & 26,116 & $99.898,1$ & 0,999 & $60.899,3$ & 0,609 \\
\hline 14,5 & 7,514 & 27,049 & $107.161,1$ & 1,072 & $65.328,3$ & 0,653 \\
\hline 15,0 & 7,773 & 27,982 & $114.678,9$ & 1,147 & $69.912,7$ & 0,699 \\
\hline 15,5 & 8,032 & 28,914 & $122.451,6$ & 1,225 & $74.647,5$ & 0,746 \\
\hline 16,0 & 8,291 & 29,847 & $130.479,1$ & 1,305 & $79.542,7$ & 0,795 \\
\hline 16,5 & 8,550 & 30,780 & $138.761,5$ & 1,388 & $84.593,3$ & 0,846 \\
\hline 17,0 & 8,809 & 31,712 & $147.298,7$ & 1,473 & $89.793,7$ & 0,898 \\
\hline
\end{tabular}

Para se estimar as perdas de carga na instalação no funcionamento nas condições máximas operacionais, foi produzido um desenho do circuito montado na forma de um Isométrico, o qual pode ser observado na Figura 4. 12. 


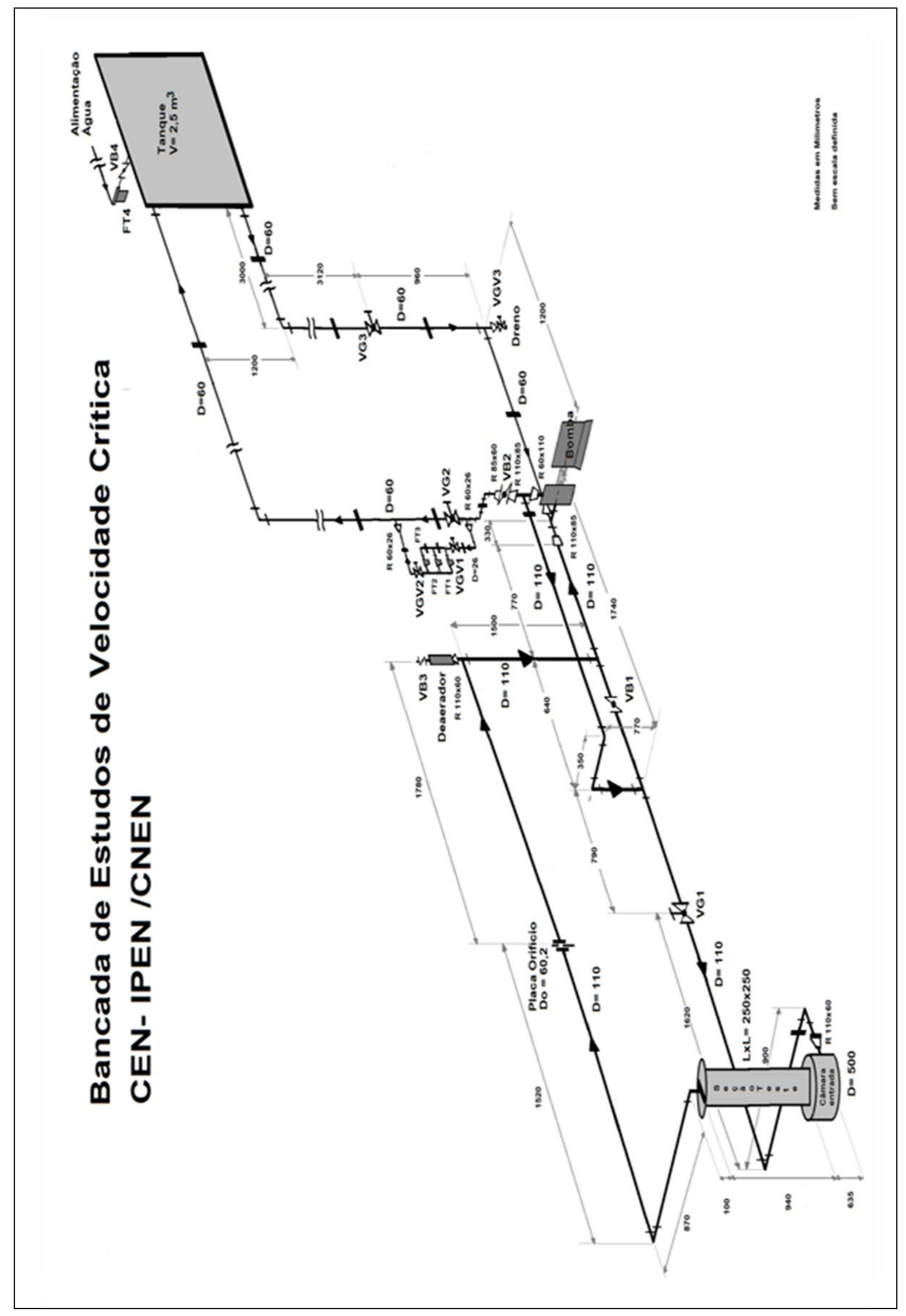

Figura 4. 12 - Isométrico da Bancada de Estudos de Velocidade Crítica montada 


\subsubsection{Estimativa da Perda de Carga na Bancada Experimental}

Para uma estimativa das perdas de carga nas condições projetadas para a ocorrência do fenômeno de colapso de placas, admitiu-se a ocorrência da velocidade crítica calculada pela equação de Miller (Eq.3.1) para as placas combustíveis típicas do RMB com as suas condições de canal de resfriamento, $U_{d}=17,0 \mathrm{~m} / \mathrm{s}$ e $Q_{\text {seção }}=31,71 \mathrm{~m}^{3} / \mathrm{h}$.

Considerou-se o escoamento sendo recalcado pela bomba e passando $31,71 \mathrm{~m}^{3} / \mathrm{h}$ pela tubulação de $\mathrm{D}=110 \mathrm{~mm}$ na direção da válvula globo de regulagem (VG1), com a válvula borboleta (VB1) totalmente fechada, e escoando pela seção de testes. O restante da vazão da bomba é recalcada pelos filtros (VGV1) retornando para o tanque, ou pode também retornar direto para o tanque (VG2). O Controle da vazão de retorno para o tanque é feito através da regulagem da válvula borboleta VB2.

A vazão que passa pela seção de testes escoa por uma placa de orifício, passa pelo desaerador e retorna pela sucção da bomba.

Os processos descritos acima podem ser observados no isométrico da bancada experimental, Figura 4. 12.

A Tabela 4. 3 apresenta os resultados estimados de perda de carga para a tubulação da bancada experimental e para a seção de testes. Os cálculos foram realizados utilizando as referências, [38], [39], [40] e [41]. Observa-se da Figura 4. 10 que para a vazão em torno de $32 \mathrm{~m}^{3} / \mathrm{h}$, a altura manométrica fornecida pela bomba é de $60 \mathrm{~m}$. As perdas estimadas mostradas atingem o valor total de $62,13 \mathrm{~m}$. Isto poderia trazer a preocupação da possibilidade de não alcançarmos a condição de colapso das placas. É importante se acrescentar que na revisão da literatura foi observado que os valores da velocidade crítica obtidas da equação de Miller (Eq. 3.1) costumam ser maiores que os obtidos na realização dos experimentos. Ho et al., [26], obteve valores experimentais de $12 \mathrm{~m} / \mathrm{s}$, enquanto a velocidade prevista pela equação de Miller era de 15,4 m/s. Outro fato importante a ser observado é a de que os cálculos de estimativas de perda de carga são sempre conservadores, conforme a literatura da área de mecânica de fluidos. 
Tabela 4. 3 - Perdas de carga para a condição de velocidade crítica

\begin{tabular}{|c|c|c|c|c|c|c|}
\hline Tubulação & $\begin{array}{l}\text { Velocidade } \\
\text { média, } \mathrm{V}_{\mathrm{T}}\end{array}$ & $\begin{array}{l}\text { Reynolds } \\
\operatorname{Re}_{\mathrm{T}}\end{array}$ & $\begin{array}{c}\text { Coeficiente } \\
\text { Atrito, } \mathrm{f}\end{array}$ & Acidentes & $\begin{array}{c}\text { Coeficiente } \\
\mathrm{K}_{\mathrm{s}}\end{array}$ & Perdas \\
\hline \multirow[t]{2}{*}{$\begin{array}{l}D=110 \mathrm{~mm} \\
D i=96 \mathrm{~mm}\end{array}$} & \multirow[t]{2}{*}{$1,22 \mathrm{~m} / \mathrm{s}$} & \multirow[t]{2}{*}{$116.835,0$} & \multirow[t]{2}{*}{0,0175} & \multirow[t]{2}{*}{$\begin{array}{l}-L_{\text {Tubos }}=12,91 \mathrm{~m} \\
\text { - } 06 \text { Joelhos } 90^{\circ} \\
\text { - } 04 \text { Tês } \\
\text { - Válvula globo } \\
\text { totalmente aberta }\end{array}$} & $\begin{array}{l}- \\
0,9 \\
2,0 \\
10\end{array}$ & Total \\
\hline & & & & & & $2,803 \mathrm{~m}$ \\
\hline \multirow[t]{2}{*}{$\begin{array}{l}\mathrm{D}=85 \mathrm{~mm} \\
\mathrm{Di}=75,6 \mathrm{~mm}\end{array}$} & \multirow[t]{2}{*}{$1,96 \mathrm{~m} / \mathrm{s}$} & \multirow[t]{2}{*}{$148.251,6$} & \multirow[t]{2}{*}{0,0165} & \multirow{2}{*}{$\begin{array}{l}-\mathrm{L}_{\text {Tubos }}=\mathbf{0 , 4 3} \mathrm{m} \\
\text { - Redução } 110 \text { x } 85 \\
\text { - Tê }\end{array}$} & \multirow{2}{*}{$\begin{array}{c}- \\
0,15 \\
2,0\end{array}$} & Total \\
\hline & & & & & & $0,440 \mathrm{~m}$ \\
\hline \multirow[t]{2}{*}{$\begin{array}{l}D=60 \mathrm{~mm} \\
D_{\mathrm{i}}=53,4 \mathrm{~mm}\end{array}$} & \multirow[t]{2}{*}{$3,93 \mathrm{~m} / \mathrm{s}$} & \multirow[t]{2}{*}{$210.013,9$} & \multirow[t]{2}{*}{0,0155} & \multirow[t]{2}{*}{$\begin{array}{c}-\mathrm{L}_{\text {Tubos }}=0,15 \text { m } \\
\text {-Expansão } 60 \text { x } 110 \\
\text { - Redução } 110 \text { x } 60\end{array}$} & & Total \\
\hline & & & & & & $0,586 \mathrm{~m}$ \\
\hline $\begin{array}{l}\text { Placa de } \\
\text { Orifício }\end{array}$ & $\begin{array}{l}\text { Velocidade } \\
\text { média, } \mathrm{V}_{\mathrm{O}}\end{array}$ & $\begin{array}{c}\text { Reynolds } \\
\operatorname{Re}_{\mathrm{T}}\end{array}$ & $\mathrm{C}_{\mathrm{D}}$ & $H_{P}=\left(1-C_{V}^{2}\right) \frac{V_{o}^{2}}{2 \cdot g}$ & $\begin{array}{c}\text { Aproximação } \\
\mathrm{CV}_{\mathrm{V}}^{2}=\mathrm{C}_{\mathrm{D}}\end{array}$ & Perdas \\
\hline $\mathrm{D}_{0}=37,0 \mathrm{~mm}$ & $8,33 \mathrm{~m} / \mathrm{s}$ & $308.210,0$ & 0,60 & & 0,60 & $1,415 \mathrm{~m}$ \\
\hline $\begin{array}{l}\text { Seção de } \\
\text { Testes }\end{array}$ & $\begin{array}{l}\text { Velocidade } \\
\text { média, } \mathrm{V}_{\mathrm{T}}\end{array}$ & $\begin{array}{c}\text { Reynolds } \\
\operatorname{Re}_{\mathrm{T}}\end{array}$ & $\begin{array}{c}\text { Coeficiente } \\
\text { Atrito, } \mathrm{f}\end{array}$ & Acidentes & $\begin{array}{c}\text { Coeficiente } \\
\mathrm{K}_{\mathrm{s}}\end{array}$ & Perdas \\
\hline $\begin{array}{l}\text { Entrada Câmara } \\
\mathrm{Di}=53,4 \mathrm{~mm} \\
\text { para } \\
\mathrm{D}=500 \mathrm{~mm}\end{array}$ & 3,93 & $210.013,9$ & 0,0155 & $\begin{array}{l}\text { - Expansão Entrada na } \\
\text { câmara de entrada }\end{array}$ & 1,05 & $0,828 \mathrm{~m}$ \\
\hline $\begin{array}{c}\text { Câmara } \\
\text { para Seção } \\
\mathrm{D}=500 \mathrm{~mm} / \\
\mathrm{D}_{\mathrm{H}}=17,59 \mathrm{~mm}\end{array}$ & 12,43 & $218.669,0$ & 0,016 & $\begin{array}{c}\text {-Saída da câmara para o } \\
\text { bocal de entrada }\end{array}$ & $\mathbf{0 , 8 0}$ & $6,300 \mathrm{~m}$ \\
\hline $\begin{array}{l}\text { Simulador } \\
\text { Elemento do } \\
\text { RMB }\end{array}$ & 17,00 & $80.500,0$ & 0,019 & $\begin{array}{l}\text { - Modelo de canais de } \\
\text { escoamento }\end{array}$ & - & $45,770 \mathrm{~m}$ \\
\hline $\begin{array}{l}\text { Simulador para } \\
\text { Canal Externo } \\
\text { Seção de Testes }\end{array}$ & 3,93 & $210.013,9$ & 0,0155 & $\begin{array}{c}\text { - Expansão Bocal de } \\
\text { saída para canal externo }\end{array}$ & $\mathbf{0 , 5 0}$ & 3,937 m \\
\hline $\begin{array}{l}\text { Canal Externo } \\
\text { para tubulação } \\
D=110 \mathrm{~mm}\end{array}$ & $1,46 \mathrm{~m} / \mathrm{s}$ & $127.749,0$ & 0,0175 & $\begin{array}{l}\text { - Redução canal externo } \\
\text { para tubulação }\end{array}$ & $\mathbf{0 , 5 0}$ & $\mathbf{0 , 0 5 4} \mathrm{m}$ \\
\hline & & & & & $\begin{array}{l}\text { Perdas } \\
\text { Totais }\end{array}$ & $62,133 m$ \\
\hline
\end{tabular}




\subsection{SISTEMA DE AQUISIÇÃO DE DADOS}

Para a realização dos experimentos foi desenvolvido um programa de monitoração e aquisição de sinais utilizando a plataforma "LabVIEW10", [47], e componentes de aquisição de dados (NI-DAQ) da "National Instruments", Figura 4. 13.

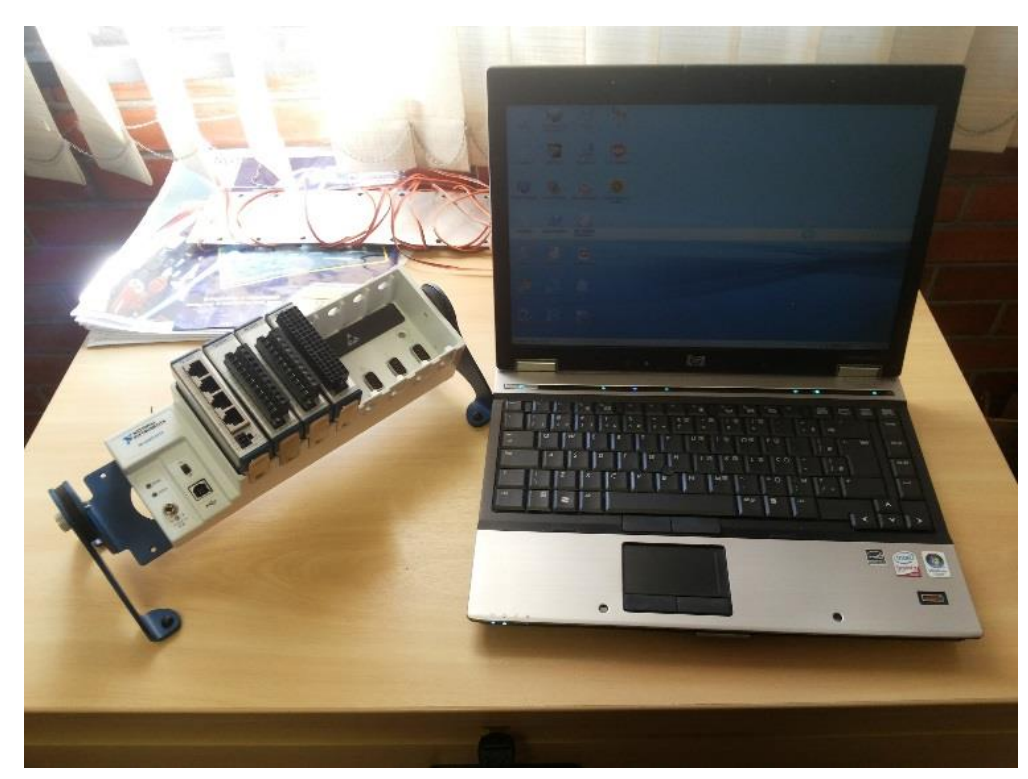

Figura 4. 13 - Aquisição de dados: Hardware NI-DAQ e o Software LabVIEW10

O sistema de aquisição de dados foi baseado em um módulo principal de aquisição de dados NI cDAQ9175 acoplado com quatro módulos condicionadores de sinais, NI9237, NI9205, NI9211 e NI9215, [48] a [54]. O Módulo de aquisição e condicionamento de sinais é acoplado a um computador portátil através de uma interface USB para gerenciamento, monitoração e aquisição dos dados experimentais.

O NI9237 é um módulo de entrada de sinais analógicos com 24 bits de resolução, frequência de amostragem máxima de $50 \mathrm{kHz}$ que complementa a ponte de "Wheatstone" para condicionamento de 4 canais simultâneos. Ele está sendo utilizado com 4 terminais NI9944 para formar a eletrônica de condicionamento dos sinais de 4 extensômetros, dois na entrada, um no centro e outro na saída de uma das placas que formam o canal de escoamento

O NI9205 corresponde a um módulo de entrada de sinais analógico com 16 bits de resolução de até trinta e dois (32) canais multiplexados, $\pm 200 \mathrm{mV} \mathrm{a} \pm 10 \mathrm{~V}$ com frequência de amostragem de $250 \mathrm{kHz}$. Está sendo utilizado para o condicionamento dos sinais dos quatro (4) microtransdutores piezoresistivos da "Kulite" instalados no canal de escoamento, um (1) sensor piezoresistivo da "Hydac" instalado na câmara de entrada e três (3) sensores 
de pressão diferencial "Validyne" instalados para medida de $\Delta \mathrm{P}$ respectivamente na seção de testes, tubo de pitot e placa de orifício.

O NI9211 é um módulo de entrada para os sinais multiplexados de até quatro (4) termopares com vinte e quatro (24) bits de resolução e frequência de amostragem de $14 \mathrm{~Hz}$. Ele possui junta fria eletrônica e pode ser programado para diferentes tipos de termopares, permite entrada de até $\pm 80 \mathrm{mV}$. Está sendo utilizado para a medida de temperatura da câmara de entrada e a temperatura do canal externo da seção de testes por meio de 2 termopares do tipo K.

O NI9215 é um módulo de entrada de sinais analógicos de quatro (4) canais simultâneos, frequência de amostragem de 100 kHz. É utilizado para o sinal do acelerômetro posicionado na carcaça externa do canal externo da seção de testes.

Para monitorar e registrar os dados dos experimentos de colapso de placas e detecção da velocidade crítica, foi desenvolvido um programa com a plataforma LabVIEW10 da "National Instruments", [49] a [53]. Esta plataforma é baseada em programação gráfica e permite a montagem de verdadeiros instrumentos virtuais (VI). A Figura 4. 14 apresenta o painel frontal do programa de monitoração e aquisição de sinais, "VCRITICAREV2.VI". Observa-se que o programa permite definir a frequência de amostragem ('rate'), a quantidade de amostras para atualização dos dados, a definição entre monitoração e gravação de dados através de um botão com lógica booleana, e a definição do arquivo aonde irão ser armazenados os dados gravados. O programa indica no painel as variáveis que estão sendo medidas através de indicadores e gráficos.

A Figura 4. 15 apresenta o diagrama de blocos com a programação gráfica e o fluxo dos dados dos sinais que estão sendo medidos. A menos dos sinais dos termopares, os dados são armazenados na forma de tensão, [V] e [mV].

Durante o desenvolvimento, os sinais dos extensômetros, pressão, pressão diferencial e do acelerômetro foram gravados com uma taxa de amostragem de $100 \mathrm{~Hz}$. Estas frequências de amostragem podem ser alteradas respeitando a capacidade dos condicionadores de sinal. 


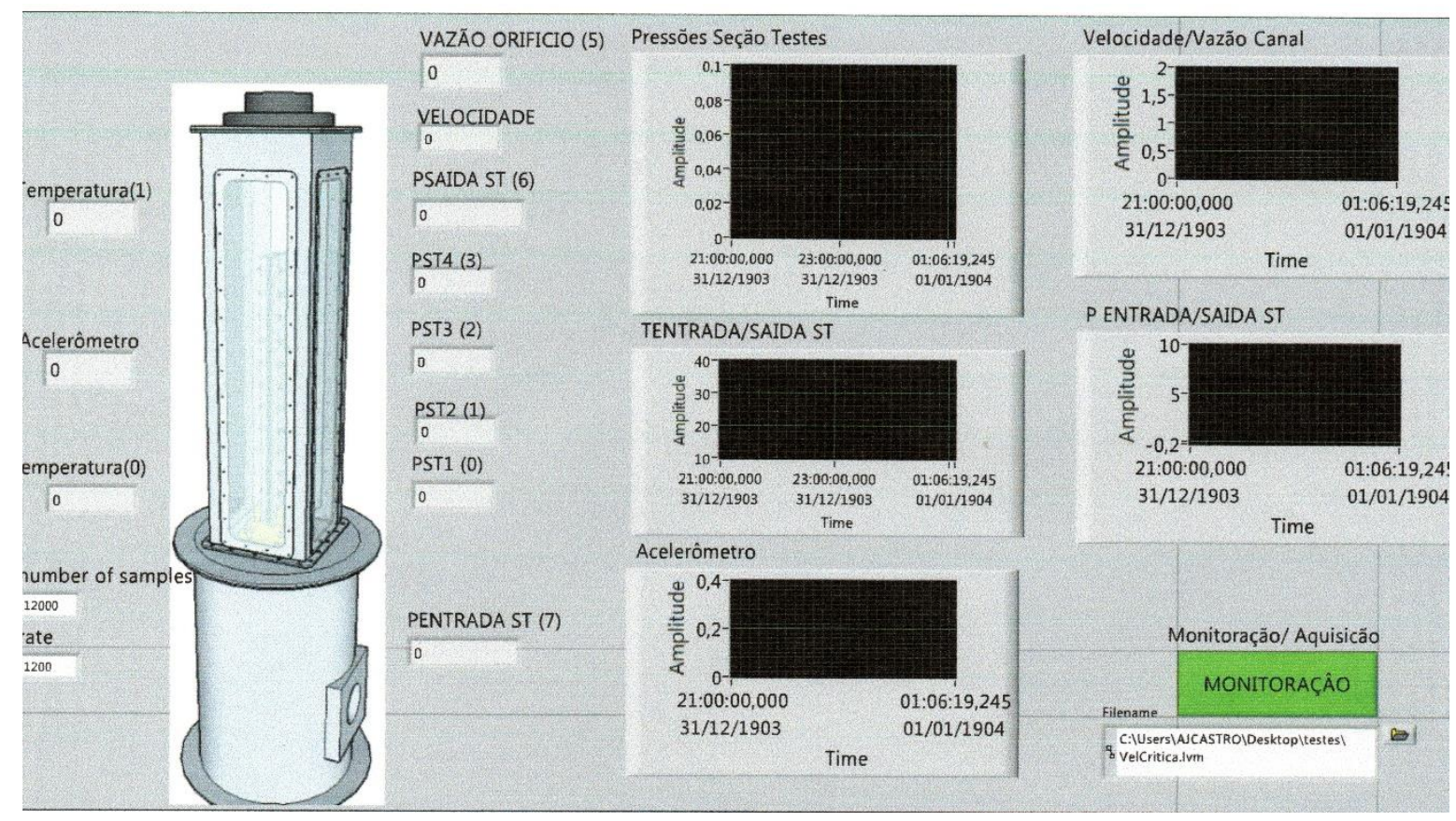

Figura 4. 14 - Painel frontal do programa de monitoração e aquisição de sinais

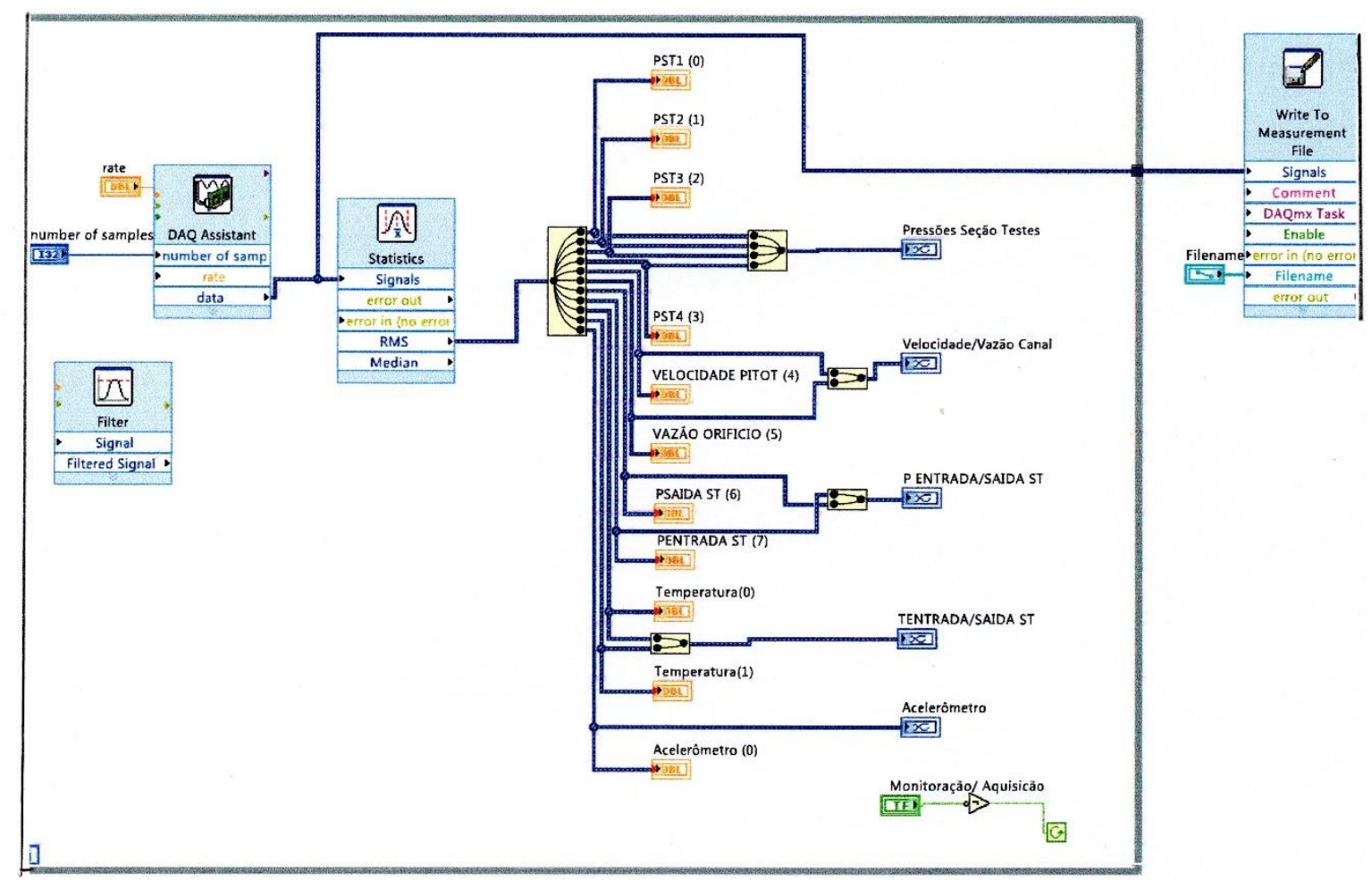

Figura 4. 15 - Diagrama de blocos do programa de monitoração e aquisição de sinais 


\subsection{TESTES DE COMISSIONAMENTO}

No comissionamento foi testado o circuito a alta pressão, reparados alguns vazamentos, realizadas calibrações/aferições da instrumentação, análise modal da seção de testes, acertos no sistema de aquisição de sinais e medidas do módulo de elasticidade do material das placas de alumínio da seção de testes.

\subsubsection{Testes de pressão}

Nestes testes ocorreram falhas de vazamentos e de ruptura da janela de acrílico devido às altas pressões. A bancada foi reparada trocando as janelas de acrílico com $6 \mathrm{~mm}$ de espessura por janelas de policarbonato com $8 \mathrm{~mm}$ de espessura, aumento do número de parafusos de fixação dos flanges inferior e superior da câmara de entrada da seção de testes, reforço mecânico e vedação na placa de fixação da seção de testes na saída da câmara de entrada para a seção de testes através do aumento dos parafusos, adição de arruelas de pressão no disco de fixação e reforço das juntas de vedação. Acrescentou-se guias entre o modelo simulador do elemento e a caixa externa da seção de testes para estabilizar o modelo e evitar vibrações externas aos canais de escoamento. Foi também acrescentado um trocador de calor para resfriamento do calor dissipado pela bomba e garantir uma temperatura uniforme durante os experimentos. A Figura 4. 16 mostra o trocador de calor acrescentado para resfriamento do calor dissipado pela bomba e a Figura 4.17 a janela de acrílico com a falha ocorrida no comissionamento.

\subsubsection{Calibração dos sensores de pressão}

Para ajuste das escalas e dos valores de pressão no programa de aquisição de dados foram calibrados 5 sensores de pressão e 3 sensores de pressão diferencial. Para a realização do trabalho, utilizou-se o calibrador Cappo P PRO conectado a uma bomba pneumática manual (PMP20V) com regulador de volume e válvula de alívio. O Cappo P PRO é um instrumento portátil para medição de pressão relativa, diferencial e vácuo. A Figura 4. 18 mostra o calibrador Cappo P PRO junto com a bomba manual PMP20V. O equipamento tem uma precisão de $0,025 \%$ do fundo de escala. Trabalhou-se com a bomba ajustada para a faixa de 0 a 7.000 mbar. 
As tabelas, Tabela 4. 4 a Tabela 4. 11, apresentam os dados de calibração dos quatro (4) microtransdutores piezoresistivos da "Kulite" do canal de escoamento, um (1) sensor piezoresistivo da "Hydac" da câmara de entrada e três (3) sensores de pressão diferencial "Validyne" para medida de $\Delta \mathrm{P}$ respectivamente na seção de testes, tubo de pitot e placa de orifício.

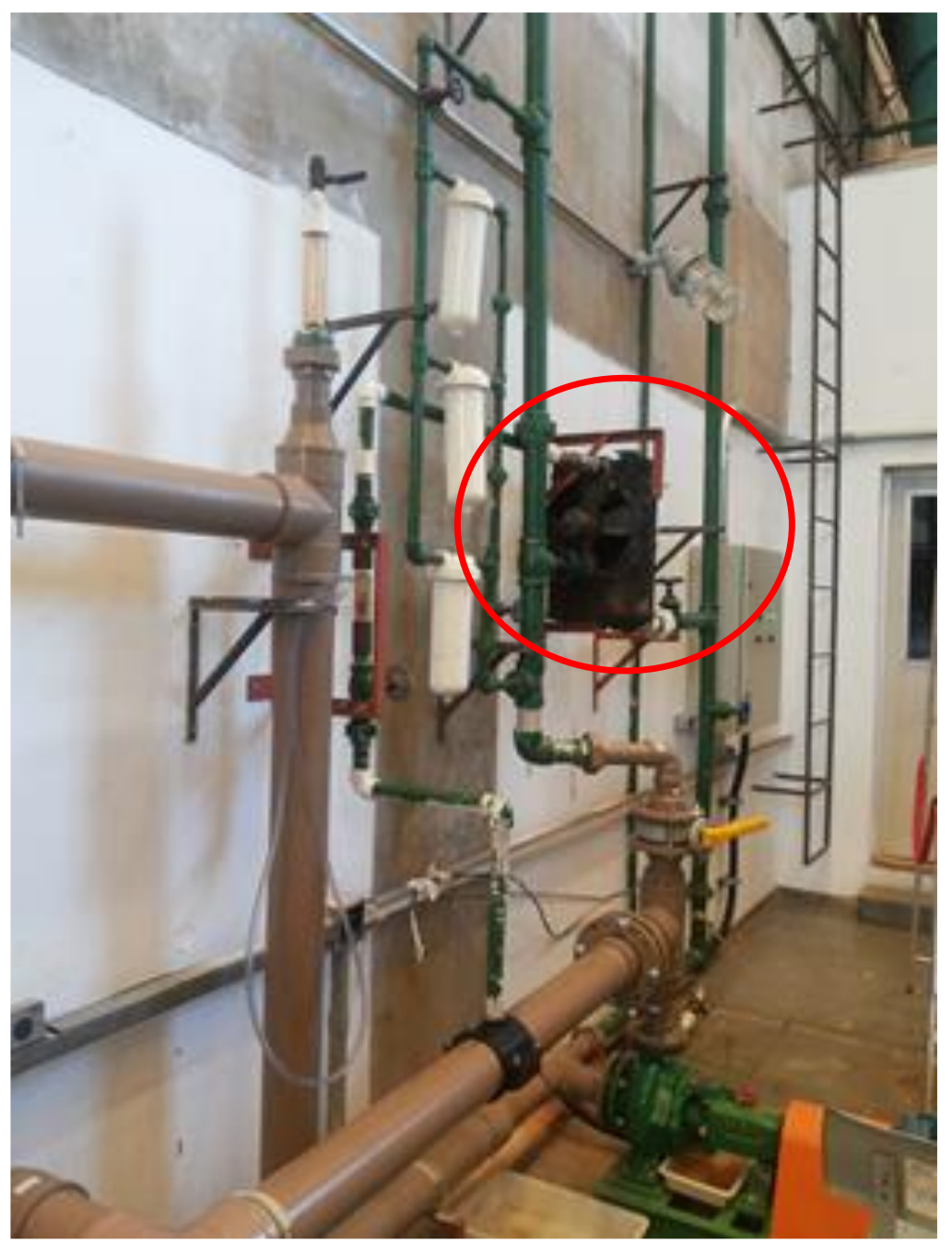

Figura 4. 16 - Trocador de Calor 


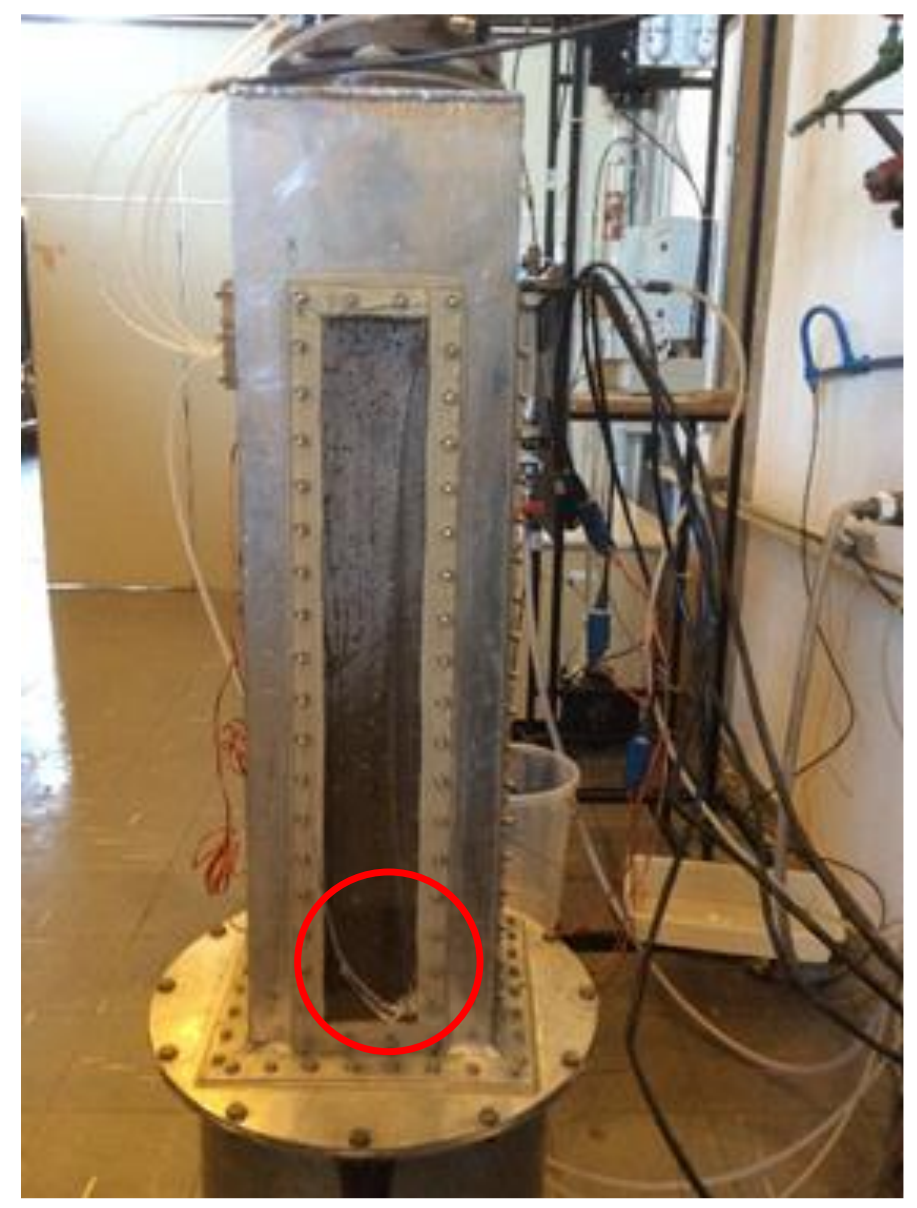

Figura 4. 17 - Falha na Janela de acrílico
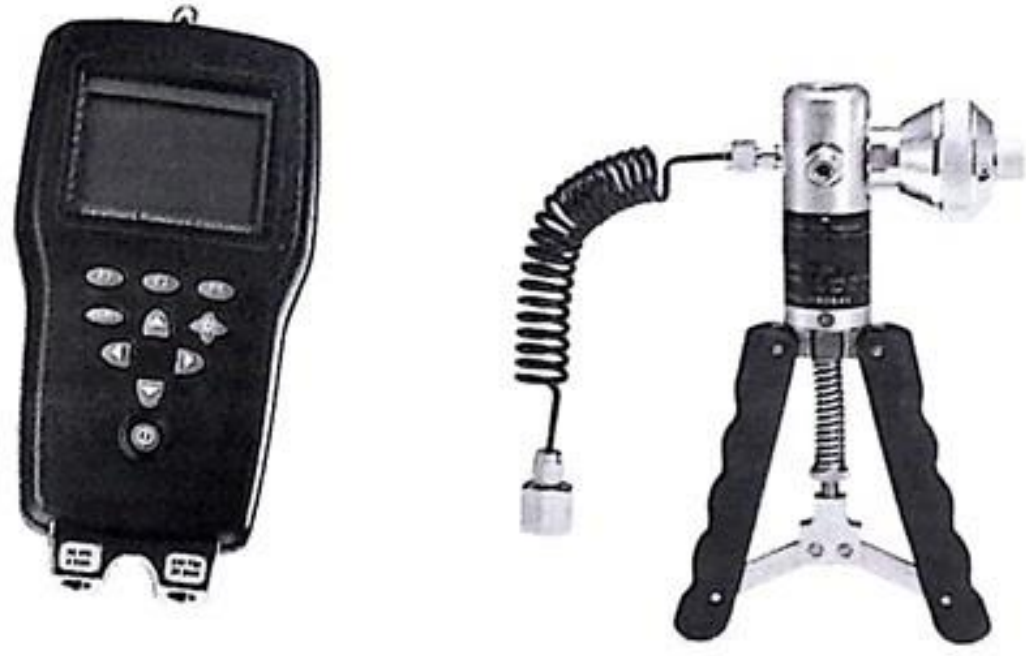

Figura 4. 18 - Calibrador Cappo P e a bomba pneumática. 
Tabela 4. 4 - Calibração do transdutor de pressão piezoresistivo, PST1

\begin{tabular}{|c|c|}
\hline \multicolumn{2}{|c|}{$\begin{array}{l}\text { TRANSDUTOR PRESSÂO PIEZORESISTIVO KULITE N.12, PST1 } \\
01 / 02 / 2016 .\end{array}$} \\
\hline \multicolumn{2}{|c|}{ Tensão Alimentação = 12VDC } \\
\hline $\mathrm{P}$ (mbar) & Tensão (mV) \\
\hline 0 & 29,12 \\
\hline 550 & 43,26 \\
\hline 1018 & 55,32 \\
\hline 1505 & 67,89 \\
\hline 2051 & 82,00 \\
\hline 2532 & 94,46 \\
\hline 3014 & 107,00 \\
\hline 3513 & 120,00 \\
\hline 4052 & 134,04 \\
\hline 4527 & 146,45 \\
\hline 5048 & 160,06 \\
\hline 5574 & 173,84 \\
\hline 6220 & 190,74 \\
\hline 5992 & 184,81 \\
\hline 5504 & 172,08 \\
\hline 4971 & 158,17 \\
\hline 4494 & 145,72 \\
\hline 3697 & 124,92 \\
\hline 3476 & 119,25 \\
\hline 3056 & 108,35 \\
\hline 2506 & 94,07 \\
\hline 2004 & 81,80 \\
\hline 1429 & 66,23 \\
\hline 925 & 53,22 \\
\hline 537 & 43,22 \\
\hline 0 & 29,38 \\
\hline
\end{tabular}


Tabela 4. 5 - Calibração do transdutor de pressão piezoresistivo PST2

\begin{tabular}{|c|c|}
\hline \multicolumn{2}{|c|}{$\begin{array}{l}\text { TRANSDUTOR PRESSÂO PIEZORESISTIVO KULITE N.13, PST2 } \\
02 / 02 / 2016\end{array}$} \\
\hline \multicolumn{2}{|c|}{ Tensão Alimentação = 12VDC } \\
\hline $\mathrm{P}$ (mbar) & Tensão (mV) \\
\hline 0 & 27,15 \\
\hline 562 & 41,51 \\
\hline 1012 & 53,03 \\
\hline 1527 & 66,22 \\
\hline 2087 & 80,64 \\
\hline 2519 & 91,77 \\
\hline 3081 & 106,30 \\
\hline 3509 & 117,37 \\
\hline 4033 & 130,96 \\
\hline 4536 & 144,04 \\
\hline 5032 & 156,98 \\
\hline 5539 & 170,20 \\
\hline 6206 & 187,64 \\
\hline 5993 & 182,10 \\
\hline 5432 & 167,47 \\
\hline 4858 & 152,49 \\
\hline 4446 & 141,80 \\
\hline 3955 & 129,04 \\
\hline 3610 & 120,13 \\
\hline 3009 & 104,55 \\
\hline 2434 & 89,66 \\
\hline 1941 & 76,98 \\
\hline 1651 & 69,48 \\
\hline 998 & 52,66 \\
\hline 481 & 39,34 \\
\hline 0 & 26,97 \\
\hline
\end{tabular}


Tabela 4. 6 - Calibração do transdutor de pressão piezoresistivo PST3

\begin{tabular}{|c|c|}
\hline \multicolumn{2}{|c|}{$\begin{array}{l}\text { TRANSDUTOR PRESSÂO PIEZORESISTIVO KULITE N.14, PST3 } \\
02 / 02 / 2016 .\end{array}$} \\
\hline \multicolumn{2}{|c|}{ Tensão Alimentação = 12VDC } \\
\hline $\mathrm{P}$ (mbar) & Tensão (mV) \\
\hline 0 & 25,68 \\
\hline 481 & 38,53 \\
\hline 1004 & 52,41 \\
\hline 1560 & 67,20 \\
\hline 2073 & 80,88 \\
\hline 2549 & 93,58 \\
\hline 3044 & 106,86 \\
\hline 3478 & 118,50 \\
\hline 4036 & 133,47 \\
\hline 4510 & 146,25 \\
\hline 5032 & 160,36 \\
\hline 5544 & 174,14 \\
\hline 6113 & 189,54 \\
\hline 5932 & 184,65 \\
\hline 5472 & 172,20 \\
\hline 4948 & 158,01 \\
\hline 4466 & 145,03 \\
\hline 4015 & 132,86 \\
\hline 3455 & 117,80 \\
\hline 3057 & 107,15 \\
\hline 2522 & 92,81 \\
\hline 1962 & 77,90 \\
\hline 1494 & 65,38 \\
\hline 1051 & 53,60 \\
\hline 587 & 41,30 \\
\hline 0 & 25,71 \\
\hline
\end{tabular}


Tabela 4. 7 - Calibração do transdutor de pressão piezoresistivo PST4

TRANSDUTOR PRESSÂO PIEZORESISTIVO KULITE N.15, PST4 $03 / 02 / 2016$.

\begin{tabular}{|c|c|}
\hline \multicolumn{2}{|c|}{ Tensão Alimentação = 12VDC } \\
\hline $\mathrm{P}$ (mbar) & Tensão (mV) \\
\hline 0 & 23,03 \\
\hline 504 & 35,82 \\
\hline 1065 & 50,09 \\
\hline 1529 & 61,94 \\
\hline 2078 & 76,01 \\
\hline 2505 & 86,99 \\
\hline 3091 & 102,08 \\
\hline 3563 & 114,28 \\
\hline 4040 & 126,64 \\
\hline 4514 & 139,06 \\
\hline 5010 & 151,80 \\
\hline 5512 & 165,00 \\
\hline 6062 & 179,40 \\
\hline 6492 & 190,62 \\
\hline 6272 & 184,91 \\
\hline 5605 & 167,52 \\
\hline 4968 & 150,99 \\
\hline 4493 & 138,64 \\
\hline 3937 & 124,24 \\
\hline 3461 & 111,61 \\
\hline 2977 & 99,42 \\
\hline 2498 & 87,09 \\
\hline 1941 & 72,77 \\
\hline 1472 & 60,57 \\
\hline 1003 & 48,72 \\
\hline 477 & 35,29 \\
\hline
\end{tabular}


Tabela 4. 8 - Calibração do transdutor de pressão HYDAC

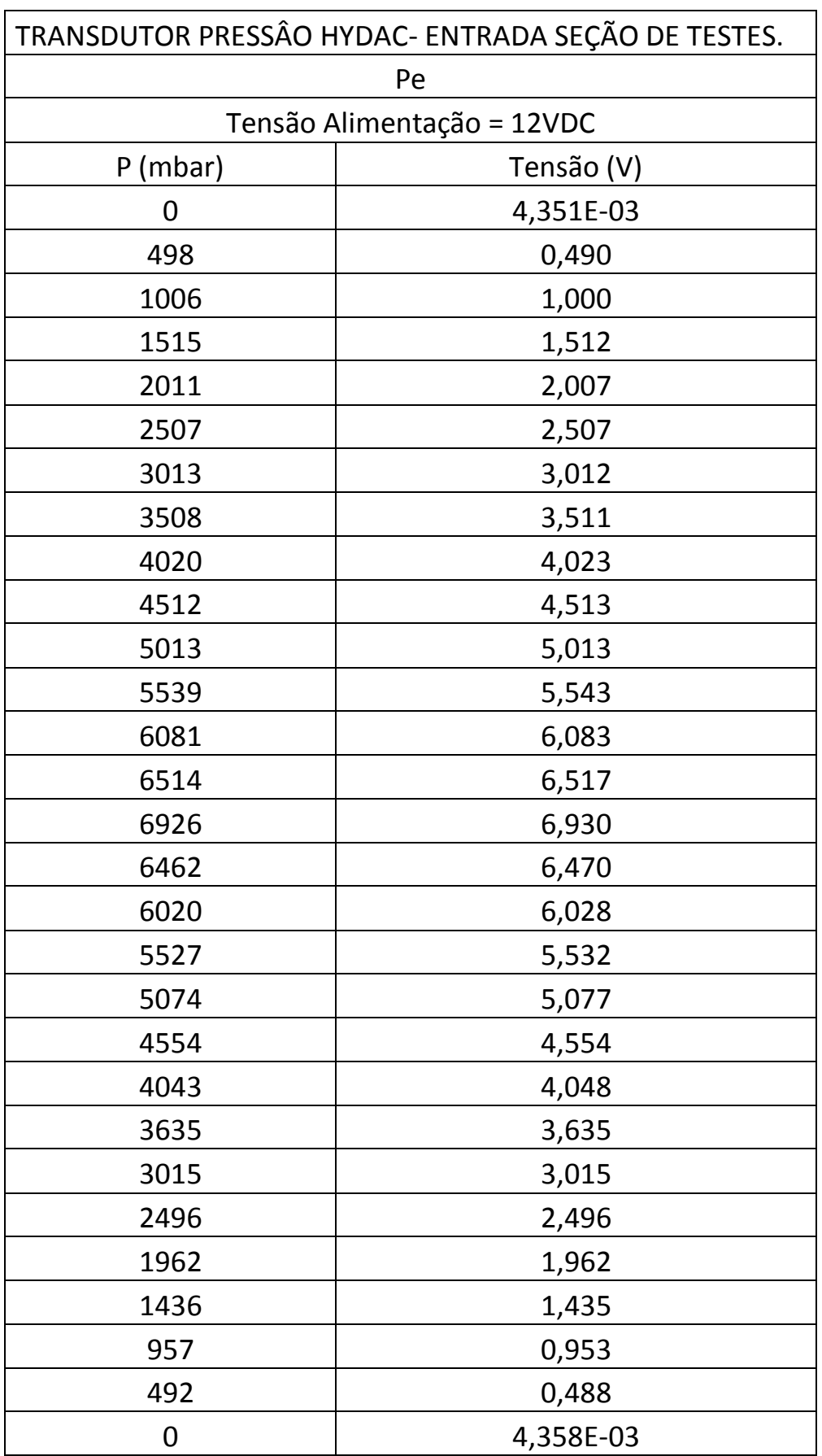


Tabela 4. 9 - Calibração do transdutor de pressão tubo pitot

\begin{tabular}{|c|c|c|}
\hline \multicolumn{3}{|c|}{ TUBO PITOT: Sensor Validyne diafragma 42} \\
\hline Zero $=6,46$ & & Span $=90,9$ \\
\hline $\mathrm{P}(\mathrm{mbar})$ & Visor (\%) & Tensão (V) \\
\hline 0 & $00,07 / 6$ & \\
\hline 260 & $6,36 / 5$ & 0,636 \\
\hline 535 & $13,12 / 1$ & 1,313 \\
\hline 765 & $18,75 / 6$ & 1,877 \\
\hline 1.000 & 24,55 & 2,458 \\
\hline 1.253 & $30,78 / 9$ & 3,082 \\
\hline 1.503 & $37,05 / 4$ & 3,709 \\
\hline 1.765 & 43,52 & 4,357 \\
\hline 2.043 & 50,53 & 5,058 \\
\hline 2.263 & $55,99 / 56,00$ & 5,604 \\
\hline 2.552 & $63,28 / 9$ & 6,335 \\
\hline 2.770 & $68,65 / 4$ & 6,872 \\
\hline 2.992 & $74,33 / 2$ & 7,440 \\
\hline 3.263 & $80,94 / 3$ & 8,101 \\
\hline 3.515 & $87,27 / 8$ & 8,735 \\
\hline 3.755 & $93,22 / 1$ & 9,330 \\
\hline 4.003 & $99,46 / 7$ & 9,955 \\
\hline 3.743 & $93,26 / 5$ & 9,333 \\
\hline 3.493 & $87,27 / 8$ & 8,735 \\
\hline 3.242 & $81,10 / 1$ & 8,117 \\
\hline 2.998 & $74,93 / 2$ & 7,500 \\
\hline 2.752 & $69,00 / 1$ & 6,906 \\
\hline 2.515 & $63,29 / 8$ & 6,334 \\
\hline 2.240 & $56,56 / 5$ & 5,660 \\
\hline 1.985 & $50,24 / 3$ & 5,028 \\
\hline 1.760 & $43,62 / 3$ & 4,367 \\
\hline 1.507 & $37,55 / 4$ & 3,759 \\
\hline 1.190 & $29,68 / 7$ & 2,971 \\
\hline 1.027 & 25,77 & 2,580 \\
\hline 757 & $19,23 / 2$ & 1,924 \\
\hline 530 & $13,42 / 1$ & 1,344 \\
\hline 238 & 6,28 & 0,627 \\
\hline 0 & 0,34 & 0,034 \\
\hline
\end{tabular}


Tabela 4. 10 - Calibração do transdutor de pressão saída seção testes

\begin{tabular}{|c|c|c|}
\hline \multicolumn{3}{|c|}{ Sensor Validyne diafragma 48: } \\
\hline Zero: 4,60 & & Span:5,00 \\
\hline $\mathrm{P}$ (mbar) & Tensão (V) & $\mathrm{mbar} / \mathrm{V}$ \\
\hline 0 & 3,00E-03 & \\
\hline 503 & 0,823 & 611,18 \\
\hline 1040 & 1,705 & 609,97 \\
\hline 1525 & 2,503 & 609,27 \\
\hline 1987 & 3,264 & 608,76 \\
\hline 2524 & 4,152 & 607,90 \\
\hline 3037 & 5,004 & 606,91 \\
\hline 3519 & 5,807 & 605,99 \\
\hline 3994 & 6,605 & 604,69 \\
\hline 4519 & 7,493 & 603,10 \\
\hline 5006 & 8,315 & 602,04 \\
\hline 5502 & 9,159 & 600,72 \\
\hline 5996 & 10,007 & 599,18 \\
\hline 5441 & 9,068 & 600,02 \\
\hline 4971 & 8,271 & 601,02 \\
\hline 4495 & 7,473 & 601,50 \\
\hline 4013 & 6,666 & 602,01 \\
\hline 3452 & 5,729 & 602,55 \\
\hline 2973 & 4,930 & 603,04 \\
\hline 2464 & 4,084 & 603,33 \\
\hline 2066 & 3,422 & 603,74 \\
\hline 1508 & 2,502 & 602,72 \\
\hline 1043 & 1,737 & 600,46 \\
\hline 481 & 0,804 & 598,26 \\
\hline 0 & $1,00 E-02$ & \\
\hline
\end{tabular}


Tabela 4. 11 - Calibração do transdutor de pressão da placa de orifício

\begin{tabular}{|c|c|c|}
\hline \multicolumn{3}{|c|}{ Sensor Validyne Diafragma 42: PLACA DE ORIFICIO Do=37,0 mm } \\
\hline Zero: 7,10 & & Span:6,38 \\
\hline $\mathrm{P}$ (mbar) & Visor \% & Tensão (V) \\
\hline 0 & 0,1 & 9,50E-03 \\
\hline 50 & 5,1 & 0,513 \\
\hline 100 & 10 & 1,004 \\
\hline 153 & 15,2 & 1,527 \\
\hline 200 & 19,9 & 1,999 \\
\hline 252 & 25,1 & 2,515 \\
\hline 300 & 29,8 & 2,991 \\
\hline 351 & 34,9 & 3,500 \\
\hline 402 & 40,0 & 4,01 \\
\hline 450 & 44,8 & 4,484 \\
\hline 502 & 49,9 & 5,000 \\
\hline 550 & 54,7 & 5,485 \\
\hline 598 & 59,6 & 5,969 \\
\hline 647 & 64,4 & 6,452 \\
\hline 699 & 69,7 & 6,981 \\
\hline 751 & 74,8 & 7,497 \\
\hline 800 & 79,7 & 7,989 \\
\hline 854 & 85,2 & 8,533 \\
\hline 909 & 90,6 & 9,083 \\
\hline 954 & 95,2 & 9,539 \\
\hline 1000 & 99,9 & 10,008 \\
\hline 902 & 90,1 & 9,030 \\
\hline 800 & 79,9 & 8,005 \\
\hline 706 & 70,5 & 7,068 \\
\hline 594 & 59,2 & 5,932 \\
\hline 549 & 54,8 & 5,490 \\
\hline 506 & 50,5 & 5,058 \\
\hline 450 & 45,0 & 4,505 \\
\hline 400 & 40,0 & 4,007 \\
\hline 347 & 34,6 & 3,468 \\
\hline 301 & 30,2 & 3,025 \\
\hline 248 & 24,9 & 2,491 \\
\hline 198 & 19,9 & 1,995 \\
\hline 150 & 15,0 & 1,502 \\
\hline 102 & 10,3 & 1,031 \\
\hline 53 & 5,5 & 0,548 \\
\hline 0 & 0,2 & $1,82 \mathrm{E}-02$ \\
\hline
\end{tabular}


As figuras, Figura 4. 19 a Figura 4. 26, apresentam as curvas que foram ajustadas para os sensores de pressão. As curvas, Figura 4. 27 e Figura 4. 28, relacionam respectivamente, a velocidade medida pelo pitot no bocal de saída da seção de testes [m/s] e a vazão medida na placa de orifício $\left[\mathrm{m}^{3} / \mathrm{h}\right]$ com os sinais de tensão [V] de saída dos seus "Validynes". Para obtenção dos ajuste e curvas de calibração foi utilizado o programa Matlab R2015a, [54] a [57].

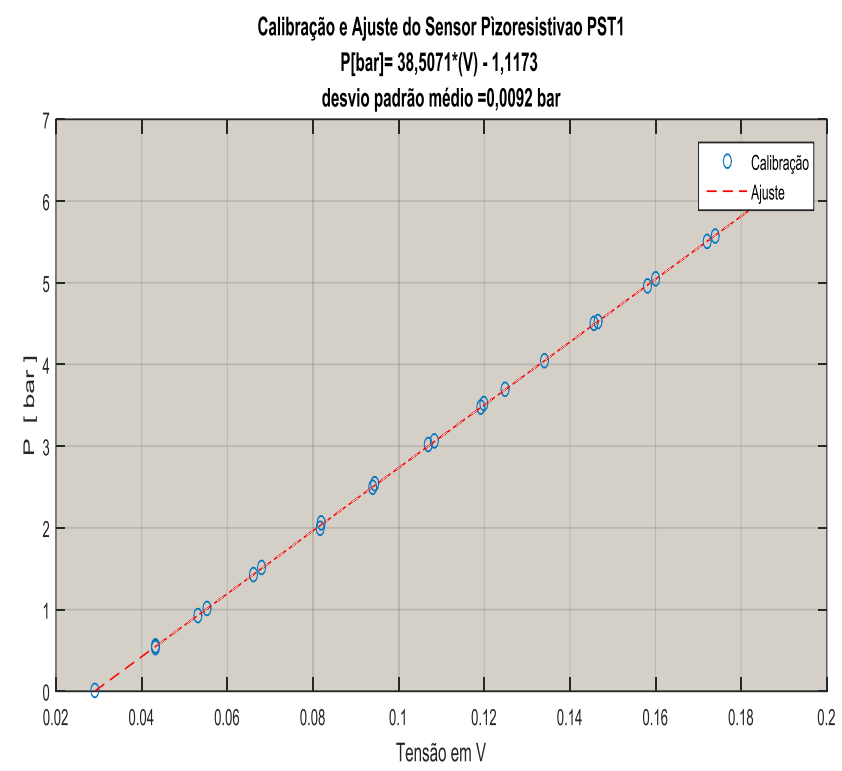

Figura 4. 19 - Ajuste da curva do sensor PST1

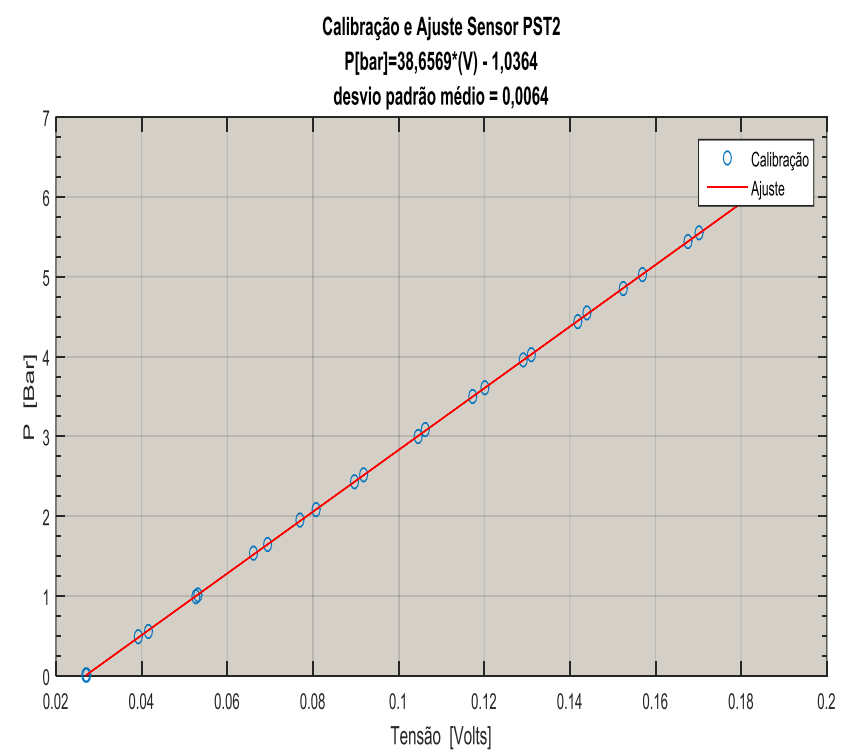

Figura 4. 20 - Ajuste da curva do sensor PST2 $_{\text {ST }}$ 


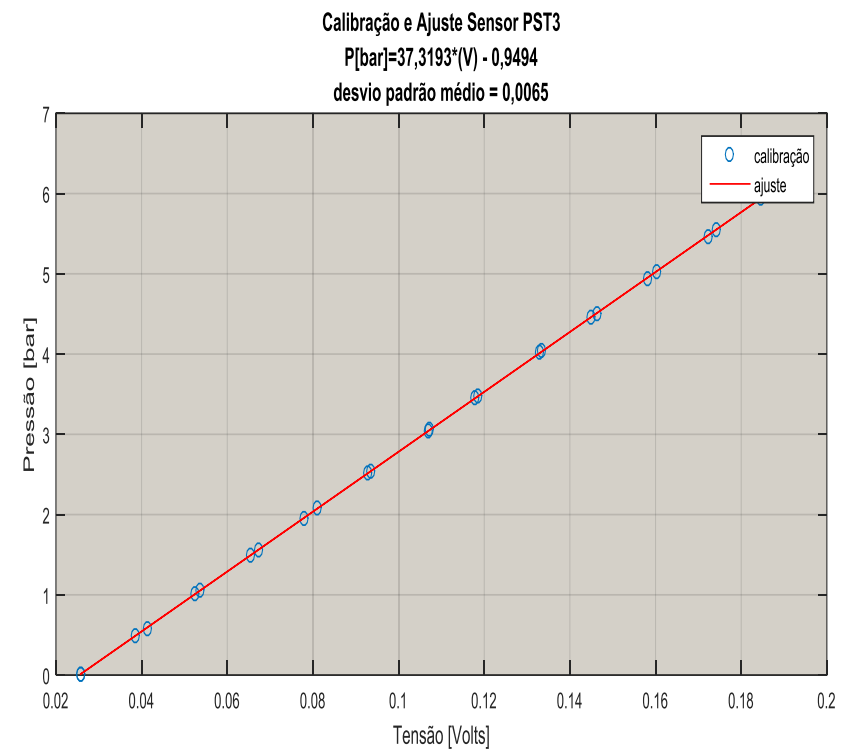

Figura 4. 21 - Ajuste da curva do sensor $P_{\text {ST3 }}$

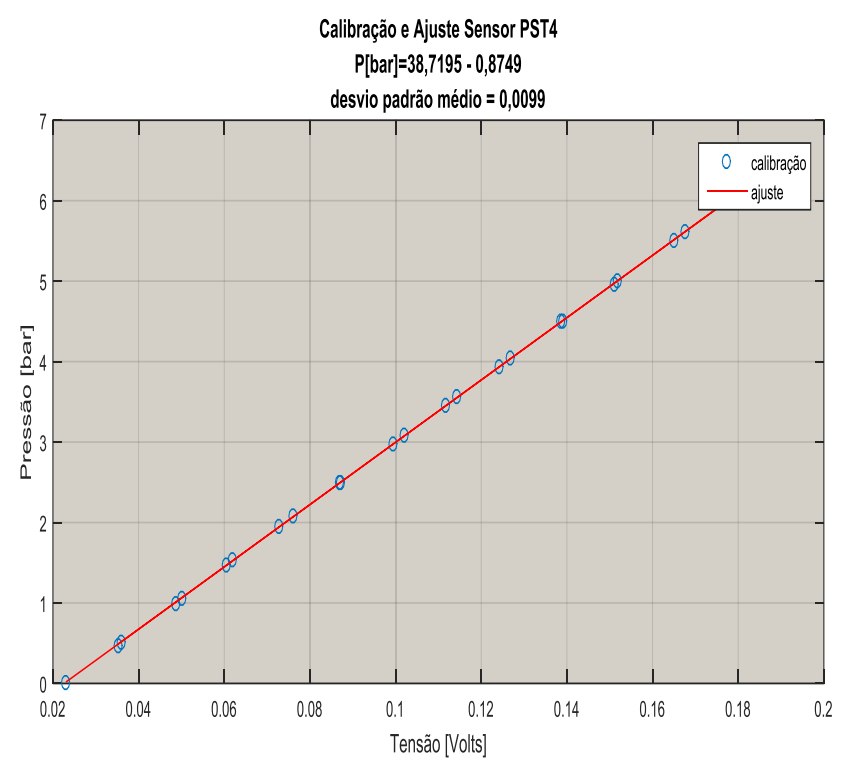

Figura 4. 22 - Ajuste da curva do sensor PST4 $_{\text {ST }}$ 


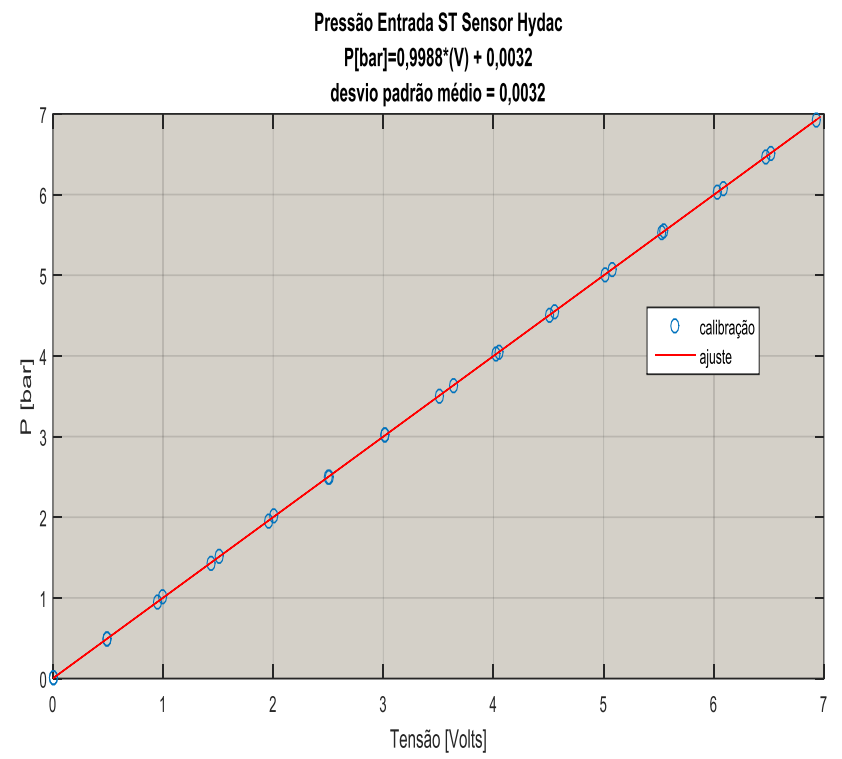

Figura 4. 23 - Ajuste da curva do sensor $P_{E}$

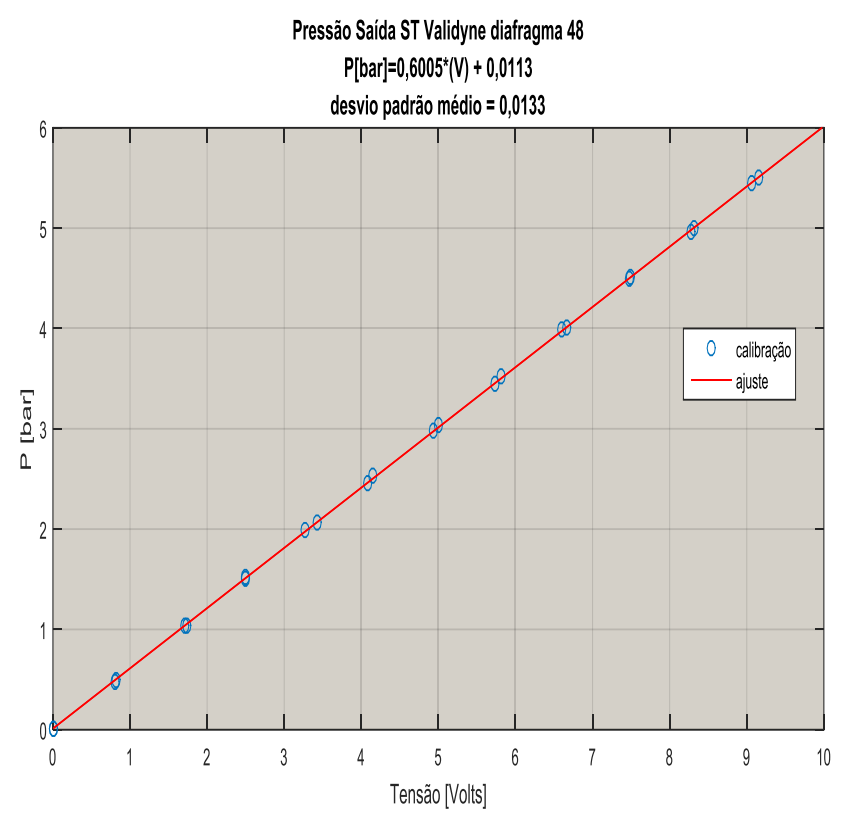

Figura 4. 24 - Ajuste da curva do sensor $P_{S}$ 


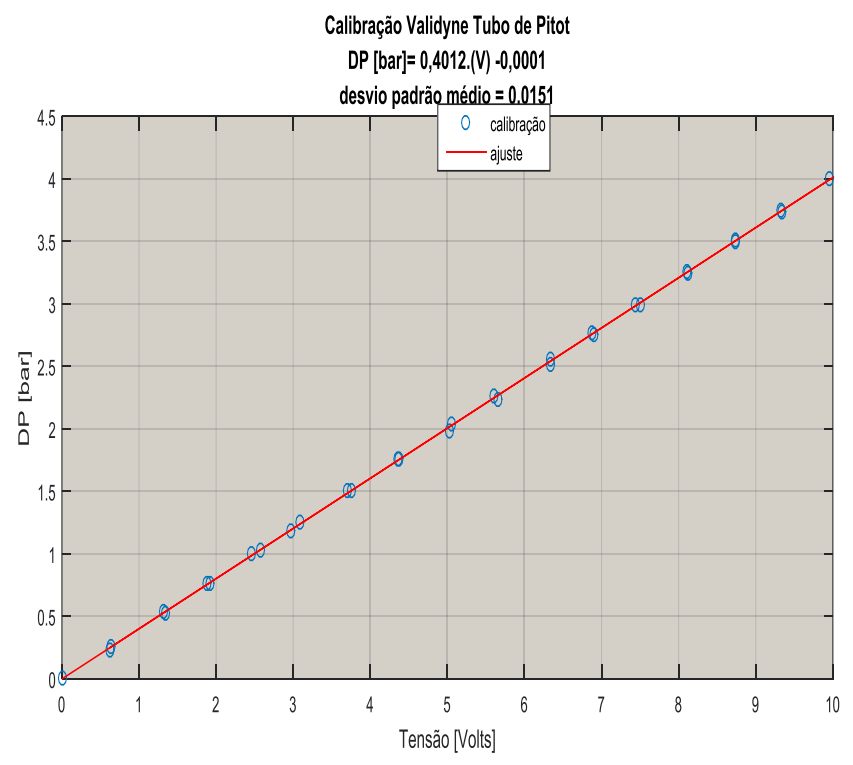

Figura 4. 25 - Calibração Validyne Tubo Pitot

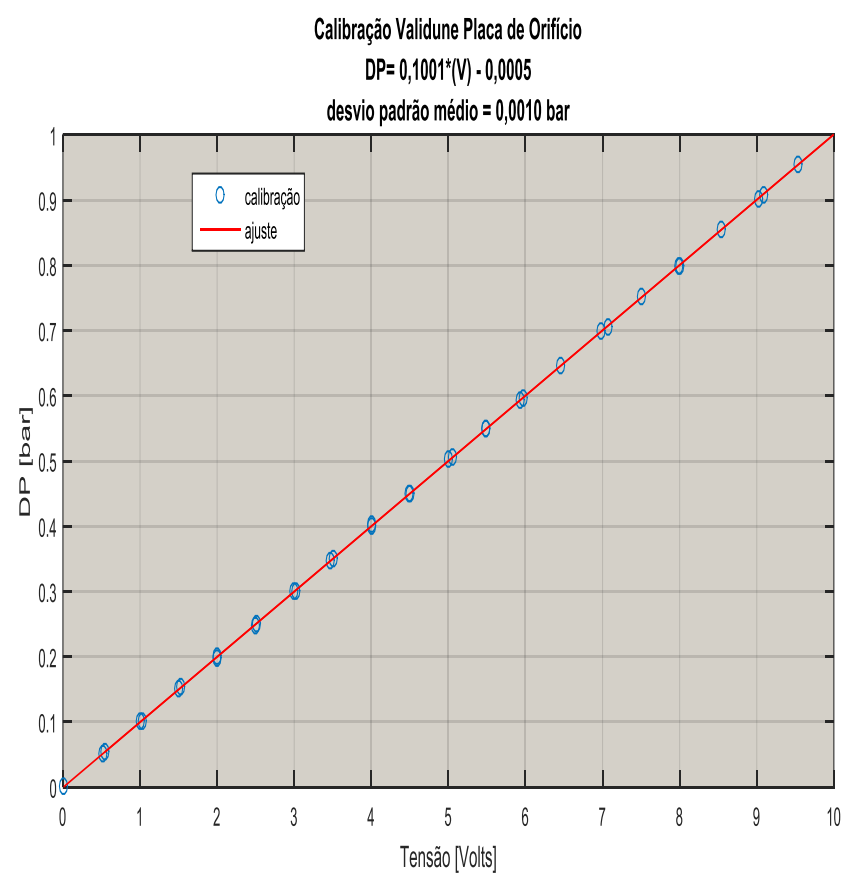

Figura 4. 26 - Calibração Validyne Placa Orifício 


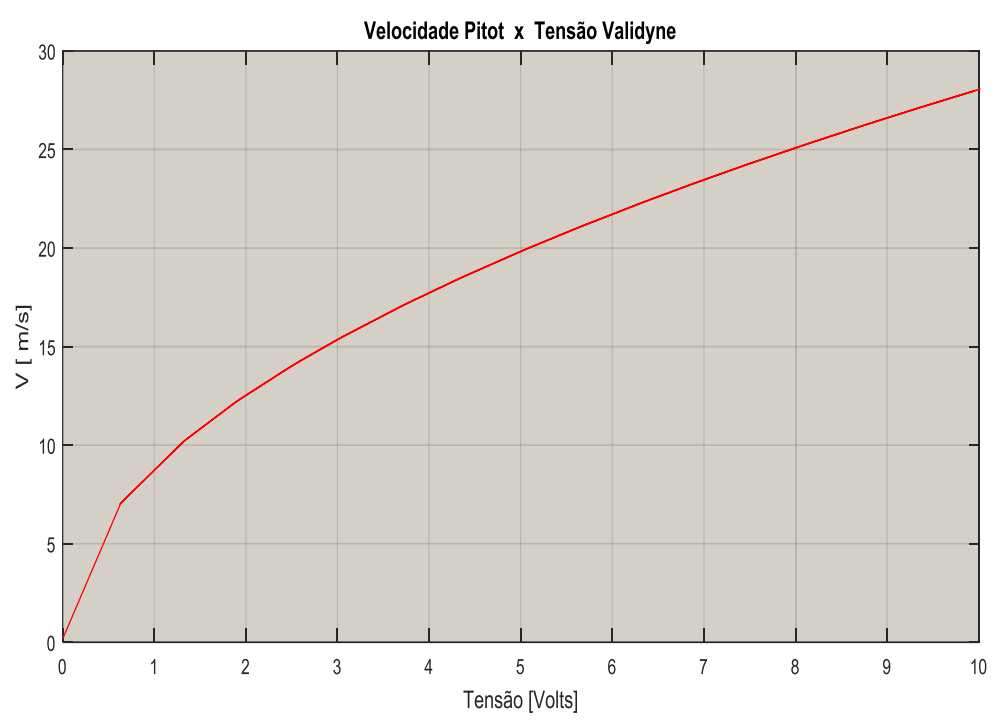

Figura 4. 27 - Ajuste da Velocidade Pitot x sinal saída Validyne

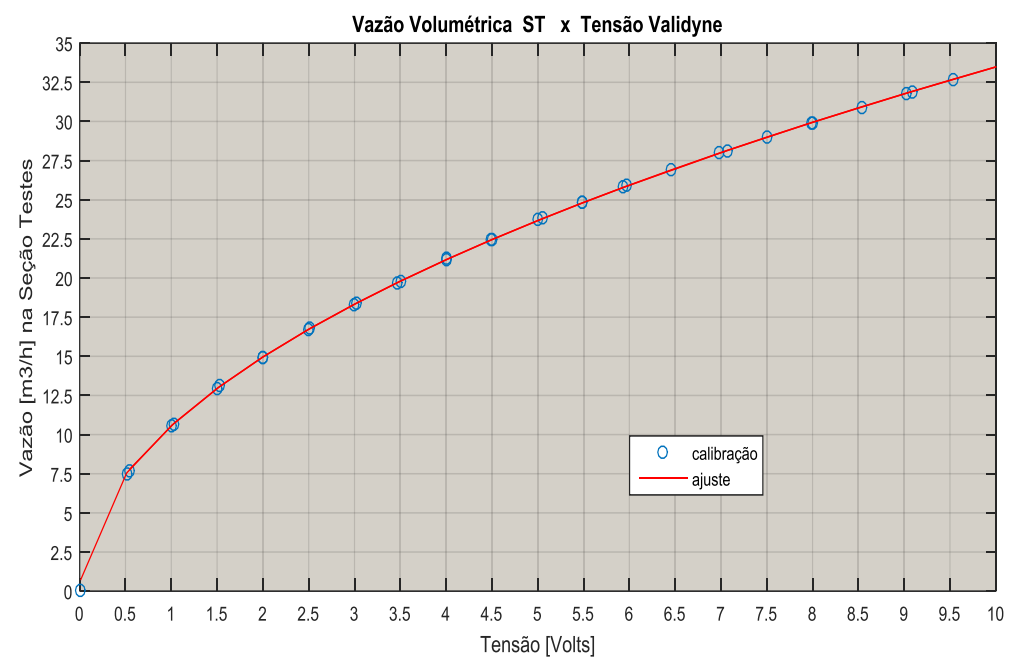

Figura 4. 28 - Ajuste vazão volumétrica seção testes x sinal saída Validyne

\subsection{TESTES E ANÁLISE MODAL DA SEÇÃO DE TESTES}

Testes de impacto na seção de testes foram realizados com o objetivo de se comissionar os sensores de deformação instalados e de se levantar alguns parâmetros característicos de vibrações das placas de alumínio que simulam os canais de refrigeração, [58] a [61]. Para a aquisição dos sinais, utilizou-se o equipamento QuantumX MX840B juntamente com o programa Catman instalado em um computador portátil que foi fornecido pelo Laboratório de análise de tensões da FEI/SBC. Este sistema é fornecido comercialmente pela empresa alemã HBM. A Figura 4.28 apresenta o sistema de aquisição de dados utilizado 
nos testes. Nesta figura podem ser observados os sinais de 4 extensômetros instalados na seção de testes, os extensômetros SG1, SG3, SG5 e SG6. Os extensômetros ímpares estão instalados na parte interna da placa correspondente ao canal central de escoamento na posições de entrada, meio e saída. O SG6 está instalado na saída do canal externo. Durante os testes, pode ser observado que os extensômetros SG2 e SG4 instalados na entrada e meio do canal externo já estavam danificados. Provávelmente, eles foram danificados durante o processo de montagem da seção de testes.

Foram realizados testes de impacto no ar e na água. As Figuras 4.29 a 4.34 abaixo apresentam os resultados principais dos ensaios. Estes resultados foram gerados utilizandose o programa Matlab R15a, [54] a [57].

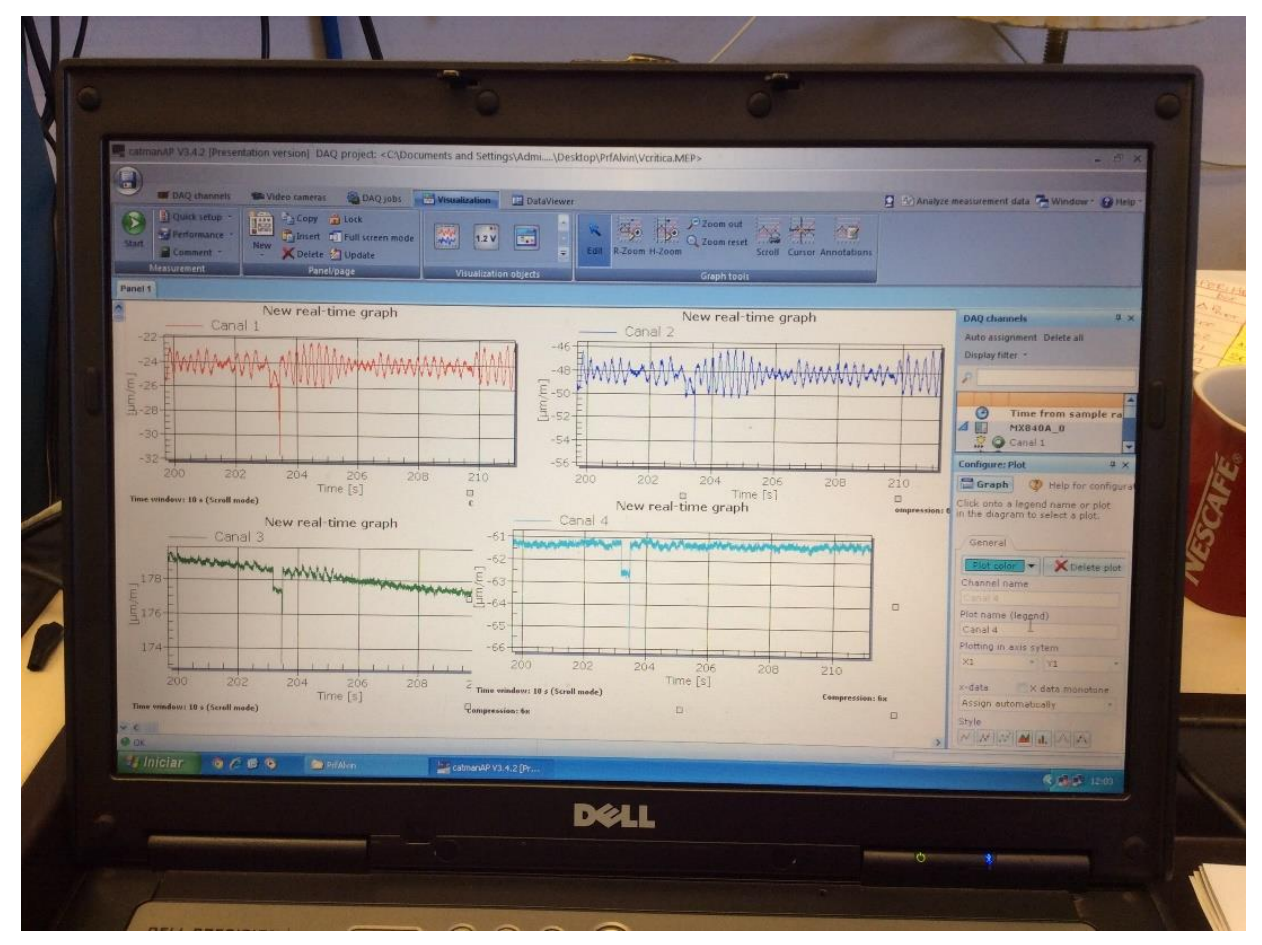

Figura 4. 29 - Sistema de aquisição de sinais dos extensômetros

Nas figuras, Figura 4. 30 a Figura 4. 35, são mostrados os resultados do ensaio realizado com a seção de testes aberta ao ambiente. $\mathrm{O}$ meio fluido era o ar. Foram induzidos pequenos impactos no corpo da seção e gravados os sinais do extensômetro.

O sinal correspondente ao extensômetro SG1, entrada do canal, apresentou uma frequência próxima de $11 \mathrm{~Hz}$ no gráfico da Transformada de Fourier (FFT) e no gráfico de Espectro de Potência (PSD). No gráfico do Espectro de Potência, também foi observado a 
frequência de $33 \mathrm{~Hz}$. No sinal do extensômetro SG3, meio do canal, foi observado a frequência de $22 \mathrm{~Hz}$ no gráfico da FFT. No gráfico do PSD, a frequência de $11 \mathrm{~Hz}$ é a principal e surge também a frequencia de $33 \mathrm{~Hz}$.

Os sinais correspondentes aos extensômetros SG5 e SG6 também apresentaram a frequência principal em $11 \mathrm{~Hz}$ nos gráficos de FFT e PSD. Este sinais foram de menor intensidade.

Tentou-se realizar um ensaio com a seção de testes com o corpo interno preenchido com água e aberta ao ar do lado externo. Os ensaios não apresentaram diferenças significativas. Possívelmente, teríamos que ter colocado a seção de testes imersa em um banho de água para verificarmos a sua influência sobre as frequências naturais da seção de testes.

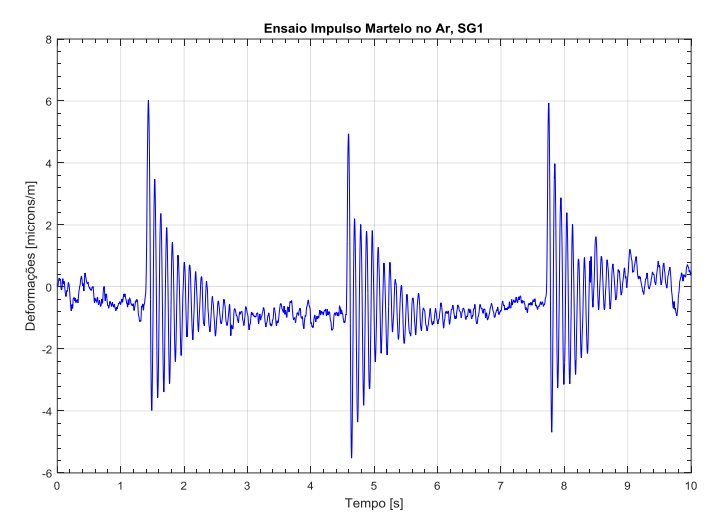

Figura 4. 30 - Sinal do Extensômetro SG1

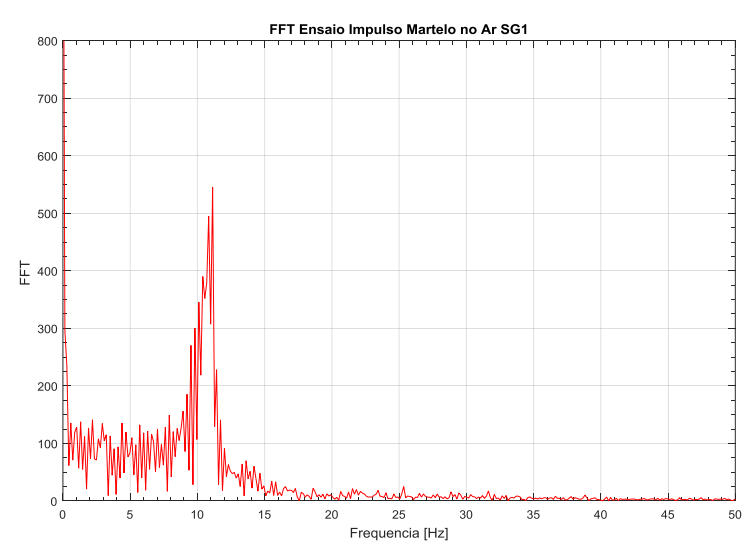

Figura 4. 31 - Transformada de Fourier (FFT) de SG1 


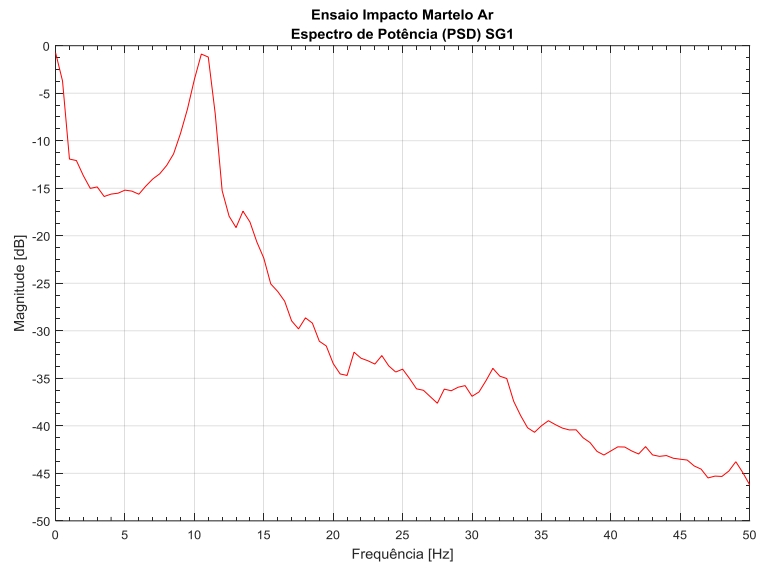

Figura 4. 32 - Espectro de Potência (PSD) do sinal SG1

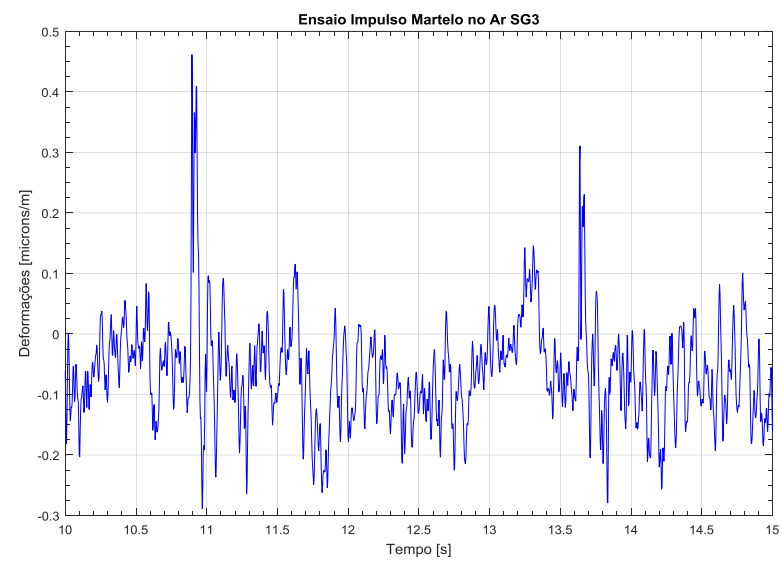

Figura 4. 33 - Sinal do Extensômetro SG3

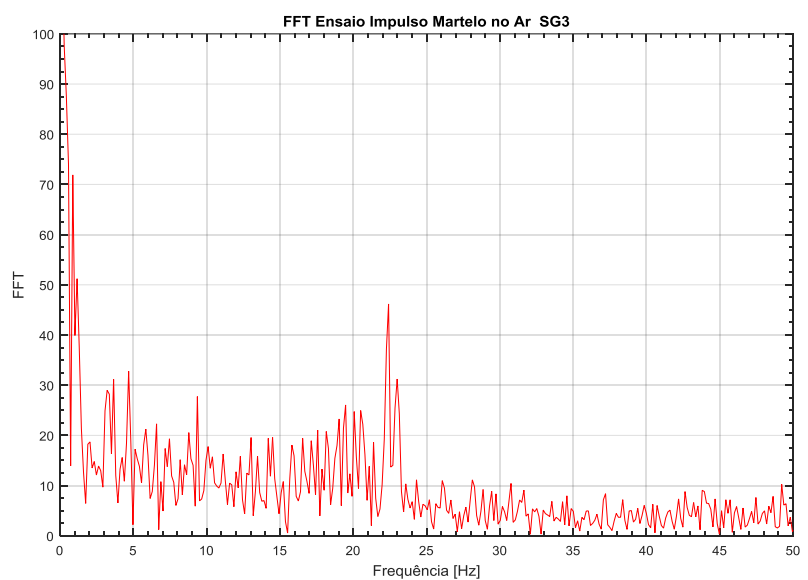

Figura 4. 34 - Transformada de Fourier (FFT) de SG3 


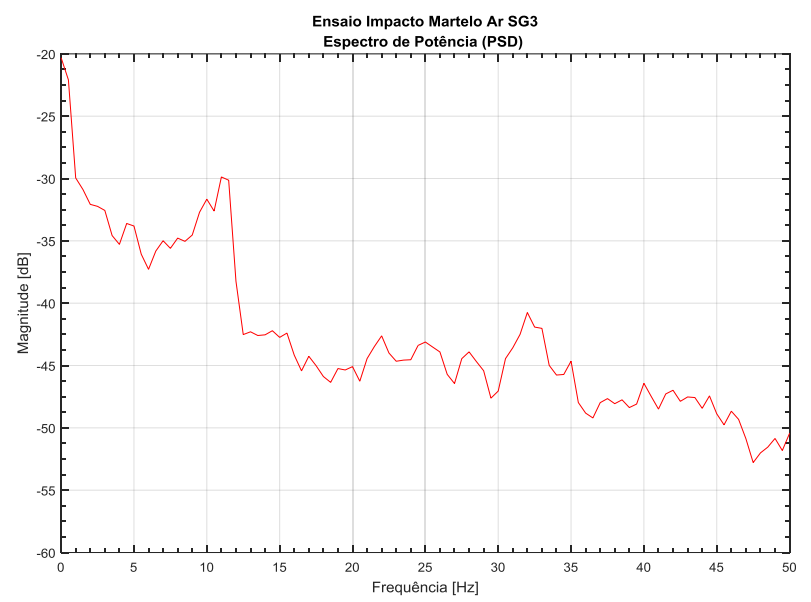

Figura 4. 35 - Espectro de Potência (PSD) do sinal SG3

Os resultados obtidos com a análise modal permitiram concluir que a seção de testes possui uma frequência natural de $1^{\circ}$ modo de vibração em torno de $11 \mathrm{~Hz}$. As frequências em torno de $22 \mathrm{~Hz}$ e $33 \mathrm{~Hz}$ são $2^{\circ}$ e $3^{\circ}$ harmônicos da frequência natural de $1^{\circ}$ modo. Não foram identificadas frequências naturais de $2^{\circ}$ e $3^{\circ}$ modo de vibração.

\subsection{ENSAIOS DE TRAÇÃO DA PLACA DE ALUMÍNIO}

Com o objetivo de se confirmar o módulo de elasticidade, E, utilizado para os cálculos da velocidade crítica de Miller realizou-se ensaios de tração com a placa de alumínio fabricada para a seção de testes. Três corpos de prova foram preparados a partir de uma placa de alumínio reserva fabricada nas mesmas condições e processo das placas da seção de testes. Estes ensaios foram realizados no laboratório de materiais do Centro Universitário da FEI/ SBC. Nas figuras, Figura 4. 36 e Figura 4. 37, podem ser visualizados os corpos de prova ensaiados e a máquina de tração. Os corpos de prova foram preparados por eletroerosão. 


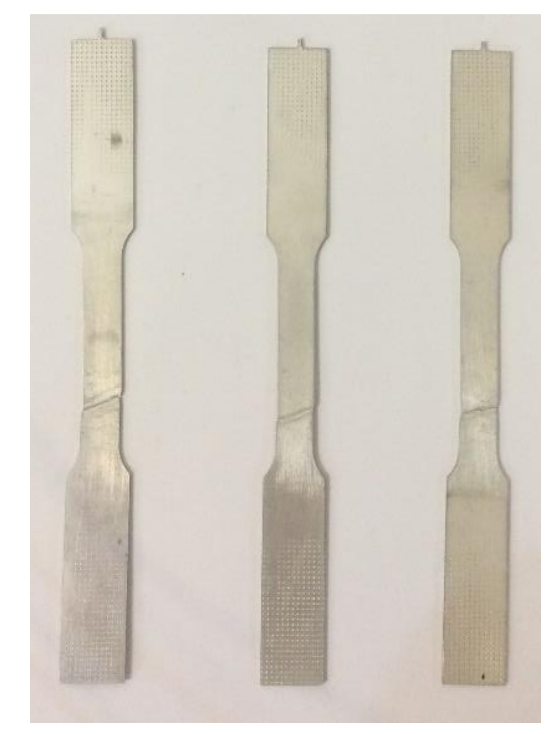

Figura 4. 36 - Corpos de Prova para os ensaios de Tração

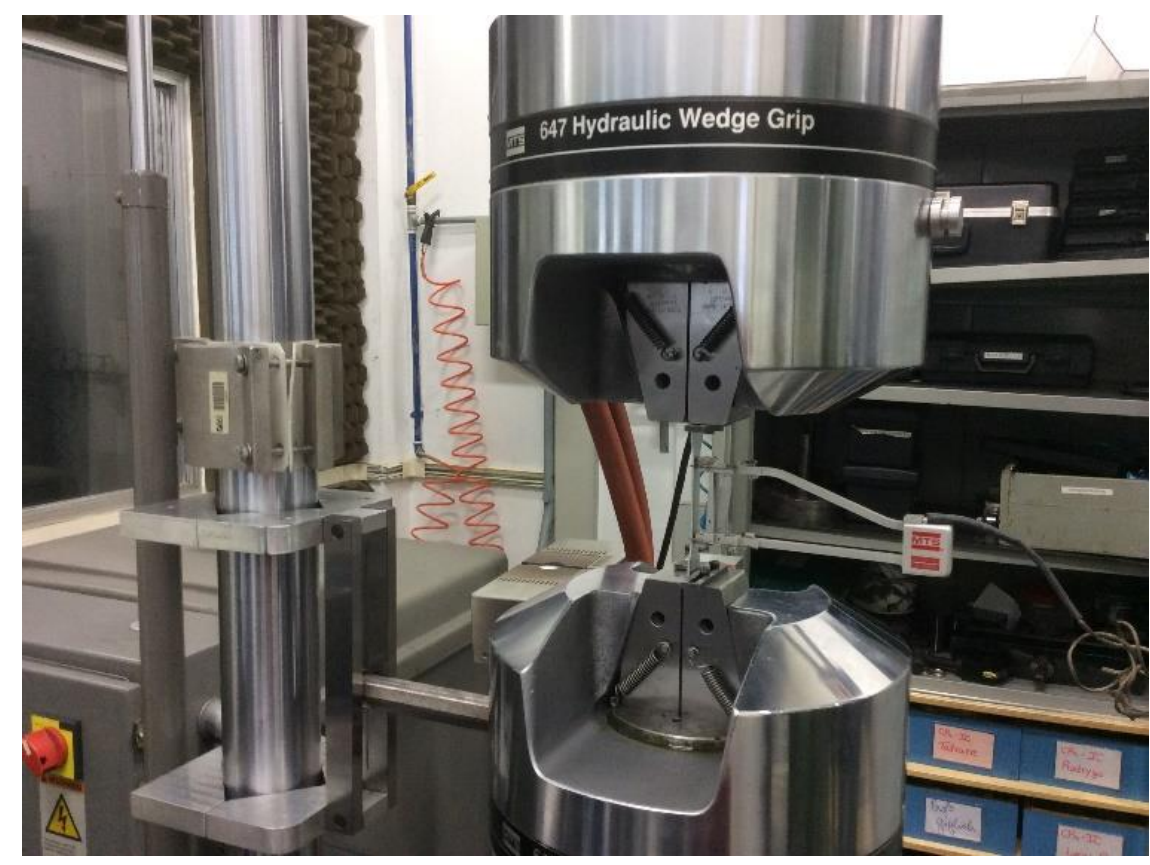

Figura 4. 37 - Máquina de ensaio de tração

Os resultados obtidos com os ensaios podem ser observados na Figura 4. 38 abaixo. Os valores obtidos para o módulo de elasticidade, E, foram de 67, 69 e $70 \mathrm{GPa}$. Utilizamos para os cálculos o valor $70 \mathrm{GPa}$ obtido da literatura, o que nos dá um erro máximo de dois por cento considerando um valor médio de $\mathbf{E}=68,7 \mathrm{GPa}$. 


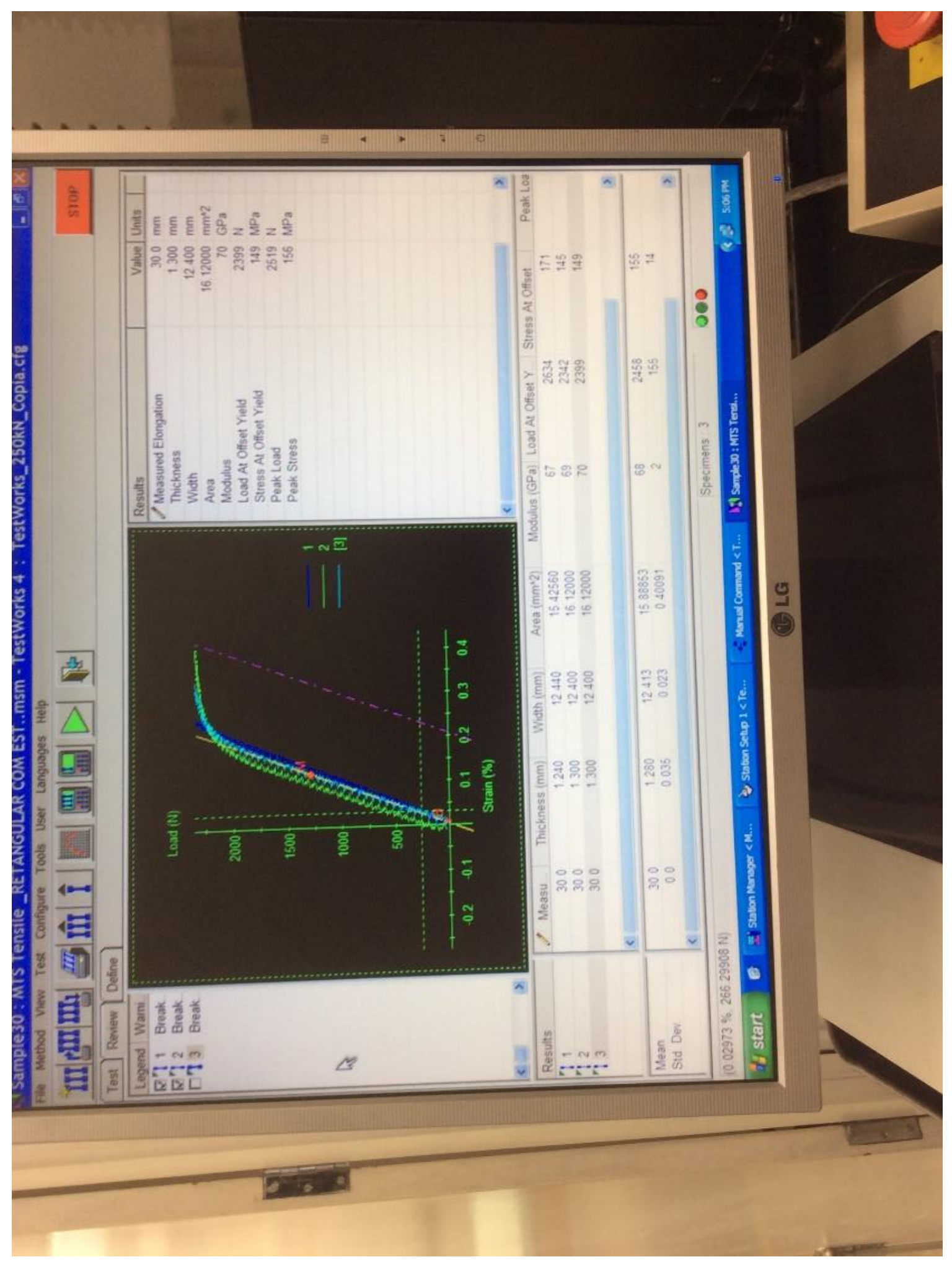

Figura 4. 38 - Resultados dos ensaios de tração 


\section{EXPERIMENTOS}

Com o término do comissionamento da bancada experimental, foram iniciados os experimentos para levantamento de dados visando estudos de instabilidade fluido elástica, testes de colapso de placas por velocidade crítica e do acoplamento fluido dinâmico da estrutura.

Foram levantados inicialmente dados experimentais da seção de testes considerando velocidades médias na seção de testes de 7,0 m/s até aproximadamente 12,0 m/s. Nesta fase inicial, o principal objetivo era testar a operação da bancada experimental, verificar a reprodutibilidade dos sinais dos sensores de deformação da seção de testes e dos sinais de pressão. Devido a problemas de incompatibilidade do condicionador de sinais do sistema de aquisição de dados da "National Instruments", o NI9237, utilizamos o sistema QuantumX da HBM para obter os sinais dos extensômetros. Esta dificuldade surgiu porque a seção de testes foi instrumentada com sensores de 350 Ohm e o condicionador da NI9237 tem sua eletrônica somente para sensores de 120 Ohm de resistência. O sistema QuantumX já havia produzido resultados muito bons durante a análise modal.

Este fato levou a condição de operarmos a aquisição de dados utilizando dois sistemas distintos. O sistema QuantumX da "HBM" para os extensômetros e o sistema da "National Instruments" para os sinais de processo. O relógio dos dois computadores foram sincronizados para podermos relacionar os sinais no tempo.

Durante vários dias, o circuito foi operado e os sinais dos sensores de deformação mostraram-se bastante confiáveis, reprodutíveis e não afetados por ruídos espúrios provenientes da rede elétrica. Terminada a operação, os sinais dos extensômetros retornavam à condição inicial demonstrando não ter havido deformações plásticas. Durante esta fase perdemos o sinal do sensor SG5, permanecendo para a etapa final os extensômetros SG1, SG3 e SG6.

Os sinais de processo obtidos com o sistema da "National Instrument" apresentaram alguns problemas com ruídos provenientes da rede elétrica. Estes problemas foram solucionados processando os sinais com filtros digitais e estatisticamente através de um programa desenvolvido no "LabVIEW10", [47] a [53], mostrado na Figura 5. 1. 


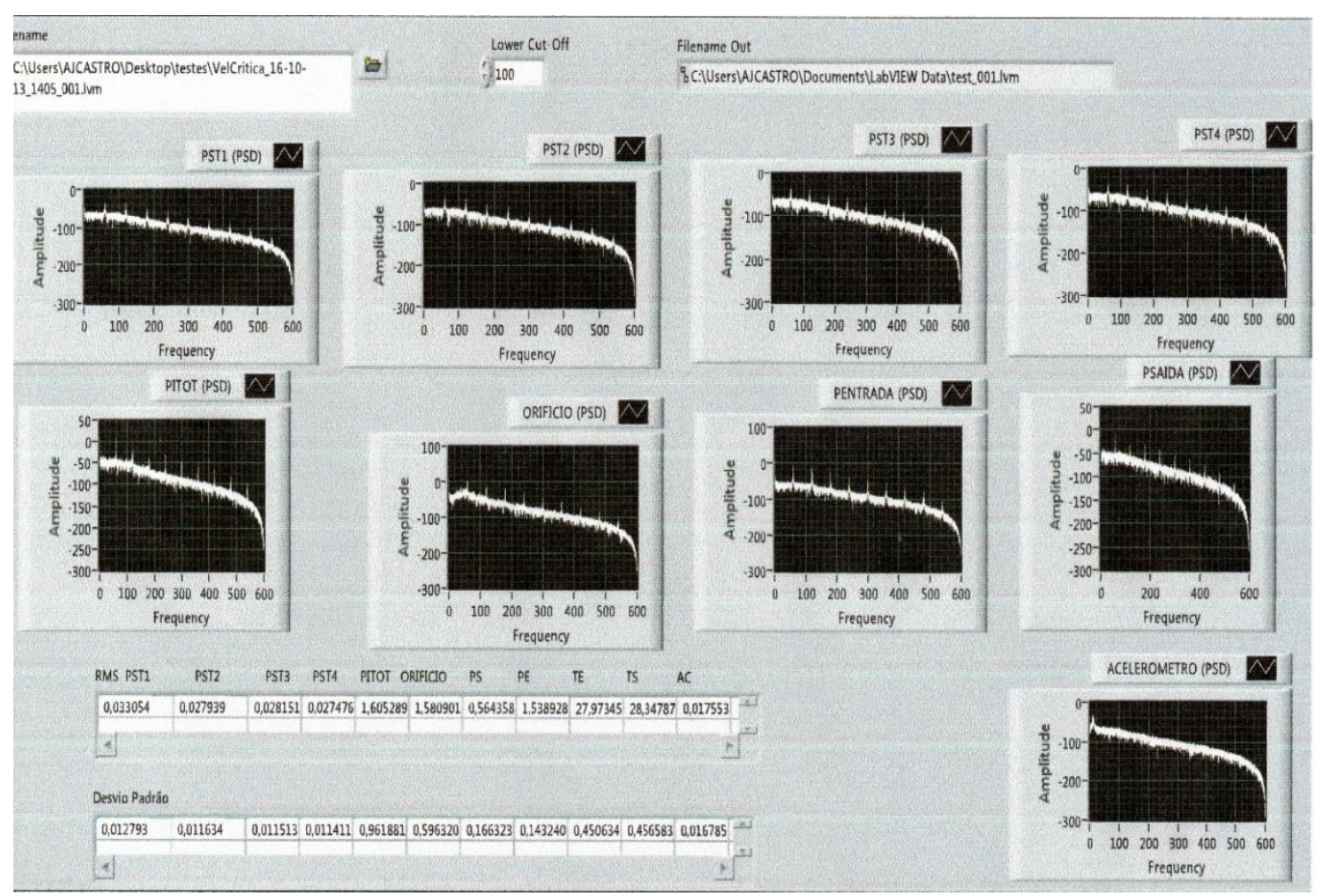

Figura 5. 1 - Programa FILTRO.VI

No painel frontal do programa FILTRO.VI, observa-se a presença da frequência da rede elétrica e dos seus harmônicos nos espectros de potência dos sinais dos sensores de pressão. Os sinais de processo passaram por um filtro passa baixa de $10 \mathrm{~Hz}$.

Resolvidas as dificuldades iniciais, veio a fase final dos experimentos com o objetivo de atingirmos a velocidade crítica. Nesta fase, iniciamos os experimentos com a velocidade média da seção de testes em torno de $6,5 \mathrm{~m} / \mathrm{s}$. A cada atuação na válvula globo para aumentar a vazão do circuito e consequentemente, a velocidade média na seção de testes, os sinais dos sensores de processo em condição de regime permanente eram monitorados e gravados com uma frequência de amostragem de $1200 \mathrm{~Hz}$ durante 10 segundos. Os sensores de deformação eram monitorados e gravados com a mesma frequência mas com um tempo maior de amostragem. Esta velocidade foi sendo aumentada de $1,0 \mathrm{~m} / \mathrm{s}$ a cada passo. A partir da velocidade média em torno de $13,0 \mathrm{~m} / \mathrm{s}$, promovemos aumentos de $0,5 \mathrm{~m} / \mathrm{s}$ e passamos a gravar os sinais durante o transiente de atuação na válvula globo pelo período de 30 segundos para os sinais de processo e no mínimo de 60 segundos para os sinais de deformação. Chegamos a condição máxima de vazão no circuito com a velocidade média no canal de $15,0 \mathrm{~m} / \mathrm{s}$. O controle do aumento de vazão no circuito e da velocidade média nos canais da seção de testes foi realizado através do acompanhamento do sinal de $\Delta \mathrm{P}$ da placa de orifício no visor digital do sensor "Validyne". 


\section{RESULTADOS}

Os dados obtidos na fase final dos experimentos para obtenção da velocidade crítica são apresentados neste capítulo. Eles foram analisados tanto no domínio do tempo como no domínio de frequência, através de rotinas no programa Matlab R15a, [54], e do programa FILTRO.VI baseado na plataforma LabVIEW10, [46]. Durante os experimentos finais para a obtenção da velocidade crítica foram realizados 13 ensaios. Nestes ensaios, a velocidade média na seção de testes foi variada de 6,5 a $15,0 \mathrm{~m} / \mathrm{s}$. A partir de $13,5 \mathrm{~m} / \mathrm{s}$ foram gravados os sinais durante o transiente de aumento de velocidade no intuito de se identificar o ponto de início do colapso e da deformação plástica das placas da seção de testes.

As tabelas, Tabela 6. 1 e Tabela 6.2, abaixo apresentam os dados de processo obtidos com o programa VCRITICA.VI do sistema de aquisição baseado no LabVIEW10. Estes dados foram processados pelo programa FILTRO.VI e analisados estatiscamente através de funções do programa Matlab R15a.

Tabela 6. 1 - Dados do experimento de velocidade crítica

\begin{tabular}{|c|c|c|c|c|c|c|c|c|c|}
\hline ENSAIO & $\begin{array}{c}\text { HORA } \\
\mathbf{1 3 / 1 0 / 1 6}\end{array}$ & $\begin{array}{c}\mathbf{P}_{\mathbf{E}} \\
{[\mathbf{k P a}]}\end{array}$ & $\begin{array}{c}\mathbf{P}_{\mathbf{S}} \\
{[\mathbf{k P a}]}\end{array}$ & $\begin{array}{c}\mathbf{V}_{\mathbf{P I T O}} \\
{[\mathbf{m} / \mathbf{s}]}\end{array}$ & $\begin{array}{c}\mathbf{Q}_{\mathbf{P . O R I F . ~}} \\
{\left[\mathbf{m}^{\mathbf{3}} \mathbf{/ h}\right]}\end{array}$ & $\begin{array}{c}\mathbf{T}_{\mathbf{E}} \\
{\left[{ }^{\circ} \mathbf{C}\right]}\end{array}$ & $\begin{array}{c}\mathbf{T}_{\mathbf{S}} \\
{\left[{ }^{\circ} \mathbf{C}\right]}\end{array}$ & $\begin{array}{c}\mathbf{A} \\
{\left[\mathbf{m} / \mathbf{s}^{\mathbf{2}}\right]}\end{array}$ & $\begin{array}{c}\mathbf{V}_{\mathbf{S T}} \\
{[\mathbf{m} / \mathbf{s}]}\end{array}$ \\
\hline 1 & $14: 05$ & 153,2 & 32,5 & 15,86 & 11,992 & 27,9 & 28,3 & 0,0105 & 6,43 \\
\hline 2 & $14: 09$ & 190,2 & 36,0 & 18,13 & 13,709 & 28,1 & 28,5 & 0,0105 & 7,35 \\
\hline 3 & $14: 12$ & 232,0 & 40,1 & 20,62 & 15,588 & 28,3 & 28,7 & 0,0100 & 8,35 \\
\hline 4 & $14: 16$ & 259,5 & 42,5 & 22,35 & 16,897 & 28,5 & 28,9 & 0,0095 & 9,06 \\
\hline 5 & $14: 20$ & 297,9 & 48,6 & 24,39 & 18,440 & 28,7 & 29,2 & 0,0112 & 9,89 \\
\hline 6 & $14: 25$ & 342,8 & 53,5 & 26,98 & 20,394 & 29,0 & 29,5 & 0,0099 & 10,93 \\
\hline 7 & $14: 29$ & 384,3 & 59,6 & 28,82 & 21,783 & 29,2 & 29,7 & 0,0111 & 11,68 \\
\hline 8 & $14: 32$ & 412,5 & 65,0 & 30,36 & 22,949 & 29,2 & 29,9 & 0,0102 & 12,30 \\
\hline 9 & $14: 35$ & 458,4 & 77,1 & 33,09 & 25,015 & 29,6 & 30,0 & 0,0112 & 13,41 \\
\hline 10 & $14: 39$ & 469,0 & 79,5 & 33,50 & 25,325 & 29,9 & 30,3 & 0,0103 & 13,58 \\
\hline 11 & $14: 43$ & 486,9 & 83,7 & 34,61 & 26,162 & 30,1 & 30,6 & 0,0104 & 14,02 \\
\hline 12 & $15: 02$ & 523,9 & 111,1 & 35,81 & 27,070 & 37,3 & 37,5 & 0,0097 & 14,51 \\
\hline 13 & $15: 06$ & 523,4 & 107,9 & 37,01 & 27,973 & 38,9 & 39,2 & 0,0090 & 15,00 \\
\hline
\end{tabular}

Da Tabela 6. 1 pode-se verificar que o $\Delta \mathrm{P}$ na seção de testes cresceu até o fim dos ensaios. A Figura 6. 1 apresenta a curva da diferença de pressão entre a entrada e saída na seção de testes, $\Delta \mathrm{P}$, contra a velocidade média na seção de testes. Nesta curva, pode ser observado que durante os experimentos havia uma tendência linear de aumento do $\Delta \mathrm{P}$. $\mathrm{A}$ partir da velocidade $14,0 \mathrm{~m} / \mathrm{s}$ houve uma queda da resistência hidráulica da seção de teste, o 
que é consequência do colapso das placas devido as deformações plásticas nos canais de escoamento, aumentando a área de escoamento e vazão do refrigerante no canal central.

Tabela 6. 2 - Desvio padrão médio dos dados de processo

\begin{tabular}{|c|c|c|c|c|c|c|c|c|}
\hline ENSAIO & $\begin{array}{c}\text { HORA } \\
\mathbf{1 3 / 1 0 / 1 6}\end{array}$ & $\begin{array}{c}\boldsymbol{\sigma}_{\text {Pe }} \\
{[\mathbf{k P a}]}\end{array}$ & $\begin{array}{c}\boldsymbol{\sigma}_{\text {Ps }} \\
{[\mathbf{k P a}]}\end{array}$ & $\begin{array}{c}\boldsymbol{\sigma}_{\text {Pitot }} \\
{[\mathbf{m} / \mathbf{s}]}\end{array}$ & $\begin{array}{c}\boldsymbol{\sigma}_{\text {P.Orif. }} \\
{\left[\mathbf{m}^{\mathbf{3}} / \mathbf{h}\right]}\end{array}$ & $\begin{array}{c}\boldsymbol{\sigma}_{\text {Te }} \\
{\left[{ }^{\circ} \mathbf{C}\right]}\end{array}$ & $\begin{array}{c}\boldsymbol{\sigma}_{\text {Ts }} \\
{\left[{ }^{\circ} \mathbf{C}\right]}\end{array}$ & $\begin{array}{c}\boldsymbol{\sigma}_{\mathbf{A}} \\
{\left[\mathbf{m} / \mathbf{s}^{\mathbf{2}}\right]}\end{array}$ \\
\hline 1 & $14: 05$ & 8,3 & 1,9 & 3,91 & 2,952 & 1,44 & 1,46 & 0,0091 \\
\hline 2 & $14: 09$ & 10,2 & 2,1 & 4,30 & 3,251 & 1,45 & 1,47 & 0,0091 \\
\hline 3 & $14: 12$ & 12,4 & 2,4 & 4,69 & 3,547 & 1,46 & 1,48 & 0,0085 \\
\hline 4 & $14: 16$ & 14,5 & 2,6 & 5,34 & 4,039 & 1,47 & 1,49 & 0,0078 \\
\hline 5 & $14: 20$ & 16,1 & 2,9 & 5,80 & 4,383 & 1,48 & 1,50 & 0,0098 \\
\hline 6 & $14: 25$ & 18,5 & 3,3 & 6,16 & 4,659 & 1,49 & 1,52 & 0,185 \\
\hline 7 & $14: 29$ & 20,4 & 3,6 & 6,67 & 5,038 & 1,50 & 1,53 & 0,0097 \\
\hline 8 & $14: 32$ & 22,2 & 4,1 & 6,99 & 5,281 & 1,51 & 1,54 & 0,0086 \\
\hline 9 & $14: 35$ & 25,1 & 5,0 & 7,62 & 5,761 & 1,52 & 1,55 & 0,0097 \\
\hline 10 & $14: 39$ & 15,6 & 3,4 & 5,94 & 4,489 & 0,89 & 0,90 & 0,0086 \\
\hline 11 & $14: 43$ & 15,8 & 3,5 & 6,17 & 4,661 & 0,89 & 0,91 & 0,0088 \\
\hline 12 & $15: 02$ & 16,5 & 4,2 & 8,54 & 6,453 & 1,11 & 1,12 & 0,0078 \\
\hline 13 & $15: 06$ & 16,6 & 3,9 & 6,47 & 4,892 & 1,16 & 1,17 & 0,0069 \\
\hline
\end{tabular}

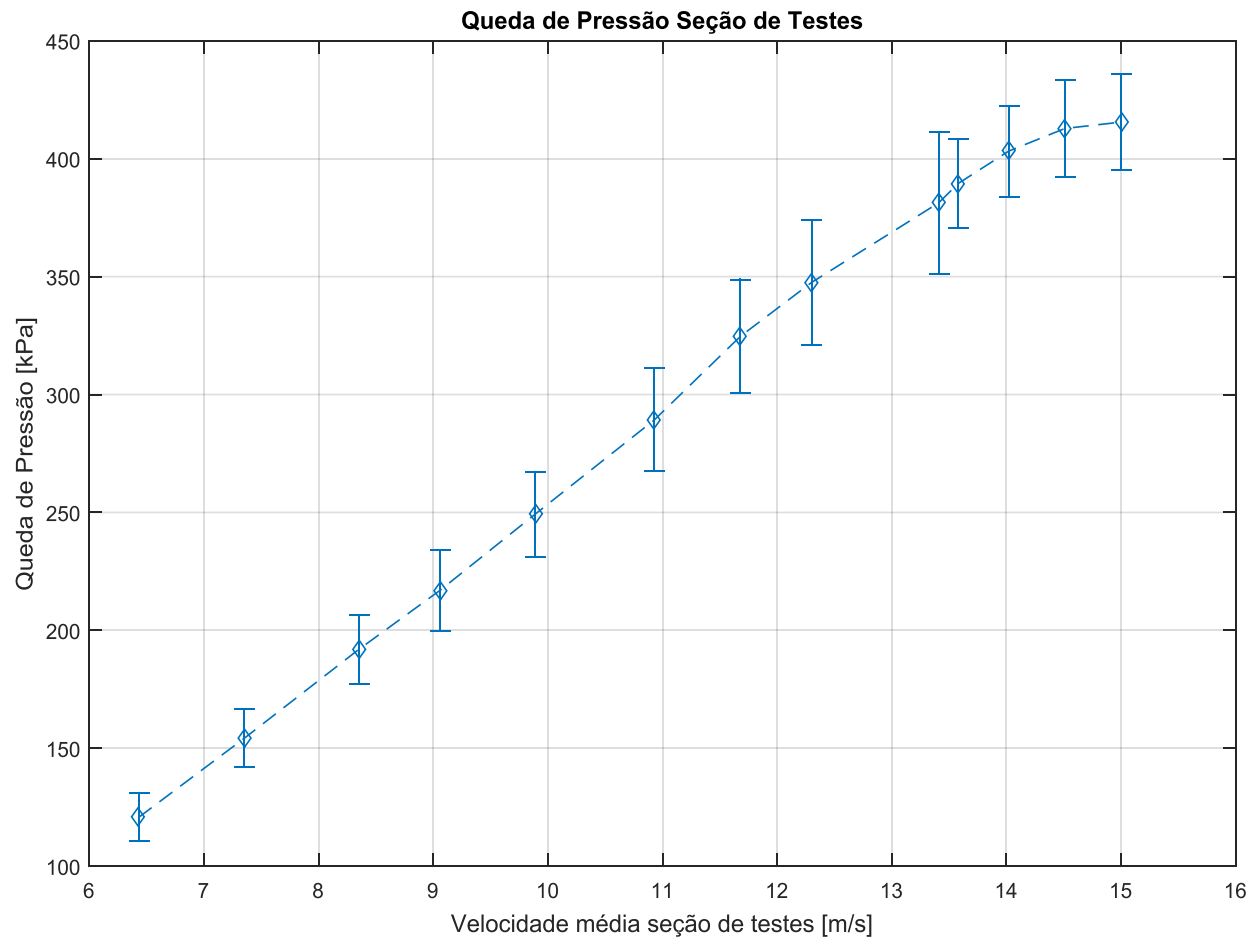

Figura 6. 1 - Queda de pressão na seção de testes 
Da Tabela 6. 1 pode-se observar também que a relação entre a $V_{\text {PITOT }} / \mathrm{V}_{\mathrm{ST}}$ foi relativamente constante em torno de 2,47 demonstrando que realmente a vazão pelo canal central era maior que nos canais laterais. A posição do tubo de pitot no bocal de saída da seção de testes era centralizada no canal central e sua fixação na parte externa não foi afetada pelas vibrações e deformações nos canais de refrigerante.

A Tabela 6. 3 apresenta os dados dos extensômetros SG1, SG3 e SG6 coletados pelo sistema QuantumX da "HBM" e processados matematicamente nos domínios do tempo e da frequência com o Matlab R15a.

Tabela 6. 3 - Dados dos Extensômetros

\begin{tabular}{|c|c|c|c|c|c|c|c|}
\hline ENSAIO & $\begin{array}{c}V_{S T} \\
{[\mathrm{~m} / \mathrm{s}]}\end{array}$ & $\begin{array}{c}\text { SG1 } \\
{[\mu \mathrm{m} / \mathrm{m}]}\end{array}$ & $\begin{array}{c}\sigma_{\mathrm{sg} 1} \\
{[\mu \mathrm{m} / \mathrm{m}]}\end{array}$ & $\begin{array}{c}\text { SG3 } \\
{[\mu \mathrm{m} / \mathrm{m}]}\end{array}$ & $\begin{array}{c}\sigma_{\mathrm{sg} 3} \\
{[\mu \mathrm{m} / \mathrm{m}]}\end{array}$ & $\begin{array}{c}\text { SG6 } \\
{[\mu \mathrm{m} / \mathrm{m}]}\end{array}$ & $\begin{array}{c}\sigma_{\mathrm{sg6}} \\
{[\mu \mathrm{m} / \mathrm{m}]}\end{array}$ \\
\hline 1 & 6,43 & 60,3 & 0,7 & 85,1 & 0,7 & 44,8 & 0,4 \\
\hline 2 & 7,35 & 76,3 & 0,6 & 107,6 & 0,7 & 49,1 & 0,4 \\
\hline 3 & 8,35 & 97,0 & 0,9 & 133,0 & 0,9 & 54,8 & 0,6 \\
\hline 4 & 9,06 & 111,5 & 0,9 & 148,5 & 0,9 & 58,6 & 0,6 \\
\hline 5 & 9,89 & 126,4 & 1,0 & 166,8 & 0,8 & 64,1 & 0,7 \\
\hline 6 & 10,93 & 133,9 & 2,7 & 187,0 & 0,9 & 74,1 & 0,9 \\
\hline 7 & 11,68 & 146,4 & 1,6 & 204,7 & 0,9 & 85,5 & 1,1 \\
\hline 8 & 12,30 & 164,8 & 2,1 & 216,2 & 0,9 & 97,1 & 1,4 \\
\hline 9 & 13,41 & 152,2 & 2,5 & 229,4 & 1,3 & 112,4 & 2,0 \\
\hline 10 & 13,58 & 235,1 & 3,7 & 236,3 & 1,2 & 121,1 & 2,1 \\
\hline 11 & 14,02 & 260,3 & 7,3 & 243,0 & 2,7 & 128,2 & 2,5 \\
\hline 12 & 14,51 & 295,9 & 24,6 & 775,8 & 22,0 & 162,0 & 7,1 \\
\hline 13 & 15,00 & 420 & 14,3 & 840,0 & 5,4 & 170,0 & 4,3 \\
\hline
\end{tabular}

Analisando a Tabela 6. 3, pode-se observar que os sinais dos extensômetros apresentaram um comportamento de aumento de deformações com a velocidade média da seção de testes de uma forma contínua e de maneira gradual. Nota-se que estas deformações são maiores no meio da seção de testes (SG3) e menores na saída (SG6). A partir de 14,0m/s, o aumento das deformações por ganho de velocidade deu um salto. Isto pode ser observado principalmente quando a velocidade variou de 14,0 para $14,5 \mathrm{~m} / \mathrm{s}$, onde a variação das microdeformações em SG3 foi de 219\% e em SG1 de 26\%. Admite-se que este foi o ponto de começo do colapso das placas e de início da deformação plástica.

As figuras, Figura 6. 2 a Figura 6. 4, mostram um comportamento das deformações da placa proporcionais a velocidade ao quadrado até $14,0 \mathrm{~m} / \mathrm{s}$, condizente com as hipóteses 
do modelo de Miller, [2], que utiliza a equação de Euler-Bernoulli aplicada a vigas largas. Também se observa que acima de 14,0 m/s, as deformações apresentaram comportamentos proporcionais a velocidades elevadas a potências de grau maiores. Este fato serve para ser utilizado para caracterização da ocorrência do colapso das placas e ocorrência da velocidade crítica a $14,5 \mathrm{~m} / \mathrm{s}$.

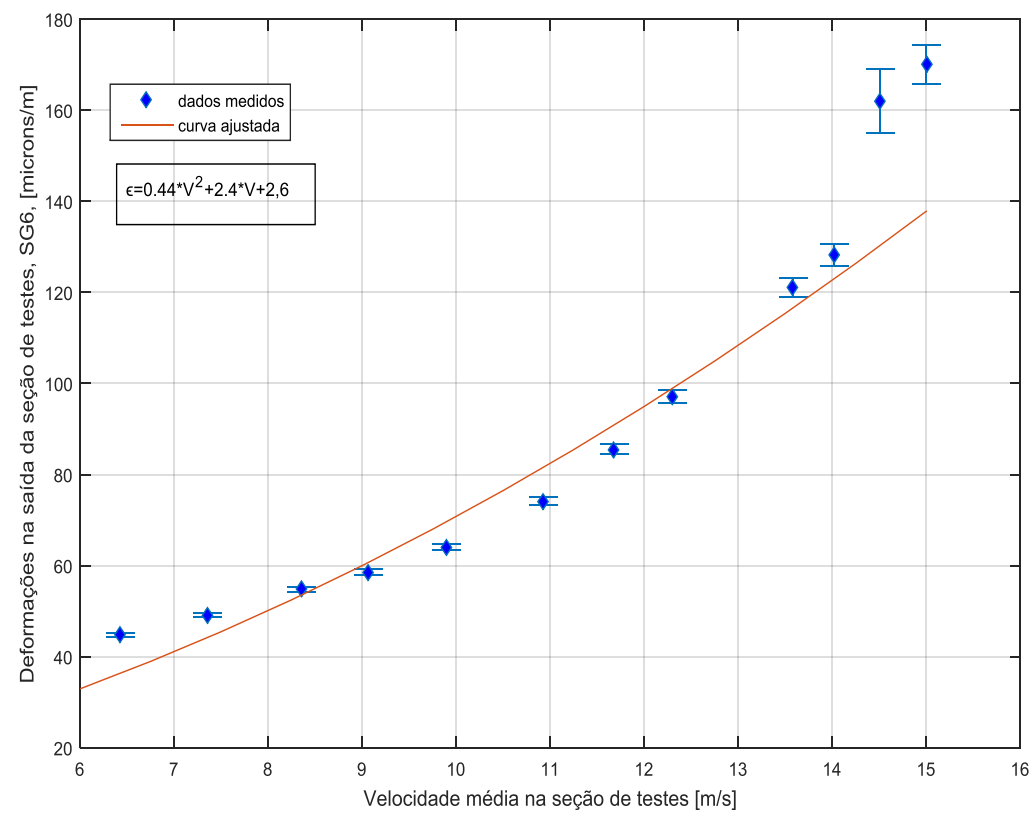

Figura 6. 2 - Deformações do extensômetro de saída da seção de testes

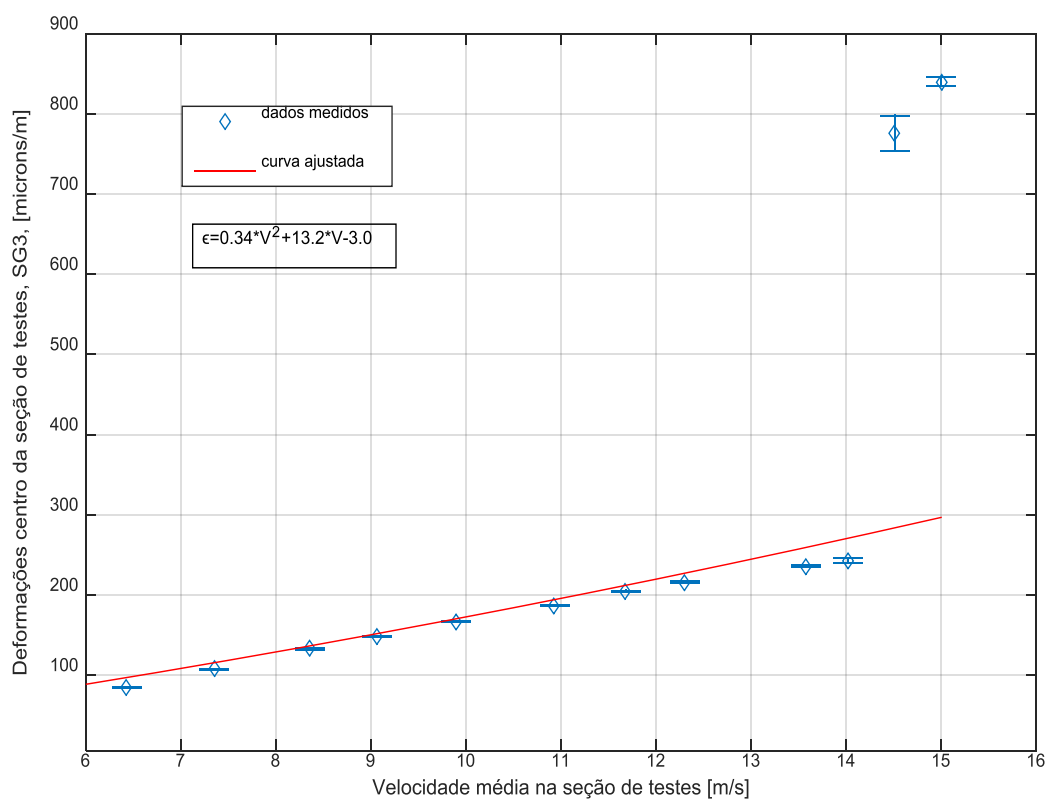

Figura 6. 3 - Deformações do extensômetro no centro da seção de testes 


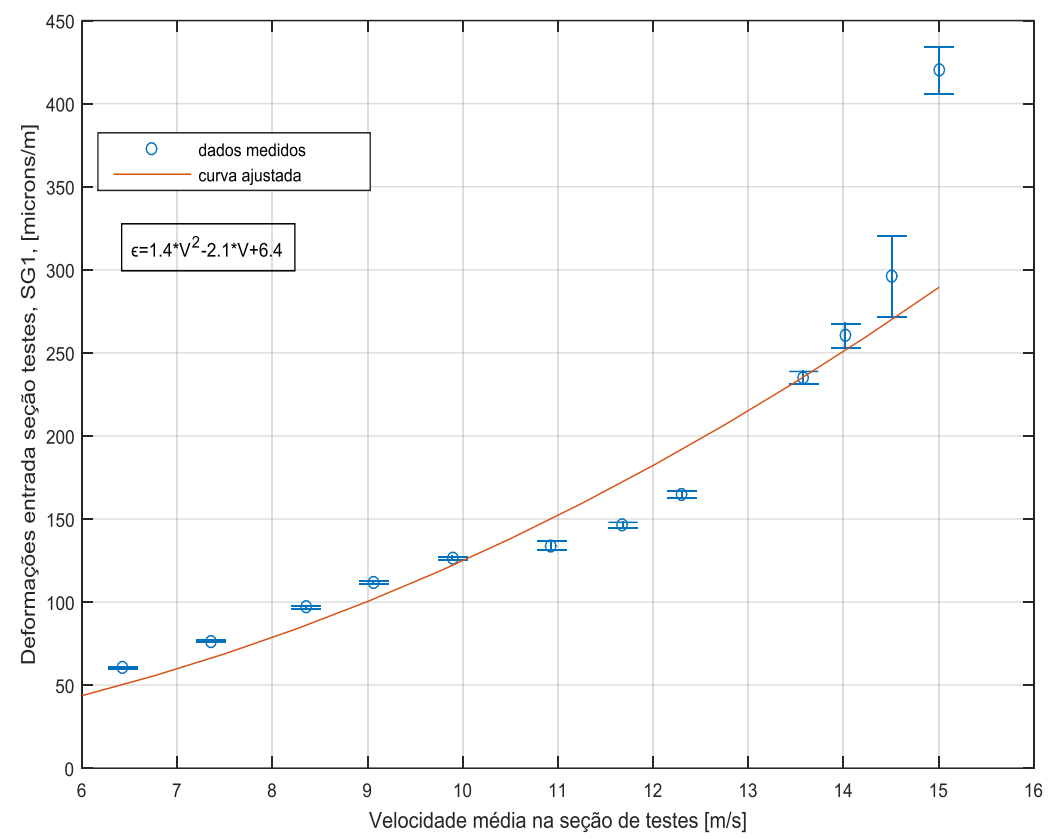

Figura 6. 4 - Deformações do extensômetro na entrada da seção de testes

As figuras, Figura 6.5 a Figura 6. 7, apresentam o transiente de 13,5 m/s para 14,0 m/s. Observa-se uma transição suave nas deformações devido ao aumento de velocidade.

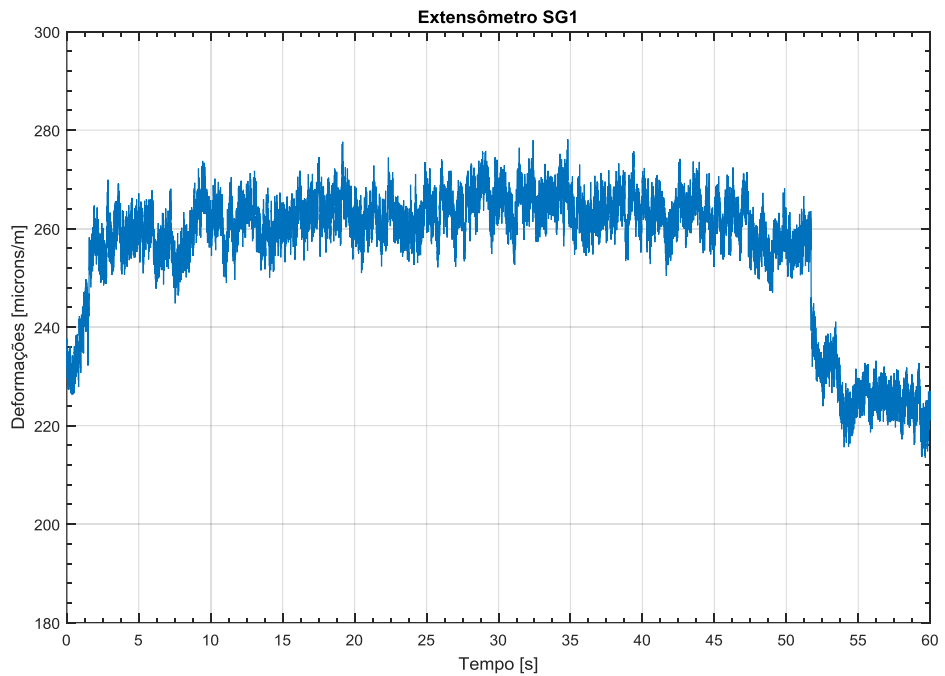

Figura 6. 5 - Sinal do extensômetro SG1 no transiente de 13,5 para 14,0 m/s 


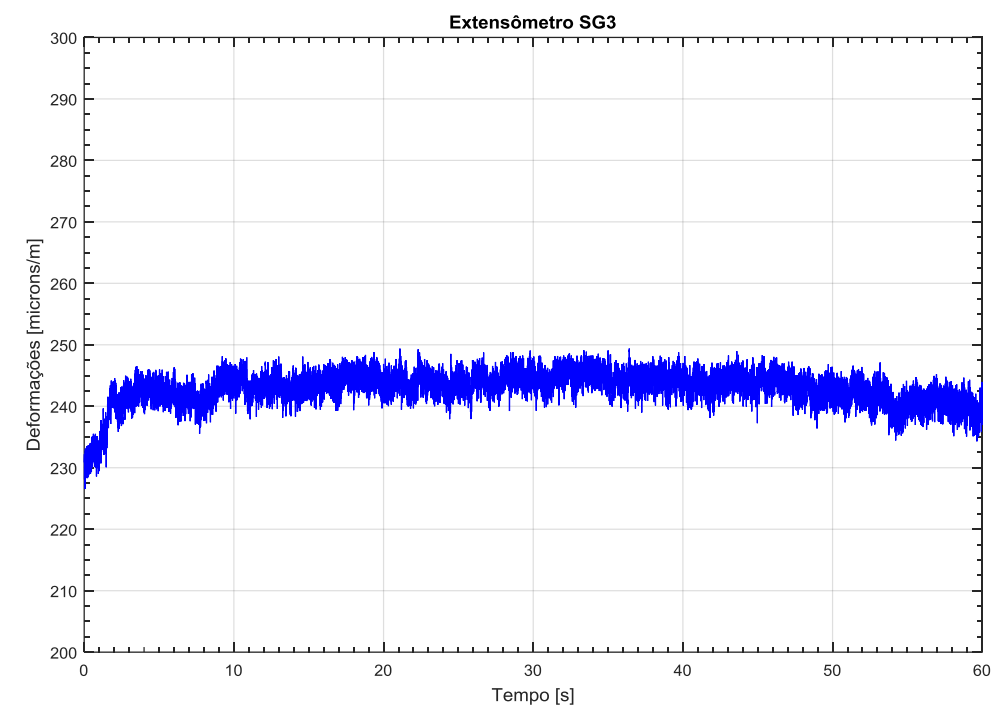

Figura 6. 6 - Sinal do extensômetro SG3 no transiente de 13,5 para 14,0 m/s

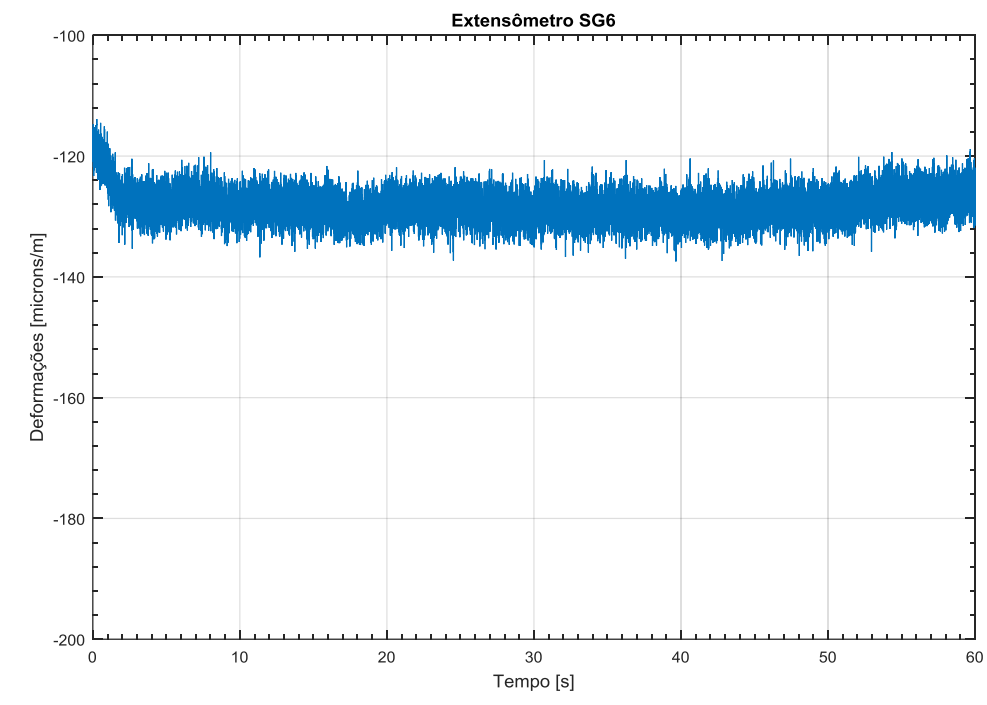

Figura 6. 7 - Sinal do extensômetro SG6 no transiente de 13,5 para 14,0 m/s

Nas figuras, Figura 6. 8 a Figura 6. 10, que representam o transiente de 14,0 m/s para $14,5 \mathrm{~m} / \mathrm{s}$, ocorre uma transição abrupta das deformações. Este ponto foi o de colapso das placas, onde as deformações tornaram-se plásticas. 


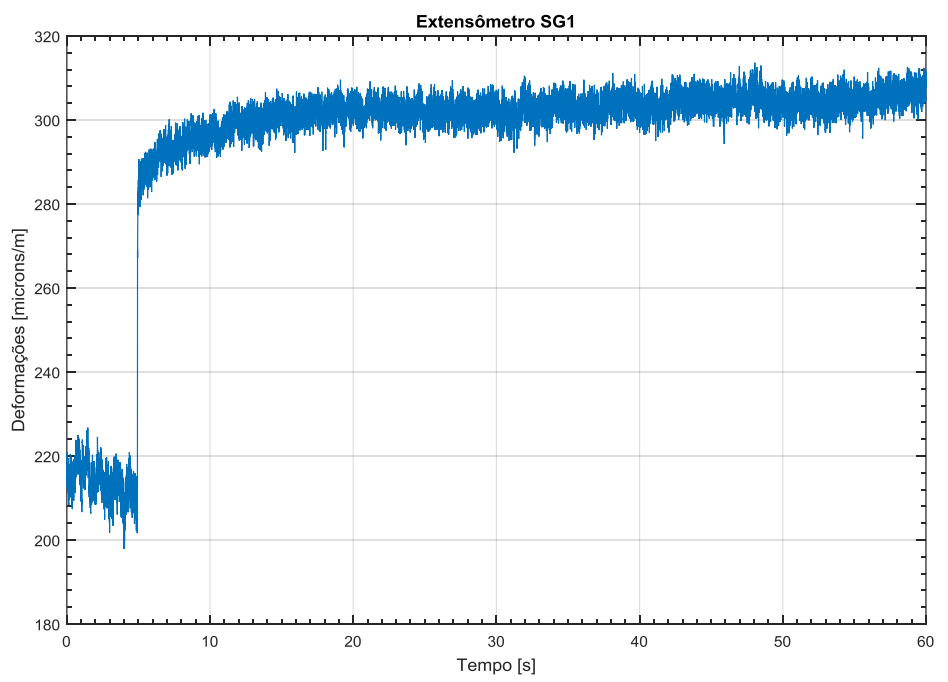

Figura 6. 8 - Sinal do extensômetro SG1 no transiente de 14,0 para 14,5 m/s

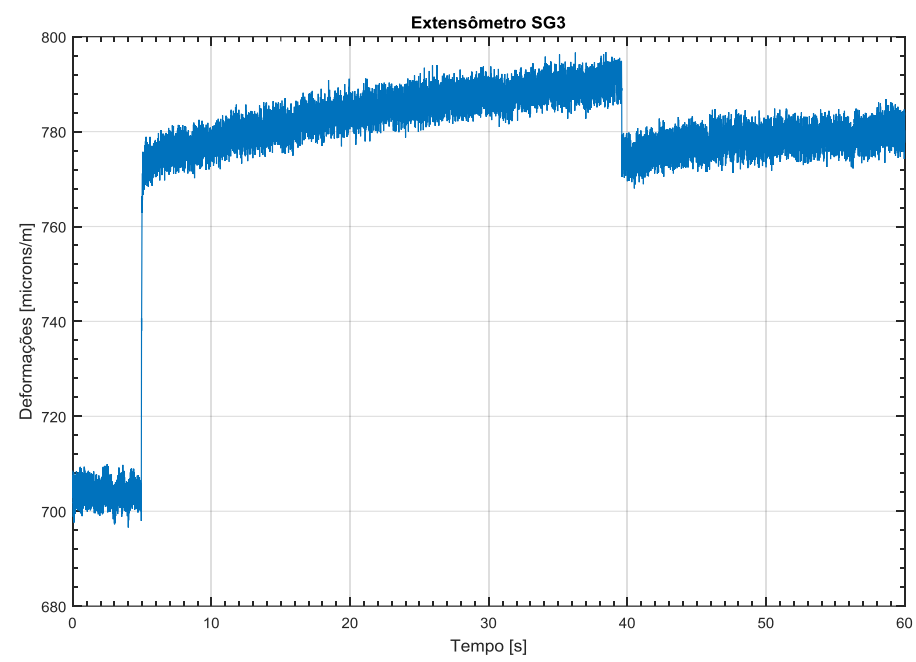

Figura 6. 9 - Sinal do extensômetro SG3 no transiente de 14,0 para 14,5 m/s

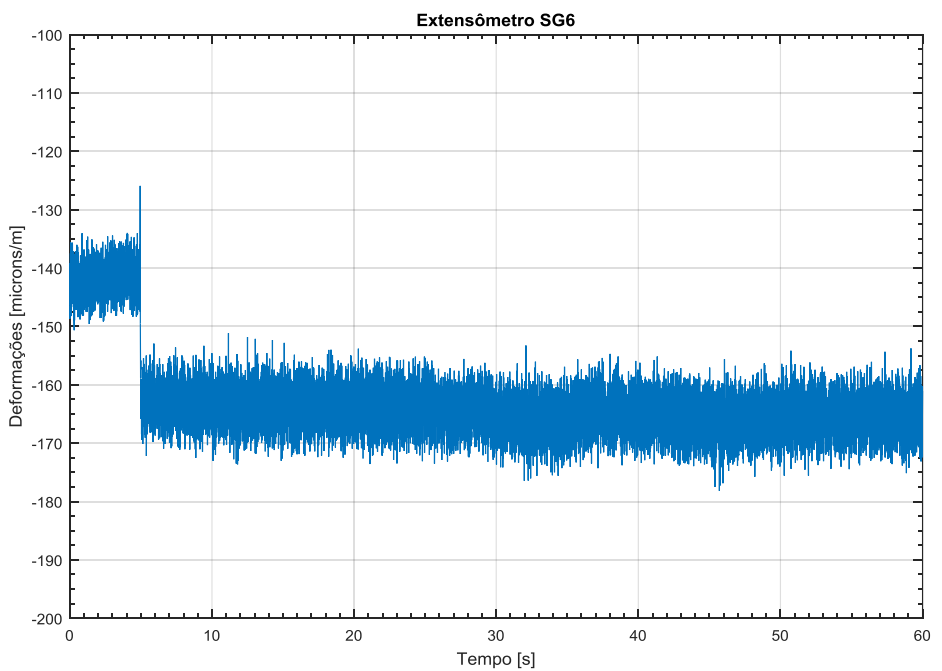

Figura 6. 10 - Sinal do extensômetro SG6 no transiente de 14,0 para 14,5 m/s 
As figuras, Figura 6. 11 a Figura 6. 13, mostram a última condição de ensaio, transiente de $14,5 \mathrm{~m} / \mathrm{s}$ para $15,0 \mathrm{~m} / \mathrm{s}$. Nota-se, os saltos nas microdeformações na entrada do canal da seção de testes. Percebe-se que o mesmo fenômeno não ocorreu no centro e na saída da seção de testes.

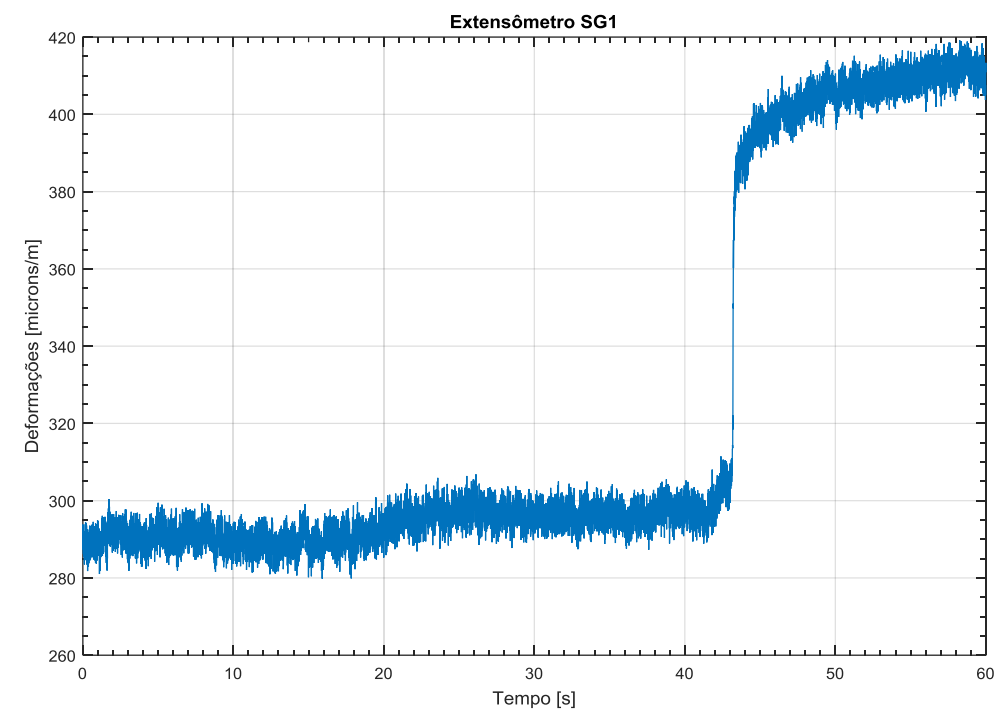

Figura 6. 11 - Sinal do extensômetro SG1 no transiente de 14,5 para $15,0 \mathrm{~m} / \mathrm{s}$

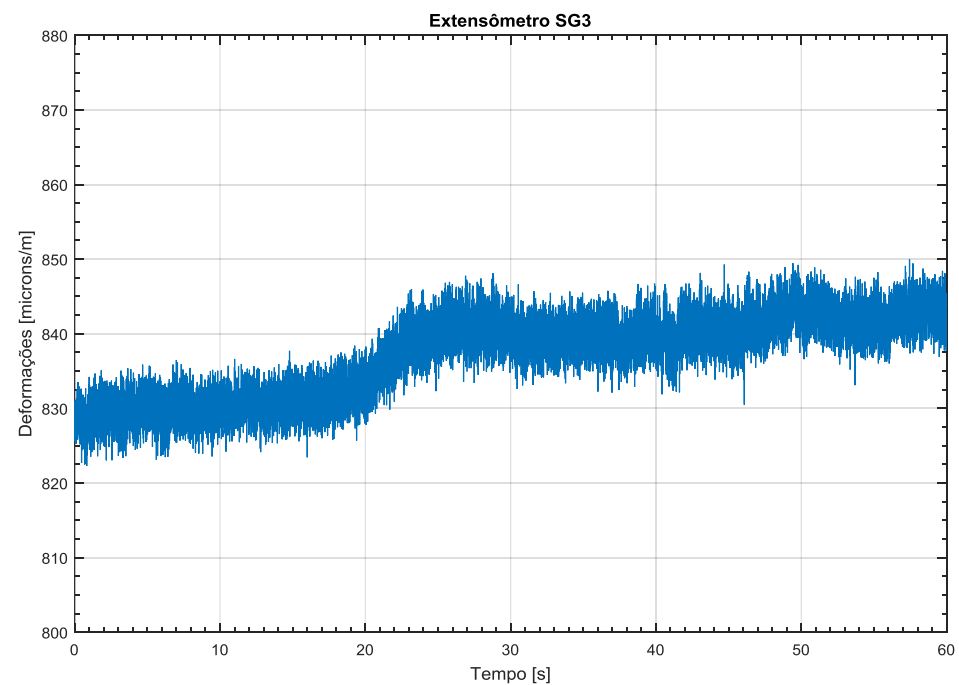

Figura 6. 12 - Sinal do extensômetro SG3 no transiente de 14,5 para $15,0 \mathrm{~m} / \mathrm{s}$ 


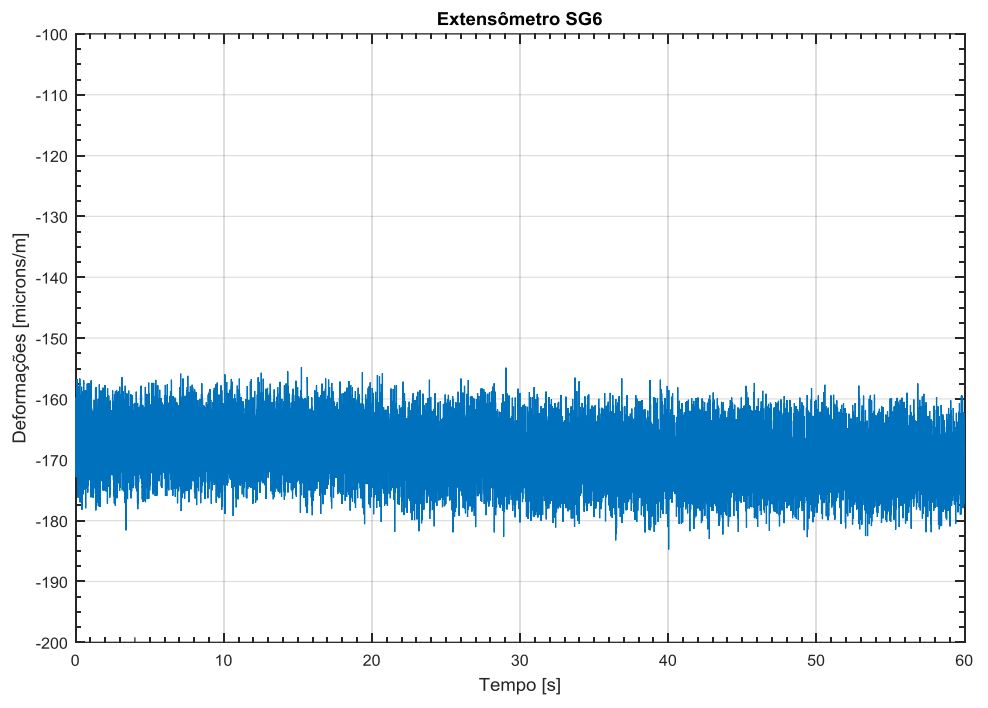

Figura 6. 13 - Sinal do extensômetro SG6 no transiente de 14,5 para 15,0 m/s

A Figura 6. 14 apresenta uma foto dos canais da seção de testes tirada após os experimentos de velocidade crítica. Percebe-se nitidamente a deformação do canal central bloqueando os canais laterais. Através de análise da imagem por meio de programa de desenho estima-se que a máxima abertura na entrada da seção de teste ocorreu no centro do canal e foi aproximadamente de $3,1 \mathrm{~mm}$.

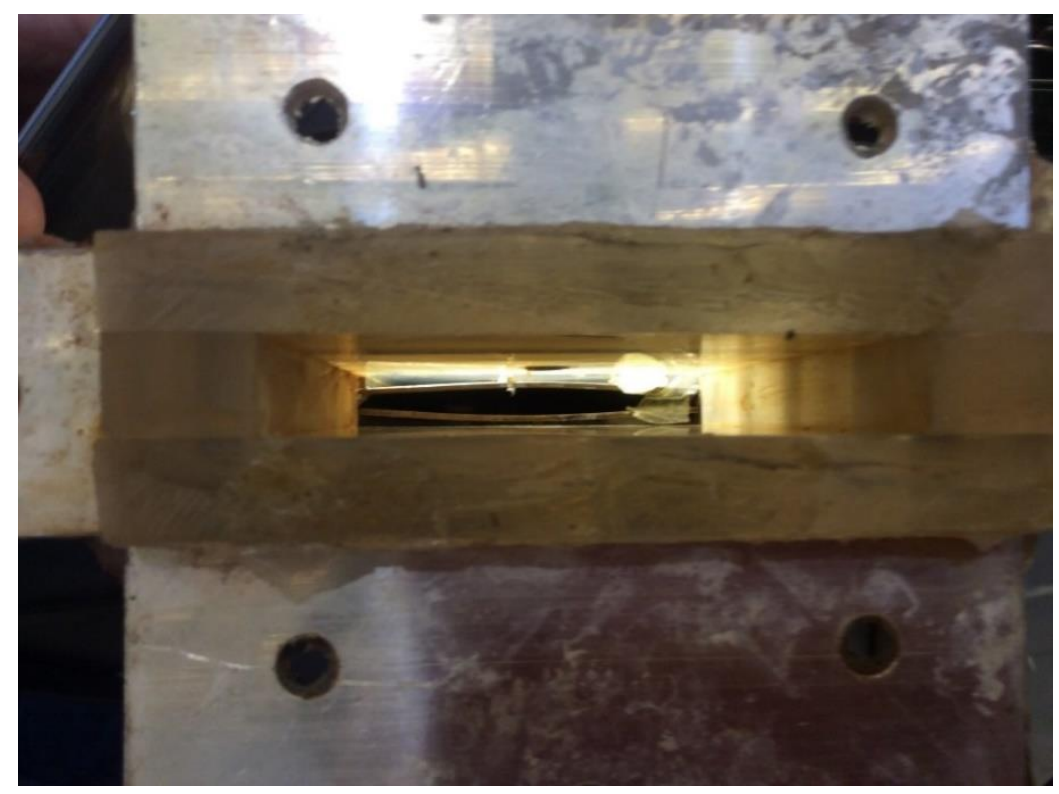

Figura 6. 14 - Vista da entrada da seção de testes após a realização dos ensaios de velocidade crítica 
As figuras, Figura 6.15 e Figura 6. 16 , apresentam fotografias da entrada da seção de testes após sua limpeza, com focos respectivamente na deformação do canal central e em suas dimensões.

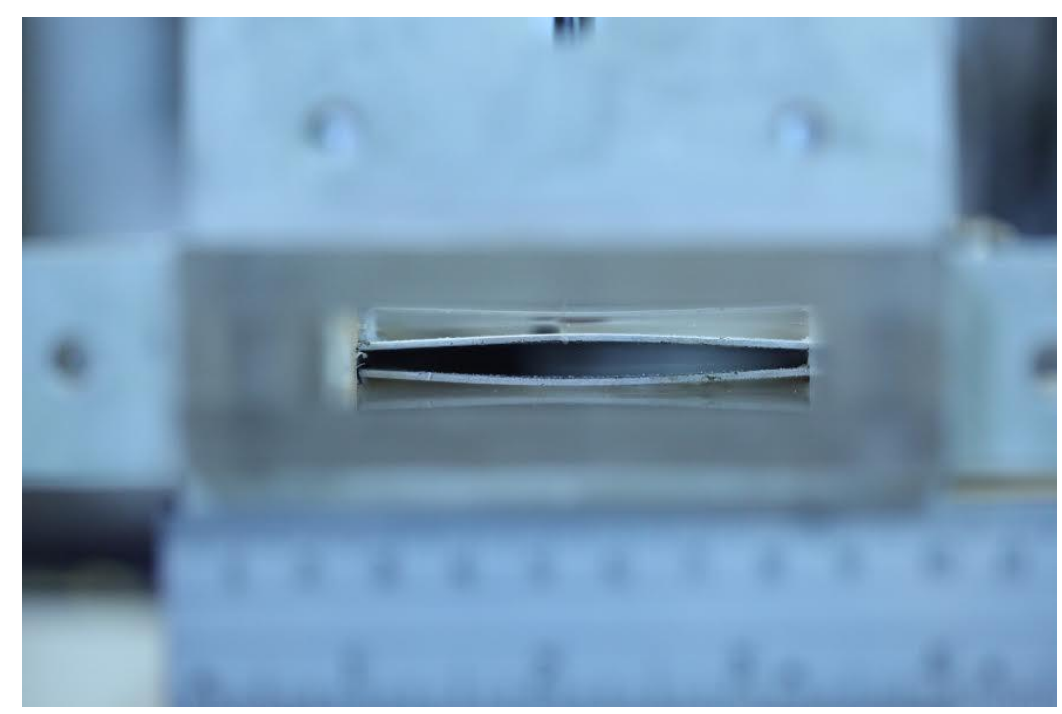

Figura 6. 15 - Vista da entrada da seção de testes após limpeza foco na deformação

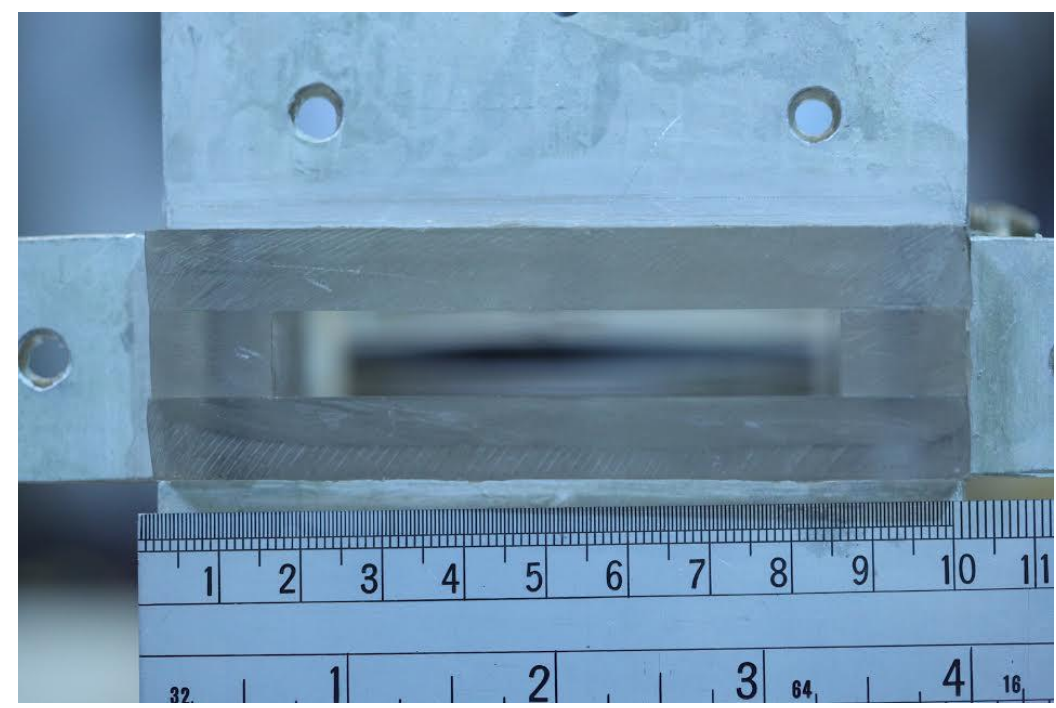

Figura 6. 16 - Vista da entrada da seção de testes após limpeza foco nas dimensões canal

Com relação as análises no campo de frequência, não se observou uma provável componente de instabilidade fluido elástico nos sinais dos extensômetros nas condições próximas a ocorrência da velocidade crítica. A Figura 6.17 apresenta o espectro de potência do extensômetro do meio da seção de testes (SG3) para diferentes velocidades médias no canal. Foi observado uma excitação ligada ao fluido (banda larga) com seu valor aumentando 
de 90 a 130 Hz com o crescimento da velocidade no canal. Esta excitação está provavelmente ligada a cavitação no meio do canal da seção de testes. A deformação no centro do canal foi bem maior que na entrada, provocando uma resistência grande ao escoamento, altas velocidades do fluido e pressões muito baixas. Neste gráfico também se observa ressonâncias na região de 300 a 500 Hz. Estas ressonâncias podem ter origem em vibrações das placas e vórtices de turbulências do fluido. Estes vórtices de turbulências são muito provavelmente produzidos na saída da seção de testes, [63]. A câmara de entrada da seção de testes (Plenum) amortece possíveis influências de fenômenos do fluido no circuito hidráulico como ressonâncias do fluido, cavitações na válvula de regulagem de vazão e pulsos de pressão da bomba.

As figuras, Figura 6. 18 a Figura 6.23 apresentam os espectros de potência dos sinais dos extensômetros nos dois últimos ensaios dos experimentos de velocidade crítica $(14,5$ $\mathrm{m} / \mathrm{s}$ e $15,0 \mathrm{~m} / \mathrm{s}$ ). Nestes gráficos foi identificado o aparecimento da frequência natural de $2^{\circ}$ modo de vibração na faixa de $74 \mathrm{~Hz}$ principalmente nos sinais do meio da seção (SG3) bem como as ressonâncias na região de 300 a 500 Hz, [63] a [65].

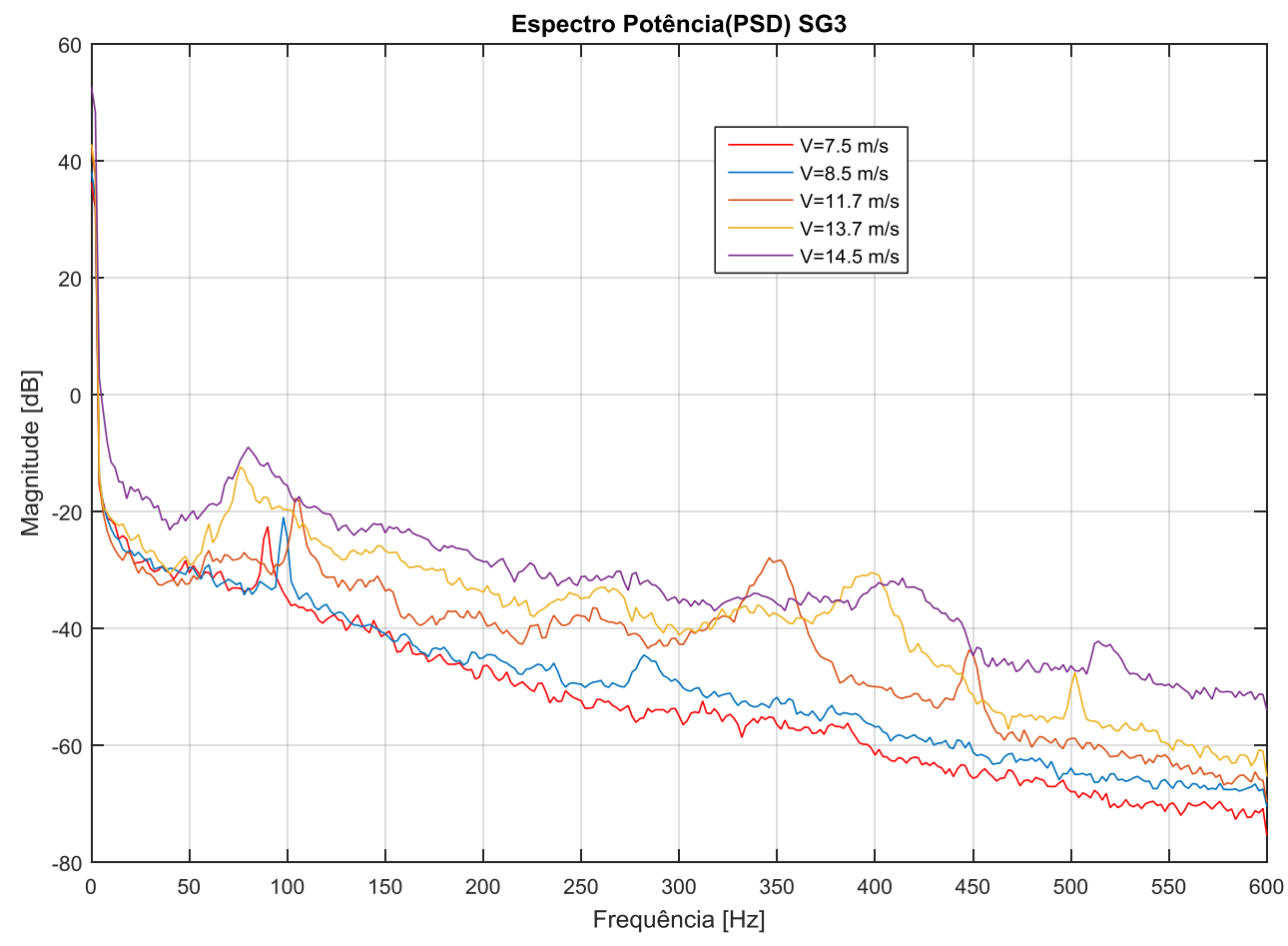

Figura 6. 17 - Espectro de potência do extensômetro no meio da seção de testes 


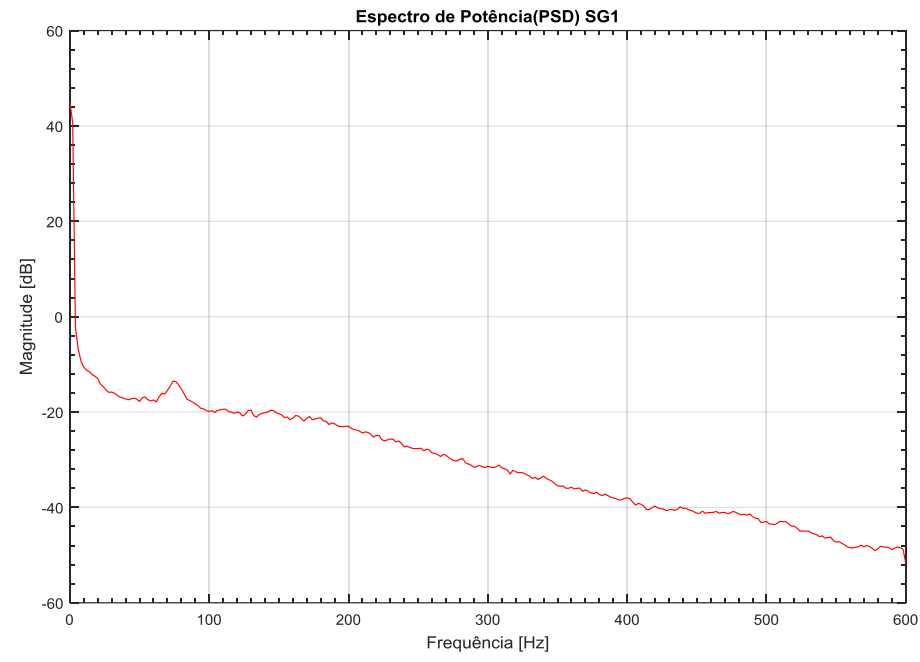

Figura 6. 18 - Espectros de Potência do sinal SG1 V=14,5 m/s

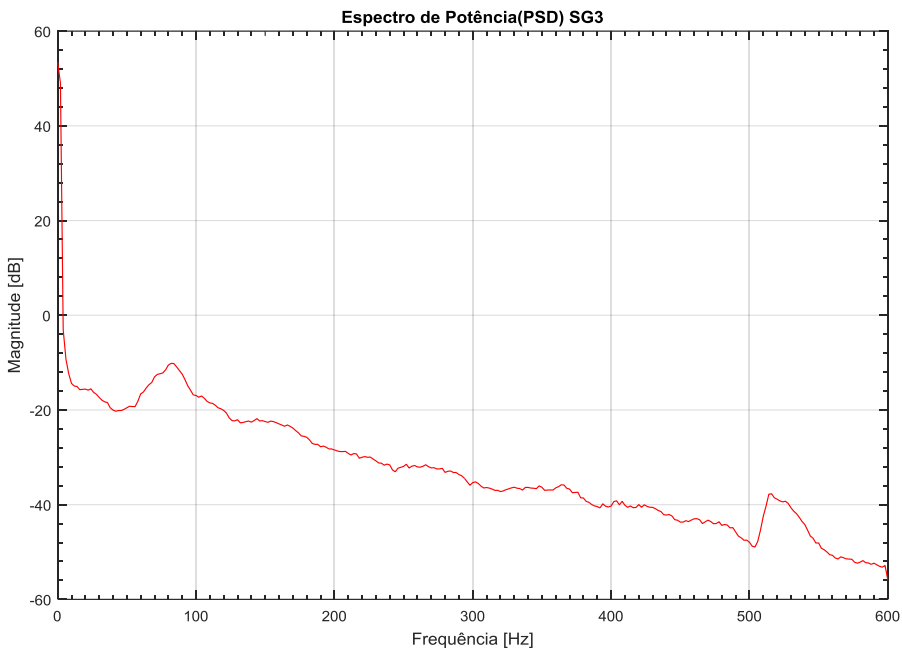

Figura 6. 19 - Espectros de Potência do sinal SG3 V=14,5 m/s

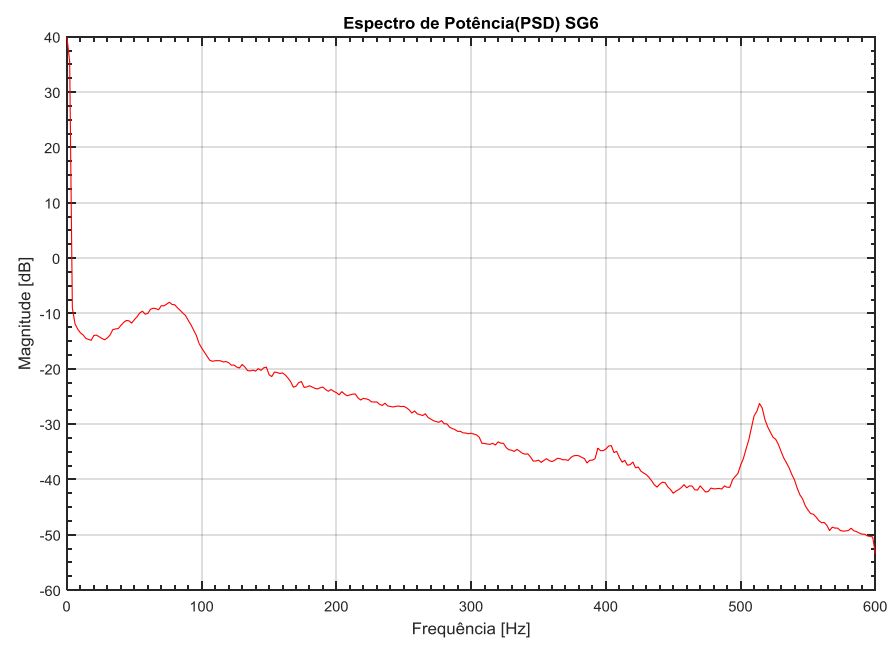

Figura 6. 20 - Espectros de Potência do sinal SG6 para V=14,5 m/s 


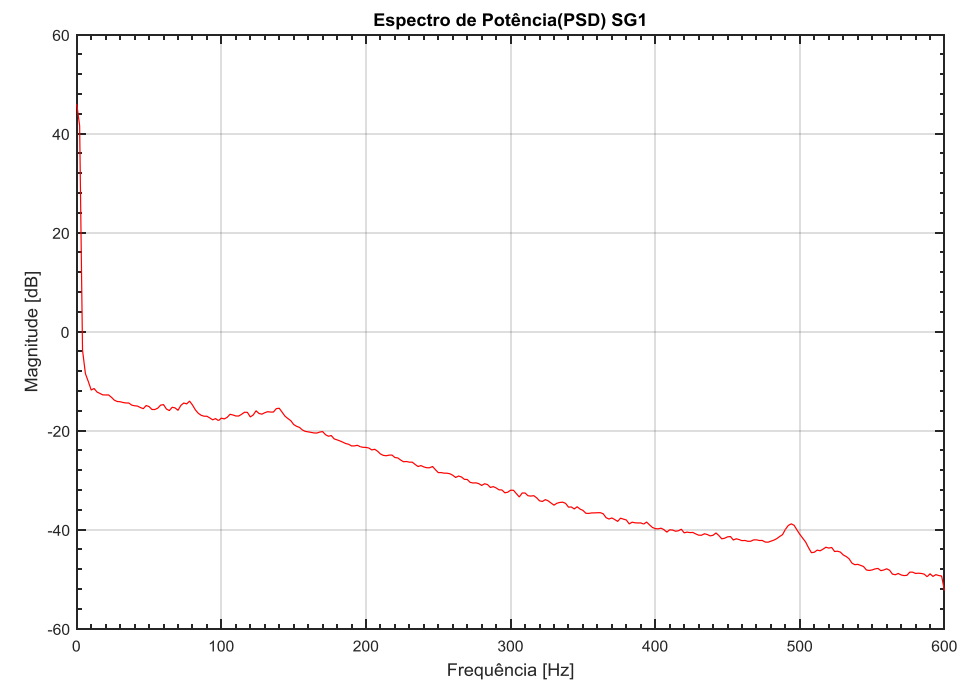

Figura 6. 21 - Espectros de Potência do sinal SG1 para V=15,0 m/s

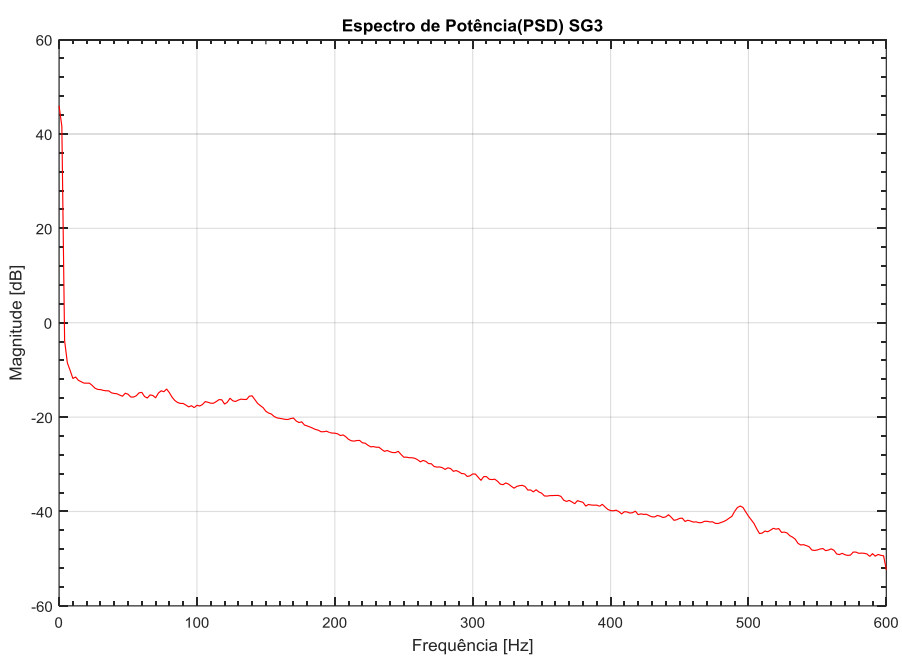

Figura 6. 22 - Espectros de Potência do sinal SG3 para V=15,0 m/s

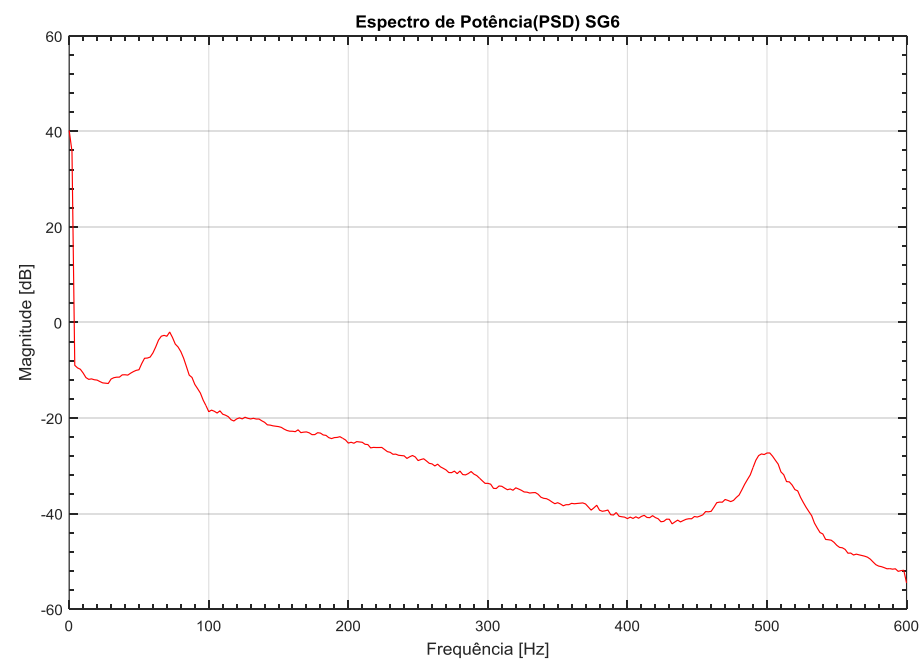

Figura 6. 23 - Espectros de Potência do sinal SG6 para V=15,0 m/s 


\section{CONCLUSÃO}

Para o desenvolvimento da bancada experimental e seção de testes foi obtido um projeto com o CNPq dentro do Edital Universal de 2012, [42]. Este projeto financiou metade dos custos propiciando a compra de material e de instrumentação para a reforma da Bancada original. O IPEN financiou a compra da nova bomba e a prestação de serviços externos de montagem.

Foram cumpridas todas as metas propostas no projeto de pesquisa:

- Identificação dos métodos existentes para medir, estimar e predizer o começo da deformação plástica (colapso) em placas planas típicas de elementos combustíveis;

- Desenvolvimento, montagem e instrumentação de uma seção de testes;

- Desenvolvimento e montagem de uma bancada experimental;

- Desenvolvimento e aprimoramento do Sistema de Aquisição de Dados;

- Realização dos experimentos de velocidade crítica;

- Validação da técnica de detecção do colapso de placas e determinação dos valores de velocidade crítica através da análise dos resultados.

Durante o desenvolvimento do projeto foram realizados quatro trabalhos de iniciação científica que envolveram estudos, otimizações, especificações e tomadas de custos para o projeto final da Bancada Experimental, Seção de Testes, Programa de Monitoração e Aquisição de Sinais para os experimentos e Estudos preliminares da Modelagem da Seção de Testes com o Ansys-CFX ${ }^{\circledR}$, [11]. Estes trabalhos foram publicados nos congressos PIBIC/IPEN de 2013, 2014 e 2015, bem como também foram apresentados no Relatório final para o projeto CNPq, [43].

Os experimentos realizados alcançaram o objetivo de chegar à condição de velocidade crítica de Miller. Houve o colapso e a consequente deformação plástica das placas que formam o canal do escoamento com a velocidade média da seção de testes de $14,5 \mathrm{~m} / \mathrm{s}$. O colapso das placas ocorreu com a velocidade equivalente a $85,5 \%$ do valor calculado pela equação de Miller que foi de 17,0 m/s. Este resultado é compatível com os experimentos de Ho et al., [26].

Os sinais dos extensômetros mostraram um comportamento das deformações da placa, proporcionais a velocidade ao quadrado até $14,0 \mathrm{~m} / \mathrm{s}$, condizente com as hipóteses do modelo de Miller, [2], que utiliza a equação de Euler-Bernoulli aplicada à viga larga. Foi observado que para velocidades acima de $14,0 \mathrm{~m} / \mathrm{s}$ as deformações apresentaram 
comportamentos proporcionais às velocidades elevadas a potências de grau maior. Este fato foi utilizado para caracterização da ocorrência do colapso das placas e ocorrência da velocidade crítica a 14,5 m/s. Esta técnica de caracterização do colapso das placas é inédita para experimentos de detecção de velocidade crítica.

O canal central da entrada da seção de testes teve uma abertura de $3,1 \mathrm{~mm}$ em seu centro, causando um grande bloqueio do escoamento nos canais laterais. Este bloqueio é observado nos sinais dos extensômetros de entrada (SG1) e do centro do canal (SG3). As maiores deformações ocorreram no centro da seção de testes, o que pode ser explicado pela teoria de Miller, [2], devido a maiores velocidades do refrigerante nos canais bloqueados. Durante os experimentos os sinais dos extensômetros apresentaram um comportamento de aumento de deformações com a velocidade média da seção de testes de uma forma contínua e de maneira gradual. Nota-se que estas deformações são maiores no meio da seção de testes (SG3) e menores na saída (SG6). A partir de 14,0m/s, o aumento das deformações por ganho de velocidade deu um salto. Isto foi observado principalmente quando a velocidade variou de 14,0 para 14,5 m/s, onde a variação das microdeformações em SG3 foi de $219 \%$ e em SG1 de 26\%. Dos resultados obtidos com os extensômetros pode-se afirmar que o bloqueio do escoamento no centro da seção de testes foi maior que na entrada. Esta conclusão tem caráter inédito em relação aos outros trabalhos apresentados na literatura.

Este comportamento foi constatado visualmente durante a desmontagem da seção de testes, ilustrado e discutido na análise de resultados apresentado neste trabalho. O bloqueio dos canais também foi observado por meio do gráfico de queda de pressão contra a velocidade média da seção de testes. Houve uma queda da resistência hidráulica da seção de testes devido ao aumento da seção transversal de escoamento no canal central.

Com relação as análises no campo de frequência, não se observou uma provável componente de instabilidade fluido elástico nos sinais dos extensômetros nas condições próximas a ocorrência da velocidade crítica. No espectro de potência do extensômetro do meio da seção de testes (SG3) foi observado uma excitação ligada ao fluido(banda larga) com seu valor aumentando de 90 a $130 \mathrm{~Hz}$ com o crescimento da velocidade no canal. Esta excitação, provavelmente, está ligada a cavitação no meio do canal da seção de testes. A deformação no centro do canal foi bem maior que na entrada, provocando uma resistência grande ao escoamento, altas velocidades do fluido e pressões muito baixas. Também foi identificado o aparecimento da frequência natural de $2^{\circ}$ modo de vibração na faixa de $74 \mathrm{~Hz}$ principalmente nos sinais do meio da seção (SG3). 
Uma conclusão importante se dá quando se compara as deformações da placa na condição de velocidade crítica com as tensões de escoamento obtidas no ensaio estático de tração para determinação do módulo de elasticidade. Os valores obtidos pelos extensômetros no centro da seção de testes para velocidade crítica foram de $850 \mu \mathrm{mm} / \mathrm{mm}$. Considerando o módulo de elasticidade medido de $\mathrm{E}=70 \mathrm{GPa}$, a tensão de escoamento resultante foi de 60 MPa pela Lei de Hooke. Nos ensaios com a máquina de tração, os resultados obtidos para tensão de escoamento da placa de alumínio foram da ordem de $150 \mathrm{MPa}$. Este resultado nos mostra a influência da dinâmica do fluido sobre o comportamento estrutural da placa. As vibrações induzidas pelo escoamento e o acoplamento fluido estrutura tem um fator importante sobre o fenômeno do colapso das placas.

Como resultado secundário, a investigação produziu dados experimentais para estudos da interação das placas combustíveis com o fluido refrigerante em uma faixa variada de vazões em condições estáveis de distribuição de pressão e temperatura para dar subsídios a projetos de elementos combustíveis do tipo placas paralelas.

Como propostas de futuros trabalhos para continuação da pesquisa utilizando a bancada desenvolvida pode-se indicar:

- estudos experimentais de deformação estática sobre a seção de testes similar a que foi ensaiada neste trabalho;

- montagem de uma nova seção de testes para estudos de velocidade crítica que permita a medição do campo de velocidade nos canais laterais com um anemômetro a laser e a distribuição de pressão com sensores dinâmicos de pressão; e

- análise da influência das tolerâncias de fabricação das placas e dos canais de escoamento.

Os dados experimentais a serem gerados com a continuação da pesquisa poderão ser utilizados para a simulação com programas de computacionais, permitindo estudos futuros de:

- distribuição de velocidade e pressão em elemento combustível tipo placas;

- levantamento de propriedades termo-hidráulicas;

- influência do campo de pressão na placa combustível (domínio sólido); e

- deformações plásticas e vibrações nas placas combustíveis. 
A análise e avaliação dos dados experimentais visa futuramente alcançar os conhecimentos básicos necessários para o desenvolvimento de modelos matemáticos e numéricos que avaliem a interação fluido estrutura de elementos combustíveis tipo placa plana. Além disso, as dificuldades vivenciadas durante a fase experimental permitirão o desenvolvimento/capacitação envolvendo os conhecimentos tecnológicos necessários para o projeto e montagem de uma nova bancada experimental, visando os estudos e testes de avaliação da estabilidade hidráulica para um elemento combustível dummy. 


\section{REFERÊNCIAS}

[1] Torres, W.M., Umbehaum, P.EA., Andrade, D.A., and Souza, J.A.B., "A MTR fuel element flow distribution measurement preliminary results", Proceedings of 2003 International Meeting on Reduced Enrichment for Research and Test Reactors, Chicago, 6 p., 2003.

[2] Miller, D.R., "Critical flow velocities for collapse of reactor parallel-plate fuel assemblies”, Knolls Atomic Power Laboratory Report, United States Atomic Energy Commission contract n W-31-109 Eng-52, New York, 1958.

[3] Silva, J.E.R., RMB-N01-00-PC-10300-RD-006-Revisão 0B “ Descrição do projeto de concepção do núcleo, componentes, estruturas e instalações associadas ao núcleo do Reator Multipropósito Brasileiro- RMB”, IPEN, Brazil, 08/2013.

[4] Snelgrove, J.L. et al., "Development of very high density fuels by the RERTR program”, RERTR International Meeting, Seoul, Korea, 1996.

[5] Snelgrove, J.L. et al., "Qualification of Uranium-molybdenium Alloy Fuel-Conclusions of an International Workshop”, 2000 International Meeting on Reduced Enrichment for Research and Test Reactors, Las Vegas, USA, 2000.

[6] Perrota, J.A., “Curso de capacitação para inspeção visual de combustíveis PWR irradiados”, IPEN, São Paulo, 2002.

[7] Hofman, G. et al., "Irradiation behavior of the CNEA experimental Uranium Silicide Dispersion Fuel Plates”, RERTR International Meeting, San Diego, USA, 1988.

[8] Chaussy, J.M. et al., "Qualification of High Density Low Enriched $\mathrm{U}_{3} \mathrm{Si}_{2}$ Fuel for Material Testing Reactor", International Meeting on Research Reactors Fuel Management(RRFM), Brugge, Belgium, 1999.

[9] U.S. Nuclear Regulatory Commission, "Safety Evaluation Report Related to the Evaluation of Low-Enriched Uranium Silicide-Aluminum Dispersion Fuel for use in NonPower Reactors”, NUREG 1313, 1988. 
[10] Silva, J.E.R., RMB-10300-002-00- “ Concepção do elemento combustivel do RMB “IPEN - Brazil , 02/2011.

[11] ANSYS-CFX - 11.0, "User Manual”, ANSYS Inc., Canonsburg, Pennsylvania United States, 2007.

[12] Marcum, W.R., "Predicting Mechanical Instability of a Cylindrical Plate under Axial Flow Conditions”, Oregon State University, 2010.

[13] Stromquist, W.K. and Sisman, O., "High Flux Reactor Fuel Assemblies Vibration and Water Flow”, 1948.

[14] Doan, R.L., “The Engineering Test Reactor- A Status Report”, Nucleonics, Vol.16, 1958.

[15] Miller, D.R., “Thermo-Elastic Stability Analysis”, Knolls Atomic Power Laboratory Report, United States Atomic Energy Commission, Report $n^{0}$ KAPL-M-DRM-12, New York, 1956.

[16] Zabriskie, W.L., “An Experimental Evaluation of Critical Flow Velocity Formulas for Parallel Plate Assemblies”, 1958.

[17] Zabriskie, W.L., "An Experimental Evaluation of the Effect of Length to Width Ratio on the Critical Flow Velocity of Single Plate Assemblies”, 1959.

[18] Kane, J.J., "The Effect of Inlet Spacing Deviations on the Flow-Induced Deflections of Parallel Plates”, Nuclear Science and Engineering, vol.15, no. 3, pp. 305-308, 1963.

[19] Groninger, R.D., and Kane, J.J., Flow induced deflections of parallel flat plates, Nuclear Science and Engineering, Vol. 16, pp. 218-226, 1963.

[20] Johansson, R.B., Hydraulic Instability of Reactor Parallel Plate Fuel Assemblies, Nuclear Engineering Science Conference, p.paper 57, 1960. 
[21] Wambsganss, M.W., Second Order Effects as Related to Critical Coolant Flow Velocities in Reactor Parallel Plate Fuel Assemblies, Nuclear Engineering and Design, Vol. 5, pp. 268-276, 1967.

[22] Smith, R. L., Dynamic Pressure Limits for Flat Plates as Related to Nuclear Fuel Elements, Washington DC, 1968.

[23] Smissaert, G.E., Static and dynamic hydro-elastic instabilities in MTR-type fuel elements Part I, introduction and experimental investigations, Nuclear Engineering and Design, Vol. 7, pp. 535-546, 1968.

[24] Kim, Y.T. and Scarton, H.A., Flow-Induced Bending of Rectangular Plates, Journal of Applied Mechanics, Vol. 44, 1977.

[25] Kim, G. and Davis, D.C., Hydraulic instabilities in flat-plate type fuel assemblies, Nuclear Science and Engineering, Vol. 158, pp. 1-17, 1995.

[26] Ho, M., Hong, G., Mack, and A.N.F., Experimental investigation of flow-induced vibration in a parallel plate reactor fuel assembly, $15^{\text {th }}$ Australian Fluid Mechanics Conference, The University of Sydney, Sydney, 4 p, 2004.

[27] ANSTO , Summary of the Preliminary Safety Analysis Report(PSAR) for the ANSTO Replacement Research Reactor Facility, 1 and 2 ,Sydney, ANSTO, 2002.

[28] IAEA-TECDOC-233, IAEA, Research Reactor Core Conversion from the use of Highly Enricheed Uranium to the use of Low Enriched Uranium Fuels Guidebook, Vienna, 1980.

[29] Oliveira,C.A., Mattar,M., "Flow velocity calculation to avoid instability in a Typical Research Reactor Core”, INAC 2011, Belo Horizonte, Brazil. 
[30] Jensen, P., “ Application of Sandwich Structure Analysis in Predicting Critical Flow Velocity for a Laminated Flat Plate”, THESIS submitted to Oregon State University for the degree of Master of Science,March 8, 2013- Oregon - USA, 2013.

[31] Maliska, C. R., Transferência de Calor e Mecânica dos Fluidos Computacional, $2^{\mathrm{a}}$ Edição, LTC - Livros Técnicos e Científicos Editora S. A., Rio de Janeiro, RJ - Brasil 2004.

[32] Anderson, J.D., Computational Fluid Dynamics - The Basics with Applications, McGraw-Hill, New York- USA, 1995.

[33] Launder, B.E. and Spalding, D.B., The Numerical Computation of Turbulent Flows, Computer Methods in Applied Mechanics and Engineering, Vol. 3, pp. 269-289, 1974.

[34] Stern, F. et al., Comprehensive Approach to Verification and Validation of CFD Simulations-Part 1: Methodology and Procedures, Journal of Fluids Engineering, Vol. 123, pp. 793-802, 2001.

[35] Wilson, R.V. et al., Comprehensive Approach to Verification and Validation of CFD Simulations - Part 2: Application for Rans Simulation of a Cargo/Container Ship, Journal of Fluids Engineering, Vol. 123, pp. 803-809, 2001.

[36] Moaveni, S., Finite Element Analysis- Theory and Application with ANSYS, PrenticeHall Incorporation, New Jersey, USA, 1999.

[37] Reddy, J.N., An Introduction to the finite Element Method, $3^{\text {rd }}$ Edition, McGraw-Hill, USA, 1999.

[38] Brunetti, F., Mecânica dos Fluidos, $2^{\mathrm{a}}$ Edição Revisada, Pearson Prentice Hall, São Paulo, SP-Brasil, 2008.

[39] Çengel, Y.A., Cimbala, J.M., Mecânica dos Fluidos- Fundamentos e Aplicações, $3^{\mathrm{a}}$ Edição, AMGH Editora Ltda, Porto Alegre, RS - Brasil, 2015. 
[40] Fox, R.W., McDonald, A.T., Pritchard, P.J., Introdução à Mecânica dos Fluidos, $8^{\mathrm{a}}$ Edição, LTC, Rio de Janeiro, RJ- Brasil, 2014.

[41] Munson, B.R., Young, D.F, Okiishi, T.H, Fundamentos da Mecânica dos Fluidos, $4^{\mathrm{a}}$ Edição, Editora Edgard Blucher, São Paulo, SP- Brasil, 2004.

[42] Andrade, D.A., et al., Projeto de Pesquisa CNPq n. 481193/2012-0 - Bancada de testes de vibrações induzidas por escoamentos em elementos combustíveis de reatores nucleares de pesquisa tipo placas paralelas, 2012.

[43] Andrade, D.A., Relatório final - Projeto de Pesquisa CNPq n. 481193/2012-0 Bancada de testes de vibrações induzidas por escoamentos em elementos combustíveis de reatores nucleares de pesquisa tipo placas paralelas.

[44] NBRISO 5167-1, ABNT 1994, Medição de vazão de fluidos por meio de instrumentos de pressão- Parte 1: Placas de orifício, bocais e tubos de venturi instalados em seção transversal de condutos forçados, RJ- Brasil, 1994.

[45] ASME , FLUID METERS -Their Theory and Application, $6^{\text {th }}$ Edition- ASME , New York- USA, 1971.

[46] LABVIEW 10, User Manual, National Instruments, 2010.

[47] National Instruments, “Data Acquisition - DAQ”, http://www.ni.com/dataacquisition.

[48] Travis, J., Kring, J., Labview for Everyone, Graphical programming made easy and fun, $3^{\text {rd }}$ Edition, Pearson Education, Inc, 2007.

[49] Bitter, R., Mohiuddin, T., Nawrocki, M., LabVIEW - Advanced Programming Techniques, $2^{\text {nd }}$ Edition, CRC-Press, 2006.

[50] Mihura, B., LabVIEW for Data Acquisition, Prentice Hall, 2001.

[51] Bishop, R.H., Learning with LabVIEW 8, Pearson, 2008. 
[52] National Instruments, "LabVIEW Environment”, http://www.ni.com/labview/, (2011).

[53] Regazzi, R.D., Pereira, P.S., Silva Jr., M.F., Soluções práticas de Instrumentação e Automação, Edição 3R.KWG- Brazil, 2005.

[54] Matlab R2015a, "Mathworks Incorporation”, Licença Acadêmica n. 258334.

[55] Morais, V., Vieira, C., Matlab 7\&6-Curso completo, FCA-Editora de Informática Ltda, Lisboa- Portugal, 2006.

[56] Chapman, S.J., Programação em Matlab para engenheiros, Cengage Learning- $2^{\mathrm{a}}$ Edição, São Paulo- SP, 2011.

[57] Matsumoto, E.Y., MATLAB R2013a: teoria e programação- guia prático, Editora Erica, São Paulo- SP, 2015.

[58] Hoffmann, K., An Introduction to Measurements using Strain Gauges, Publisher: Hottinger Baldwin Messtechnik GmbH, Darmstadt, German, 1989.

[59] Shigley, J.E., Mechanical Engineering Design, $3^{\text {rd }}$ Edition - McGraw-Hill Kogakusha - Ltd, Tokyo- Japan, 1977.

[60] Beer, F.P., Johnston, E.R., Resistência dos Materiais, $4^{\text {a }}$ Edição - McGraw-Hill, São Paulo -SP, 2006.

[61] Holman, J.P., Experimental Methods for Engineers, $8^{\text {th }}$ Edition - McGraw-Hill, New York, 2012.

[62] Knudsen, J.G., Katz, D.L., Fluid Dynamics and Heat Transfer, McGraw-Hill Kogakusha - Ltd, Tokyo- Japan, 1958.

[63] Blevins, R.D., Flow Induced Vibration, $2^{\text {nd }}$ Reprint Edition - Krieger Publishing Company, Florida- USA, 2001. 
[64] Macedo, L.V.S., Perrota, J. A., Structural analysis of PWR fuel assemblies, $13^{\text {rd }}$ SMIRTStructural Mechanics in Reactor Technology, Brazil, 1995.

[65] Paidoussis, M.P., A Review of flow-induced vibrations in Reactors and Reactor components, Nuclear Engineering and Design, Vol. 74, pp. 31-60, 1982. 